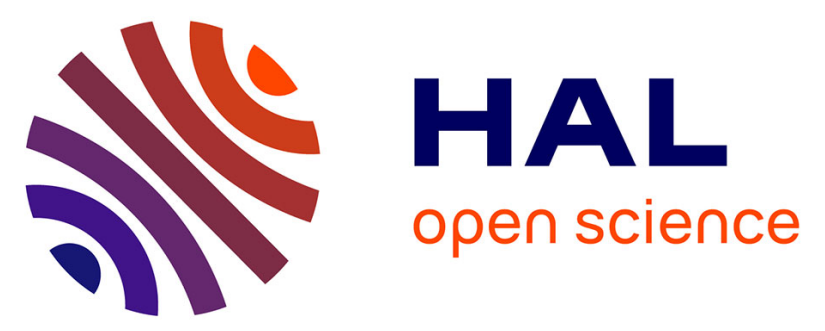

\title{
Auto-degradable and biocompatible superparamagnetic iron oxide nanoparticles/polypeptides colloidal polyion complexes with high density of magnetic material
} Bin Wang, Olivier Sandre, Kunzhou Wang, Haishan Shi, Kun Xiong, Yu-Bin Huang, Tingting Wu, Minhao Yan, Jérémie Courtois

\section{To cite this version:}

Bin Wang, Olivier Sandre, Kunzhou Wang, Haishan Shi, Kun Xiong, et al.. Auto-degradable and biocompatible superparamagnetic iron oxide nanoparticles/polypeptides colloidal polyion complexes with high density of magnetic material. Materials Science and Engineering: C, 2019, 104, pp.109920. 10.1016/j.msec.2019.109920 . hal-02167584

\author{
HAL Id: hal-02167584 \\ https://hal.science/hal-02167584
}

Submitted on 28 Jun 2019

HAL is a multi-disciplinary open access archive for the deposit and dissemination of scientific research documents, whether they are published or not. The documents may come from teaching and research institutions in France or abroad, or from public or private research centers.
L'archive ouverte pluridisciplinaire HAL, est destinée au dépôt et à la diffusion de documents scientifiques de niveau recherche, publiés ou non, émanant des établissements d'enseignement et de recherche français ou étrangers, des laboratoires publics ou privés. 
Author manuscript version of paper accepted for publication in Mater. Sci. Eng. C, 2019, 109920, after peer review and technical editing by the publisher. DOI: 10.1016/j.msec.2019.109920

Regular article

\section{Auto-degradable and biocompatible superparamagnetic iron oxide nanoparticles/polypeptides colloidal polyion complexes with high density of magnetic material}

Bin Wang ${ }^{a}$, Olivier Sandre ${ }^{b}$, Kunzhou Wang ${ }^{a}$, Haishan Shi ${ }^{c}$, Kun Xiong ${ }^{a}$, Yu-bin Huang ${ }^{\mathrm{d}}$, Tingting $\mathrm{Wu}^{\mathrm{e}}$, Minhao Yan $^{\mathrm{a}, *}$ and Jérémie Courtois ${ }^{\mathrm{a}, *}$

${ }^{a}$ State Key Laboratory of Environment-friendly Energy Materials, Southwest University of Science and Technology, Mianyang 621010, China.

${ }^{b}$ Univ. Bordeaux, CNRS, Bordeaux INP, LCPO, UMR 5629, F-33600, Pessac, France.

${ }^{c}$ College of Chemistry and Materials Science, Jinan University, Guangzhou 510632, China.

${ }^{d}$ State Key Laboratory of Polymer Physics and Chemistry, Changchun Institute of Applied Chemistry, Chinese Academy of Sciences, Changchun 130022, P. R. China.

${ }^{e}$ Department of Bone and Joint Surgery, Institute of Orthopedic Diseases, The first Affiliated Hospital, Jinan University, Guangzhou, 510630, China.

* Corresponding authors.

E-mail addresses: yanminhao@swust.edu.cn (M. Yan), jeremiecourtois@,swust.edu.cn (J. Courtois).

Graphical abstract (size: $5 \mathrm{~cm}$ high $\times 13 \mathrm{~cm}$ broad):

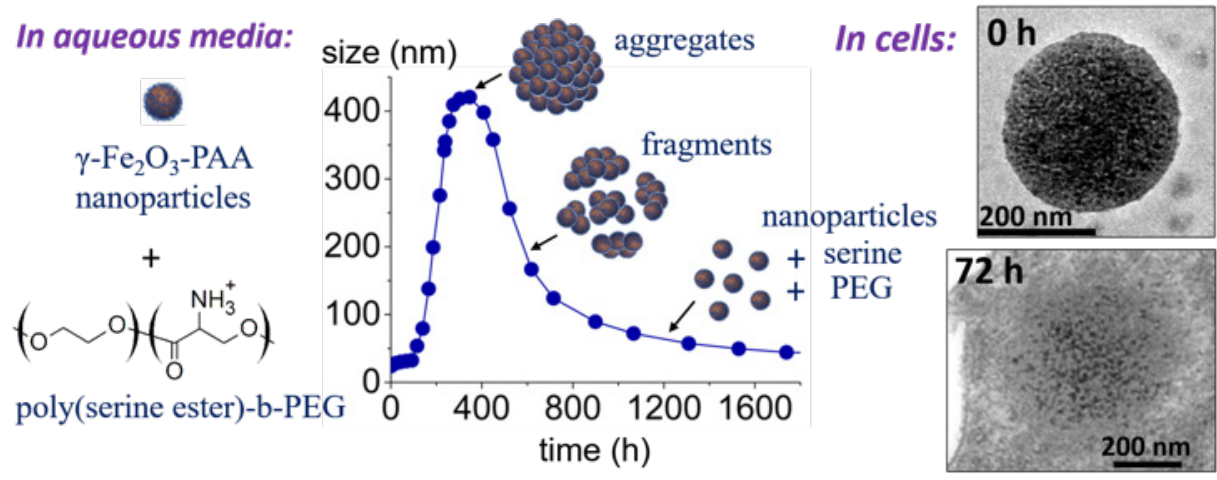


Author manuscript version of paper accepted for publication in Mater. Sci. Eng. C, 2019, 109920, after peer review and technical editing by the publisher. DOI: 10.1016/j.msec.2019.109920

\begin{abstract}
Hypothesis: superparamagnetic iron oxide nanoparticles (SPIONs) are extensively used as building block of colloidal nanocomposites for biomedical applications. Strategies employed to embed them in a biodegradable and biocompatible polymer matrix often fail to achieve a high density of loading which would greatly benefit to applications such as imaging and hyperthermia. In this study, poly(acrylic acid) coated SPION $\left(\gamma-\mathrm{Fe}_{2} \mathrm{O}_{3}-\mathrm{PAA}\right)$ are self-assembled with hydrolysable poly(serine ester) by electrostatic complexation, leading to perfectly defined spherical particles with ultra-high density of magnetic material and an ability to auto-degrade into individual SPION and biocompatible byproducts.
\end{abstract}

Experiments: self-assembly and auto-degradation of $\gamma-\mathrm{Fe}_{2} \mathrm{O}_{3}-\mathrm{PAA} /$ poly(serine ester) and $\gamma-\mathrm{Fe}_{2} \mathrm{O}_{3}-\mathrm{PAA} /$ poly(serine ester)- $b$-PEG colloidal particles are studied by light scattering and microscopy. Colloidal stability in bio-fluids, hyperthermia under alternating magnetic field, cellular uptake, cytotoxicity and degradation of $\gamma-\mathrm{Fe}_{2} \mathrm{O}_{3}-\mathrm{PAA} /$ poly(serine ester)- $b$-PEG in living cells are investigated.

Findings: a remarkably slow electrostatic complexation leads to dense superparamagnetic $\gamma-\mathrm{Fe}_{2} \mathrm{O}_{3}-\mathrm{PAA} /$ poly(serine ester)- $b$-PEG polyion complexes (PICs) with controlled sizes $(150-500 \mathrm{~nm})$ and times of degradation in aqueous solvents $(700-5000 \mathrm{~h})$. The material shows good sustainability during hyperthermia, is well taken up by MC3T3 cells and non-cytotoxic. TEM images reveal a mechanism of degradation by "peeling" and fragmentation. In cells, PICs are reduced into individual SPIONs within $72 \mathrm{~h}$. 
Author manuscript version of paper accepted for publication in Mater. Sci. Eng. C, 2019, 109920, after peer review and technical editing by the publisher. DOI: 10.1016/j.msec.2019.109920

\section{Keywords:}

Superparamagnetic iron oxide nanoparticle (SPION)

Polypeptide-based polyester

Polyion complex

Magnetic hyperthermia

Electrostatic complexation

Biodegradable

\section{Introduction}

Nanomaterials have matured significantly during the last decade as they have transitioned from lab bench science to applied technology. It is reasonable to expect that their utilization will rapidly increase and their eco- and bio-toxicities are therefore major concerns. Long-term effects of nanomaterials on environment and living systems are difficult to anticipate and study. ${ }^{[1-3]}$ The most direct approach to overcome toxicity issues is to design stable environment-friendly or biocompatible nanomaterials. However, their long-term effects will remain questioned. A smart alternative is therefore to develop nanomaterials with ability to self-degrade "by-design" into biocompatible sub-units. This way, toxicity issues are reduced to a time-scale for which exhaustive toxicological studies are possible whereas, at longer time scale, nanomaterials will no longer exist in their original form but as innocuous byproducts. In this work, focus is put on colloidal assemblies of nanoparticles. Particularly, we developed sub-micrometer polyionic complex clusters of Superparamagnetic Iron Oxide Nanoparticles (SPION) and 
Author manuscript version of paper accepted for publication in Mater. Sci. Eng. C, 2019, 109920, after peer review and technical editing by the publisher. DOI: 10.1016/j.msec.2019.109920

polyelectrolytes with an ability to auto-degrade into single nanoparticles and biocompatible molecular byproducts that can be eliminated through renal system. SPIONs are widely applied in materials science, biotechnology and nanomedicine. In bio-applications, SPIONs are mainly used as MRI contrast agents, drug delivery vectors and magnetic hyperthermia tools. ${ }^{[4-10]}$ For such applications, clustering iron oxide nanocrystals into colloidal aggregates bring several advantages such as higher macroscopic magnetic response, enhanced contrast in imaging and higher generation of heat in the case of hyperthermia treatment. ${ }^{[1-15]}$ Various strategies have been employed to aggregate SPIONs into colloidal nano- and micro-sized objects. $^{[11,16-21]}$

One of them consists in embedding SPIONs in a hydrolysable biocompatible polyester matrix, ${ }^{[22-26]}$ but with some difficulty to reach the high content in magnetic material required by applications. ${ }^{[24,26,27]}$ Another way is to densely pack SPIONs with oppositely charged polyelectrolytes into spherical or rod-like polyion complexes (PICs). ${ }^{[28-30]}$ Entropically driven self-assembly allows synthesis route as simple as direct mixing of the oppositely charged species. ${ }^{[31]}$ Dense PICs can be obtained by self-assembly of poly(acrylic acid) coated sub-10 $\mathrm{nm}$ maghemite nanoparticles $\left(\gamma-\mathrm{Fe}_{2} \mathrm{O}_{3}-\mathrm{PAA}\right)$ and either cationic homopolyelectrolytes, ${ }^{[30,31]}$ or cationic-block-neutral copolymer. Utilization of diblock copolymers helps to obtain colloidally stable spherical and monodisperse PICs. ${ }^{[28]}$ Sizes and microstructures of these PICs depend on concentration and charge ratio of the oppositely charged species during synthesis. Well-defined shapes, lower 
Author manuscript version of paper accepted for publication in Mater. Sci. Eng. C, 2019, 109920, after peer review and technical editing by the publisher. DOI: 10.1016/j.msec.2019.109920

polydispersity and higher densities of the clusters are obtained when building blocks are mixed at higher concentrations and at charge stoichiometry. ${ }^{[29,30,32]}$

Interaction between chemically stable $\gamma-\mathrm{Fe}_{2} \mathrm{O}_{3}-\mathrm{PAA} /$ copolymer rod-like PICs and living cells was studied in vitro. ${ }^{[33]}$ Observation by TEM revealed that $24 \mathrm{~h}$ after incubation, the PICs were internalized by cells and, interestingly, partly degraded into smaller fragments, suggesting that byproducts will be generated over time. These byproducts include $\gamma-\mathrm{Fe}_{2} \mathrm{O}_{3}$-PAA nanoparticles which have been recognized for their biocompatibility, ${ }^{[33,34,7]}$ but also potentially stable and toxic nano-sized fragments, polycations, ${ }^{[35]}$ and their various degradation products.

In the present study, issues arising from the long-term fate of $\gamma-\mathrm{Fe}_{2} \mathrm{O}_{3}$ PAA/polyelectrolyte PICs are overcome by replacing industrial cationic polyelectrolytes with biocompatible and biodegradable ones. ${ }^{[36]} \gamma-\mathrm{Fe}_{2} \mathrm{O}_{3}-\mathrm{PAA}$ nanoparticles are complexed with either poly(serine ester) (pSe) or poly(serine ester)-block-poly(ethylene glycol) (pSe-b-PEG), resulting in dense superparamagnetic colloidal clusters. On the one hand, positive charges of serine units allow self-assembly driven by electrostatic interaction with the negative charges of $\gamma-\mathrm{Fe}_{2} \mathrm{O}_{3}$-PAA nanoparticles, whilst hydrolysis of the ester bonds of pSe triggers its depolymerization and the complete disassembly of the nanostructured edifices in aqueous media over time on the other hand.

The first part of this article is dedicated to the physicochemical study of the synthesis of the auto-degradable PICs. Self-assembly of nanoparticles and polymers according to concentration and charge ratio are investigated. Kinetics and mechanisms of degradation are analyzed by light scattering and microscopy. 
Author manuscript version of paper accepted for publication in Mater. Sci. Eng. C, 2019, 109920, after peer review and technical editing by the publisher. DOI: 10.1016/j.msec.2019.109920

In the second part are presented results which aim to demonstrate the reliability of $\gamma-\mathrm{Fe}_{2} \mathrm{O}_{3}-\mathrm{PAA} / \mathrm{pSe}-b$-PEG PICs as biocompatible tools for biomedical applications. Heat generation induced by alternating magnetic field (AMF) stimulation, colloidal stability of $\gamma-\mathrm{Fe}_{2} \mathrm{O}_{3}-\mathrm{PAA} / \mathrm{pSe}-b$-PEG PICs in bio-fluids, amount of materials internalized by MC3T3-E1 cells and cell viability up to $72 \mathrm{~h}$ after incubation are investigated. Finally, rapid degradation of $\gamma-\mathrm{Fe}_{2} \mathrm{O}_{3}-\mathrm{PAA} / \mathrm{pSe}-b-\mathrm{PEG}$ PICs in cells was demonstrated by TEM analysis of cells in resin sections.

\section{Materials and methods}

\subsection{Synthesis and characterization}

\subsubsection{Materials}

$\mathrm{FeCl}_{2} \cdot 4 \mathrm{H}_{2} \mathrm{O} ; \mathrm{FeCl}_{3}$ in solution at $27 \mathrm{wt} \%$ in $\mathrm{H}_{2} \mathrm{O}$, poly(sodium acrylate) $\left(M_{w}=2000 \mathrm{~g}\right.$ $\mathrm{mol}^{-1}$, molar mass dispersity $\left.=1.7\right)$, DL-serine $(\geq 98 \%)$, poly $($ ethylene glycol $)\left(M_{W}=\right.$ $\left.10000 \mathrm{~g} \mathrm{~mol}^{-1}\right)\left(\mathrm{PEG}_{10 \mathrm{~K}}\right)$, Dulbecco's Phosphate Buffer Saline $\mathrm{CaCl}_{2}$ and $\mathrm{MgCl}_{2}$ free (PBS1×, powder), Dulbecco's Modified Eagle Medium (DMEM) without glucose, Lglutamine, phenol red, sodium pyruvate and sodium bicarbonate (powder) and RPMI 1640 cell culture medium with L-glutamine, without glucose and sodium bicarbonate (powder) were purchased from Aldrich. Fetal Bovine Serum (FBS no.10099-141) used for Dynamic Light Scattering (DLS) experiments was purchased from Gibco, USA. Simulated Body Fluid was prepared following the procedure described by Kokubo et al. ${ }^{[37]}$ SPI-Pon 812 epoxy resin Monomer (glyceringlycidether) (CAS: 90529-77-4) was purchased from SPI. All reagents and solvents were commercial grade and used as 
Author manuscript version of paper accepted for publication in Mater. Sci. Eng. C, 2019, 109920, after peer review and technical editing by the publisher. DOI: 10.1016/j.msec.2019.109920

received without further purification. $18 \mathrm{M} \Omega \mathrm{cm}$ resistivity MilliQ ${ }^{\circledR}$ quality (Millipore) deionized water was used.

\subsubsection{Synthesis and characterization of poly(acrylic acid) coated iron oxide nanoparticles $\left(\gamma-\mathrm{Fe}_{2} \mathrm{O}_{3}\right.$-PAA)}

Poly(acrylic acid) (PAA) coated iron oxide nanoparticles were prepared following reported protocols. In brief, magnetite $\left(\mathrm{Fe}_{3} \mathrm{O}_{4}\right)$ nanocrystals were synthesized by co-precipitation of iron (II) and iron (III) salts in aqueous alkaline medium at room temperature. ${ }^{[38]}$ The nanocrystals were then transferred in diluted nitric acid $(\mathrm{pH}=$ 1.8) and oxidized by the addition of $\mathrm{Fe}\left(\mathrm{NO}_{3}\right)_{3}$ at boiling temperature for $30 \mathrm{~min}$. Change in colour of the dispersion from black to dark red-orange indicates formation of maghemite $\left(\gamma-\mathrm{Fe}_{2} \mathrm{O}_{3}\right) \cdot{ }^{[39]}$ In order to decrease their polydispersity, $\gamma$ $\mathrm{Fe}_{2} \mathrm{O}_{3}$ nanoparticles were size-sorted by four subsequent liquid-liquid phase separations induced by the addition of nitric acid. ${ }^{[38,40,41]}$ Transmission Electron Microscopy (TEM) images of the obtained maghemite nanocrystals show almost spherical particles (Figure S1, Supporting Information). The size distribution of the particles is described by a log-normal function with a median diameter of $9.3 \mathrm{~nm}$ and a standard width of logarithm $\sigma=0.18$. Average size of the particles and maghemite structure are confirmed by XRD (Figure S2, Supporting Information). DLS analysis of nanocrystal dispersion at $\mathrm{pH}=1.8$ reveals a single population of particles with a hydrodynamic diameter $D_{H}\left(\gamma-\mathrm{Fe}_{2} \mathrm{O}_{3}, \mathrm{pH}=1.8\right)=29 \pm 1 \mathrm{~nm}$ and a polydispersity index PDI $=0.25 \pm 0.05$. The positively charged surface of the particles at low pH with $\xi_{p}\left(\gamma-\mathrm{Fe}_{2} \mathrm{O}_{3}, \mathrm{pH}=1.8\right)=+30 \mathrm{mV}$ ensures their colloidal stability. ${ }^{[42]}$ The molecular weight of $\gamma-\mathrm{Fe}_{2} \mathrm{O}_{3}$ nanoparticles was determined by 
Author manuscript version of paper accepted for publication in Mater. Sci. Eng. C, 2019, 109920, after peer review and technical editing by the publisher. DOI: 10.1016/j.msec.2019.109920

Static Light Scattering (SLS) and found to be $5.82 \times 10^{6} \mathrm{~g} \mathrm{~mol}^{-1}$ (Supporting Information).

The bare maghemite nanocrystals were then coated with poly(acrylic acid) (PAA) oligomers $\left(M_{w}=2000 \mathrm{~g} \mathrm{~mol}^{-1}\right)$ using the precipitation-redispersion process. ${ }^{[4,44]}$ $D_{H}$ and polydispersity of $\gamma-\mathrm{Fe}_{2} \mathrm{O}_{3}$-PAA dispersion at $\mathrm{pH}=7$ are $34 \pm 1 \mathrm{~nm}$ and $0.25 \pm 0.05$, respectively. This $D_{H}$ is $5 \mathrm{~nm}$ larger than that of the bare particles, indicating the presence of PAA layer surrounding the particles which has been measured by Small Angle Neutron Scattering to be $1.25 \mathrm{~nm}$ thick. ${ }^{[45]}$ Colloidal stability of $\gamma-\mathrm{Fe}_{2} \mathrm{O}_{3}$-PAA is function of the negative charges density of the PAA layer, which depends on the $\mathrm{pH}$ of the dispersion. ${ }^{[43]}$ Surface charge density of $\gamma$ $\mathrm{Fe}_{2} \mathrm{O}_{3}$-PAA depending on $\mathrm{pH}$ was determined by acid-base titration according to the method developed by M. Szekeres (Figure S3, Supporting Information). ${ }^{[46]}$ At $\mathrm{pH}=7$, the amount of surface carboxylate groups is $0.577 \mathrm{mmol}$ per $\mathrm{g}$ of iron oxide, corresponding to $3347 \pm 50$ negative elementary charges per nanoparticle and correlated to a $\xi_{p}$ of $-48 \mathrm{mV}$ which is negative enough to prevent aggregation. ${ }^{[47]}$

The superparamagnetic behaviour of $\gamma-\mathrm{Fe}_{2} \mathrm{O}_{3}$ and $\gamma-\mathrm{Fe}_{2} \mathrm{O}_{3}-\mathrm{PAA}$ nanoparticle dispersions were evidenced by vibrating sample magnetometry (VSM) with respective values of magnetization at saturation of $46.2 \mathrm{emu} \mathrm{g}^{-1}$ and $44.1 \mathrm{emu} \mathrm{g}^{-1}$ (Figure S4, Supporting Information).

In this work, the nanoparticle concentration is defined by the percentage by weight of iron oxide in the dispersion and is determined from the whole UV-Vis spectrum measurement between 220 and $800 \mathrm{~nm}$ using a priory made master curve obtained by 
Author manuscript version of paper accepted for publication in Mater. Sci. Eng. C, 2019, 109920, after peer review and technical editing by the publisher. DOI: 10.1016/j.msec.2019.109920

independent iron titration by Inductively Coupled Plasma Atomic Emission Spectroscopy (ICP-AES) (Figure S5, Supporting Information). The method is both very sensitive and non-disruptive. ${ }^{[48]}$

\subsubsection{Synthesis of poly(serine ester) (pSe) and poly(serine ester)-b-poly(ethylene glycol) (pSe-b-PEG)}

pSe homopolyelectrolytes and pSe- $b$-PEG diblock copolymer were synthesized according to previously reported protocol. ${ }^{[36]}$ The $M_{w}$ were determined by gel permeation chromatography (GPC). Briefly, poly(N-trityl serine lactone) with $M_{w}(\mathrm{pTSL})=33050 \mathrm{~g}$ $\mathrm{mol}^{-1}$ (pTSL $\left.33 \mathrm{~K}\right)$, and poly(N-trityl serine lactone)- $b$-PEG with $M_{w}(\mathrm{pTSL})=33050 \mathrm{~g} \mathrm{~mol}^{-}$

${ }^{1}$ and $M_{w}(\mathrm{PEG})=10000 \mathrm{~g} \mathrm{~mol}^{-1}\left(\mathrm{pTSL}_{33 \mathrm{~K}}-b-\mathrm{PEG}_{10 \mathrm{~K}}\right)$, were synthesized via ring-opening polymerization of N-trityl serine lactone with diethyl zinc as catalyst. Trityl groups were further removed by trifluoroacetic acid and methanol in dichloromethane at room temperature. This de-protection procedure induces a polyelectrolyte backbone degradation about $20 \%$ whereas the $\mathrm{PEG}_{10 \mathrm{~K}}$ block did not degrade. ${ }^{[36,49]}$ The obtained pSe and pSe- $b$-PEG with acetate counter-ions are characterized by a $M_{w}(\mathrm{pSe}$, Acetate $)=$ $11840 \mathrm{~g} \mathrm{~mol}^{-1}$, corresponding to an average degree of polymerization $D P(\mathrm{pSe})=80$.

\subsubsection{Preparation of $\gamma-\mathrm{Fe}_{2} \mathrm{O}_{3}-\mathrm{PAA} / \mathrm{pSe}$ and $\gamma-\mathrm{Fe}_{2} \mathrm{O}_{3}-\mathrm{PAA} / \mathrm{pSe}-b$-PEG polyion complexes (PICs)}

$\gamma-\mathrm{Fe}_{2} \mathrm{O}_{3}-\mathrm{PAA} / \mathrm{pSe}$ (respectively $\gamma-\mathrm{Fe}_{2} \mathrm{O}_{3}-\mathrm{PAA} / \mathrm{pSe}-b$-PEG) PICs were prepared at room temperature by direct mixing of $\gamma-\mathrm{Fe}_{2} \mathrm{O}_{3}-\mathrm{PAA}$ nanoparticle dispersions and pSe (respectively pSe- $b$-PEG) solutions in the same solvent (water or Phosphate Buffer Saline $(\mathrm{PBS} 1 \times))$ and at the same weight concentrations $\left(\left[\gamma-\mathrm{Fe}_{2} \mathrm{O}_{3}\right]=\right.$ [polymer]). The charge ratio in reactive species $Z$ of a nanoparticle/polymer 
Author manuscript version of paper accepted for publication in Mater. Sci. Eng. C, 2019, 109920, after peer review and technical editing by the publisher. DOI: 10.1016/j.msec.2019.109920

mixture is calculated as the amount of negative charges brought by the carboxylate groups of the $\gamma-\mathrm{Fe}_{2} \mathrm{O}_{3}$-PAA dispersion divided by the amount of positive charges brought by the ammonium groups of the polyelectrolyte solution. Desired values of $Z$ are obtained by mixing nanoparticles and polymer solutions in appropriated volumes. $Z$ are calculated considering $0.577 \mathrm{mmol}$ of negative charges per $\mathrm{g}$ of iron oxide (determined by acid-base titration of $\gamma-\mathrm{Fe}_{2} \mathrm{O}_{3}-\mathrm{PAA}$ ) and 80 positive charges ( $D P$ of $\mathrm{pSe}$ blocks) per polymer chain. Indeed, $p K a$ of the amino group of serine being 9.15, approximation is made that all the amino groups of pSe blocks are charged $\left(-\mathrm{NH}_{3}{ }^{+}\right)$at $\mathrm{pH} \approx 7$. Preparation and composition of the samples are detailed in the Supporting Information (Table S1 and S2).

\subsection{Experimental methods}

\subsubsection{Dynamic Light Scattering (DLS)}

DLS experiments were made on a Brookhaven 90plus instrument to measure the collective diffusion coefficient $D$. The wavelength of the light source was $\lambda=$ $632.8 \mathrm{~nm}$, the scattering angle $\theta=90^{\circ}$, and the temperature $T=25^{\circ} \mathrm{C}$. The autocorrelation functions of the scattered light were interpreted using both the method of $2^{\text {nd }}$ order cumulants and the CONTIN fitting procedure provided by the instrument software. Hydrodynamic diameters $\left(D_{H}\right)$ of colloids were calculated according to the Stokes-Einstein relation, $D_{H}=k_{B} T / 3 \pi \eta D$, where $k_{B}$ is the Boltzmann constant, $T$ the temperature and $\eta$ the solvent viscosity $(0.89 \mathrm{mPa} \mathrm{s})$.

\subsubsection{Electron microscopy}


Author manuscript version of paper accepted for publication in Mater. Sci. Eng. C, 2019, 109920, after peer review and technical editing by the publisher. DOI: 10.1016/j.msec.2019.109920

Transmission Electron Microscopy (TEM) and Scanning Electron Microscopy (SEM) analysis of $\gamma$ - $\mathrm{Fe}_{2} \mathrm{O}_{3}-\mathrm{PAA} / \mathrm{pSe}$ and $\gamma-\mathrm{Fe}_{2} \mathrm{O}_{3}-\mathrm{PAA} / \mathrm{pSe}-b$-PEG PICs were performed on a Zeiss Libra200FE microscope (TEM) and a Zeiss EVO 18 (SEM). For TEM study of cells, the following protocol was applied. $\gamma-\mathrm{Fe}_{2} \mathrm{O}_{3}-\mathrm{PAA} / \mathrm{pSe}-b$ PEG PICs (synthesized at $c=6 \times 10^{-4} \mathrm{wt} \%$ and $Z=1$ in PBS1 $1 \times, t=304 \mathrm{~h}, D_{H}=$ $414 \mathrm{~nm}$ ) were incubated with MC3T3-E1 cells at $\left[\gamma-\mathrm{Fe}_{2} \mathrm{O}_{3}\right]=6 \times 10^{-3} \mathrm{wt} \%$ for 24 $\mathrm{h}, 48 \mathrm{~h}$ and $72 \mathrm{~h}$ (see: Cell culture and Incubation of cells with $\gamma-\mathrm{Fe}_{2} \mathrm{O}_{3}-\mathrm{PAA} / \mathrm{pSe}$ $b-P E G$ for details). After incubation, excess of medium was removed, and cells were washed in $0.2 \mathrm{M}$ PBS $(\mathrm{pH}=7.4)$ and fixed in $2 \%$ glutaraldehyde-phosphate buffer $0.1 \mathrm{M}$ for $1 \mathrm{~h}$ at room temperature. Fixed cells were washed in $0.2 \mathrm{M}$ PBS. Then, they were postfixed in $1 \%$ osmium-phosphate buffer $0.1 \mathrm{M}$ for $2 \mathrm{~h}$ at $20^{\circ} \mathrm{C}$ in dark conditions. After 0.1 M PBS washes, the samples were dehydrated in increasing concentrations of ethanol/acetone mixtures and embedded in SPI-Pon 812 epoxy resin. $70 \mathrm{~nm}$-thick sections were cut with an ultramicrotome (LEICA, UC7), stained in uranyl acetate and lead citrate, and analyzed with a Hitachi HT7700 electron microscope.

\subsubsection{Magnetic hyperthermia}

The experimental setup used for magnetic field hyperthermia is described in previous publication. ${ }^{[50]}$ In brief, a radiofrequency power generator delivers current to a 4-turn coil of $55 \mathrm{~mm}$ outer diameter. In our experiment, quasi-sinusoidal alternating magnetic field at $f=755 \mathrm{kHz}$ and $B_{0}=13 \mathrm{mT}$ (field strength $H_{0}=10$ kA m ${ }^{-1}$ ) was generated. $\gamma$ - $\mathrm{Fe}_{2} \mathrm{O}_{3}-\mathrm{PAA} / \mathrm{pSe}-b$-PEG PICs (synthesized at $c=6 \times 10^{-4}$ 
Author manuscript version of paper accepted for publication in Mater. Sci. Eng. C, 2019, 109920, after peer review and technical editing by the publisher. DOI: 10.1016/j.msec.2019.109920

$\mathrm{wt} \%$ and $Z=1$ in water) were concentrated by solvent evaporation to $\left[\gamma-\mathrm{Fe}_{2} \mathrm{O}_{3}\right]=$ $8.8 \times 10^{-3} \mathrm{wt}^{\%} 374 \mathrm{~h}$ after direct mixing. Sample $(2 \mathrm{~mL}$ in a closed polystyrene cuvette with an immerged optic fibre temperature probe, Opens ${ }^{\mathrm{TM}}$, Quebec city, Quebec CA) was placed inside the coil. The macroscopic temperature of the sample was measured every second. Once thermal equilibrium was reached to an initial temperature about $38^{\circ} \mathrm{C}$ set by a water circulation jacket, the alternating magnetic field was applied for $33 \mathrm{~min}$ and then switched off. After recovery of thermal equilibrium, magnetic field was applied a second time for $51 \mathrm{~min}$.

\subsubsection{Relaxometry}

Longitudinal $(r 1)$ and transverse $(r 2)$ relaxation rates of hydrogen nuclear spins were measured at $1.41 \mathrm{~T}\left(60 \mathrm{MHz}{ }^{1} \mathrm{H}\right.$ resonance, i. e. close to the 1.5 Tesla clinical MRI scanners) and $37{ }^{\circ} \mathrm{C}$ on a Bruker Minispec mq60 relaxometer using respectively an inversion-recovery (IR) and Carr-Purcell-Meiboom-Gill (CPMG) spin-echo sequences. Repetition time (TR), echo time (TE), and number of data points were adjusted carefully to minimize the experimental uncertainty on the measured $T_{1}$ and $T_{2}$ values for a series of iron concentrations [Fe] of 5, 2, and 0.4 $\mathrm{mM}$ for individual $\gamma-\mathrm{Fe}_{2} \mathrm{O}_{3}$-PAA nanoparticles, and of $0.0752,0.0251$ and 0.00835 $\mathrm{mM}$ for $\gamma-\mathrm{Fe}_{2} \mathrm{O}_{3}-\mathrm{PAA} / \mathrm{pSe}-b$-PEG PICs. The receiver gain was adjusted between 45 and $53 \mathrm{~dB}$ to optimize signal-to-noise ratio without saturation. For the IR sequence, initial delay time was adjusted around $T_{1} / 10$, while the final delay was at least $3 T_{1}$, and the recycling delay (RD) at least $5 T_{1}$, according to recommendations for relaxometry measurements. ${ }^{[51]} \mathrm{RD}$ was kept constant for the 
Author manuscript version of paper accepted for publication in Mater. Sci. Eng. C, 2019, 109920, after peer review and technical editing by the publisher. DOI: 10.1016/j.msec.2019.109920

CPMG sequence, while choosing an echo time (TE) around $T_{2} / 50$ and a number of data points from 150 to 250 , the decay curve of transverse magnetization being fitted by a mono-exponential law. Relaxivities were obtained from the slope of the linear variation with $[\mathrm{Fe}]$ in $\mathrm{mM}$ of the longitudinal (respectively transverse) decay rate of water ${ }^{1} \mathrm{H}$ after subtraction of respective value measured on pure water.

\subsubsection{Transfer of $\gamma-\mathrm{Fe}_{2} \mathrm{O}_{3}-\mathrm{PAA} / \mathrm{pSe}-b$-PEG polyion complexes in bio-fluids for DLS analysis} $\gamma-\mathrm{Fe}_{2} \mathrm{O}_{3}-\mathrm{PAA} / \mathrm{pSe}-b$-PEG PICs at $Z=1$ were prepared in water at $T=25{ }^{\circ} \mathrm{C}$ from solutions at $\left[\gamma-\mathrm{Fe}_{2} \mathrm{O}_{3}\right]=[\mathrm{pSe}]=6 \times 10^{-4} \mathrm{wt} \% .342 \mathrm{~h}$ after mixing, cluster dispersion with $D_{H}=417 \pm 15 \mathrm{~nm}$ was concentrated to $\left[\gamma-\mathrm{Fe}_{2} \mathrm{O}_{3}\right]=7.2 \times 10^{-3} \mathrm{wt} \%$ by solvent evaporation and transferred into Simulated Body Fluid (SBF), DMEM, DMEM supplemented with $3.7 \mathrm{~g} \mathrm{~L}^{-1}$ of $\mathrm{NaHCO}_{3}$, DMEM containing $10 \mathrm{vol} \%$ of fetal bovine serum (FBS), RPMI, RPMI supplemented with $2 \mathrm{~g} \mathrm{~L}^{-1}$ of $\mathrm{NaHCO}_{3}$ and RPMI containing 10 vol\% of FBS as $\left[\gamma-\mathrm{Fe}_{2} \mathrm{O}_{3}\right]=6 \times 10^{-4} \mathrm{wt} \%$. Samples were then incubated at $T=37{ }^{\circ} \mathrm{C}$ and shaken at 79 rpm. $D_{H}$ measurements were performed at $T=37^{\circ} \mathrm{C}$.

\subsubsection{Cell culture, incubation with $\gamma-\mathrm{Fe}_{2} \mathrm{O}_{3}-\mathrm{PAA} / \mathrm{pSe}-b$-PEG, cell viability assessment and amount of iron oxide internalized}

Cell culture: MC3T3-E1 (CRL-2593, ATCC, USA) and HepG2 cells (HB-8065, ATCC, USA) were maintained in cell culture flasks and sub-cultivated in a cell incubator at $37{ }^{\circ} \mathrm{C}\left(5 \% \mathrm{CO}_{2}\right.$ atmosphere, $95 \%$ relative humidity). Minimum Essential Medium Alpha Basic ( $\alpha$-MEM, Gibco, USA) with 10 vol\% fetal bovine 
Author manuscript version of paper accepted for publication in Mater. Sci. Eng. C, 2019, 109920, after peer review and technical editing by the publisher. DOI: 10.1016/j.msec.2019.109920

serum (FBS, PAN Biotech, Germany) and DMEM with 10 vol\% FBS and 1\% Penicillin-Streptomycin solution (Gibco, USA) were respectively applied for MC3T3-E1 and HepG2 cell cultures. Media were replenished daily. After 4 passages for MC3T3-E1 and 7 passages for HepG2, cells were detached by $0.25 \%$ trypsin/EDTA (Gibco, USA) as soon as they were confluent in the bottom of the culture flasks and used for the seeding and viability assessments. Cells were directly seeded onto 96-well tissue culture plates with an initial density of $2 \times 10^{4}$ cells per well.

Incubation of cells with $\gamma-\mathrm{Fe}_{2} \mathrm{O}_{3}-\mathrm{PAA} / \mathrm{pSe}-\mathrm{b}-\mathrm{PEG}$ : $\gamma-\mathrm{Fe}_{2} \mathrm{O}_{3}-\mathrm{PAA} / \mathrm{pSe}-b-\mathrm{PEG}$ PICs (synthesized at $c=6 \times 10^{-4} \mathrm{wt} \%$ and $Z=1$ in PBS1 $1 \times, t=304 \mathrm{~h}$ after direct mixing, $D_{H}=414 \pm 10 \mathrm{~nm}$ ) were concentrated by solvent evaporation to $\left[\gamma-\mathrm{Fe}_{2} \mathrm{O}_{3}\right]=7.2 \times$ $10^{-2} \mathrm{wt} \%$, sterilized by UV irradiation and transferred into culture media. After the $24 \mathrm{~h}$ required for cellular adhesion, culture media were replaced by freshly prepared media containing the $\gamma-\mathrm{Fe}_{2} \mathrm{O}_{3}$-PAA/pSe- $b$-PEG PICs $(200 \mu \mathrm{L}$ per well) so that concentrations in iron oxide in wells were respectively $0,6 \times 10^{-5}, 6 \times 10^{-4}$, $6 \times 10^{-3}$ and $6 \times 10^{-2} \mathrm{wt} \%$ (corresponding to $[\mathrm{Fe}]=0,7.51 \times 10^{-3}, 7.51 \times 10^{-2}$, 0.751 and $7.51 \mathrm{mM}$, respectively). After being co-cultured with $\gamma-\mathrm{Fe}_{2} \mathrm{O}_{3}$-PAA /pSe- $b$-PEG PICs for respectively $24 \mathrm{~h}, 48 \mathrm{~h}$ and $72 \mathrm{~h}$, the supernatants were collected and cells gently washed eight times with PBS (200 $\mu \mathrm{L}$ per well).

Cell viability assessment: quantitative cell viability assessments were conducted using a Cell Counting Kit-8 (CCK-8, Dojindo, Japan). This assay is based on the conversion of WST-8 (monosodium salt) into a highly water-soluble formazan dye upon bioreduction in the presence of an electron carrier (1-Methoxy PMS), 
Author manuscript version of paper accepted for publication in Mater. Sci. Eng. C, 2019, 109920, after peer review and technical editing by the publisher. DOI: 10.1016/j.msec.2019.109920

enabling the determination of the number of viable cells by UV-vis spectrometry. After incubation of cells with $\gamma-\mathrm{Fe}_{2} \mathrm{O}_{3}-\mathrm{PAA} / \mathrm{pSe}-b$-PEG PICs, the PBS washes were slowly sucked out and CCK-8 working solution $(120 \mu \mathrm{L})$ was directly added into each well. Subsequently, the plates were incubated at $37^{\circ} \mathrm{C}$ for $1 \mathrm{~h}$. Then, supernatant $(100 \mu \mathrm{L})$ was extracted from each well and transferred into a new 96well plate. Optical Densities (OD), which correspond to the absorbance of the isolated supernatants at $450 \mathrm{~nm}$, were measured using a microplate reader (Varioskan Flash Multimode Reader, Thermo Scientific, USA). The numbers of living cells corresponding to the respective OD values were determined using calibration curves (Figure S6, Supporting Information).

Determination of the amount of iron oxide adsorbed and internalized by cells: Immediately after cell viability assessment, cells were extensively washed with PBS and detached by $0.25 \%$ trypsin/EDTA mixture (Gibco, USA) $(50 \mu \mathrm{L}$ per well). After $5 \mathrm{~min}$, the trypsinized cells were mixed with PBS (150 $\mu \mathrm{L}$ per well) and collected. Then, the collected samples (cells with adsorbed or internalized $\gamma-$ $\mathrm{Fe}_{2} \mathrm{O}_{3}-\mathrm{PAA} / \mathrm{pSe}-b$-PEG material) were digested in $35 \mathrm{vol} \% \mathrm{HCl}$ and their contents in iron determined by Inductively Coupled Plasma Mass Spectrometry (ICP-MS, ThermoFisher iCAP6500ICP-MS). The corresponding numbers of cells were determined during cell viability assessments (see Cell viability assessment in this part).

\section{Results and discussion}

\subsection{Properties of $\gamma-\mathrm{Fe}_{2} \mathrm{O}_{3}$-PAA, pSe and pSe- $b$-PEG}


Author manuscript version of paper accepted for publication in Mater. Sci. Eng. C, 2019, 109920, after peer review and technical editing by the publisher. DOI: 10.1016/j.msec.2019.109920

Superparamagnetic iron oxide nanoparticles, $9.3 \mathrm{~nm}$ in diameter, coated with poly(acrylic acid) oligomers $\left(\gamma\right.$ - $\mathrm{Fe}_{2} \mathrm{O}_{3}$-PAA), poly(serine ester) (pSe) and poly(serine ester- $b$-PEG) (pSe- $b$-PEG) are the building blocks used in this study. A schematic representation of the $\gamma-\mathrm{Fe}_{2} \mathrm{O}_{3}$-PAA nanoparticles, their physical properties, and molecular structures of pSe and pSe- $b$-PEG are presented in Figure 1. In aqueous media and at neutral $\mathrm{pH}$, the nanoparticles have negatively charged surface carboxylate groups correlated with a $\xi_{p}(\gamma-$ $\mathrm{Fe}_{2} \mathrm{O}_{3}-\mathrm{PAA}$ at $0.06 \mathrm{wt} \%$ in $\left.\mathrm{H}_{2} \mathrm{O}, \mathrm{pH}=7\right)=-48 \mathrm{mV}$ whereas pSe and pSe- $b$-PEG have positive charges all along pSe blocks with $\xi_{p}\left(\right.$ pSe at $0.06 \mathrm{wt} \%$ in $\left.\mathrm{H}_{2} \mathrm{O}, \mathrm{pH}=7\right)=+22 \mathrm{mV}$ due to the ammonium groups of serine units. Polyion complexation between these oppositely charged building blocks drives their self-assembly into nanoparticles/polymer clusters, also named polyion complexes (PICs) in the article.

\subsection{Synthesis and degradation of $\gamma-\mathrm{Fe}_{2} \mathrm{O}_{3}-\mathrm{PAA} / \mathrm{pSe}$ polyion complexes}

Figure 2a presents hydrodynamic diameters $\left(D_{H}\right)$ of mixtures of $\gamma-\mathrm{Fe}_{2} \mathrm{O}_{3}-\mathrm{PAA}$ and pSe homopolyelectrolytes in water at charge ratio $Z=1$ and at different concentrations (see Experimental section) as a function of time. Aggregation phenomenon depends on concentration of reactive species. When nanoparticles and pSe are mixed at $c=6 \times 10^{-3} \mathrm{wt} \%$ (with $c=\left[\gamma-\mathrm{Fe}_{2} \mathrm{O}_{3}\right]=[\mathrm{pSe}]$ ), aggregation does not occurs as attested by the constant value of $D_{H}$ over time (Figure 2, red symbols). This is probably because, at this concentration of charged species, the ionic strength $\left(I_{S}\right)$ is high enough to screen electrostatic interaction. At $c=6 \times 10^{-4}$ $\mathrm{wt} \%$ (Figure $2 \mathrm{a}$, dark red symbols), $D_{H}$ reaches a value of $\approx 220 \mathrm{~nm} 210 \mathrm{~h}$ after mixing, which is evidence of the formation of PICs. Complexation at this 
Author manuscript version of paper accepted for publication in Mater. Sci. Eng. C, 2019, 109920, after peer review and technical editing by the publisher. DOI: 10.1016/j.msec.2019.109920

concentration in the presence of added $\mathrm{NH}_{4} \mathrm{Cl}$ electrolyte was studied by DLS to determine the influence of the ionic strength (Figure S7, Supporting Information). Results show that aggregation occurs at $\left[\mathrm{NH}_{4} \mathrm{Cl}\right]=0.1 \mathrm{M}$ but does not at $\left[\mathrm{NH}_{4} \mathrm{Cl}\right]$ $=1 \mathrm{M}$, which proves the electrostatic nature of the association. ${ }^{[31,52]}$ Thus, among the attractive intermolecular interactions, long-range van der Waals forces are not sufficient to trigger co-assembly ; short-range Coulombic forces are required. ${ }^{[31]}$ An interesting phenomenon is the delayed aggregation of nanoparticles and $\mathrm{pSe}$ chains at $c=6 \times 10^{-4} \mathrm{wt}^{\%}$ (Figure 2a, dark red symbols). Indeed, the $D_{H}$ of the mixture remains at the constant value of single nanoparticles during $45 \mathrm{~h}$ before it starts to increase. A possible explanation is that at this concentration, $I_{S}$ is at a critical value for which electrostatic interactions are almost screened. Consequently, oppositely charged species only aggregate slowly and particle growth occurs in a reaction-controlled manner rather than diffusion-controlled. That allows the formation of dense colloidal clusters instead of formation of a fractal macroscopic precipitate. ${ }^{[31]}$ As concentration and therefore $I_{S}$ decrease, larger clusters are formed and with faster kinetics. Once aggregation starts, increases of $D_{H}$ according to the time are almost linear with values of $1.42 \mathrm{~nm} \mathrm{~h}^{-1}$, $1.73 \mathrm{~nm} \mathrm{~h}^{-1}$ and $2.80 \mathrm{~nm} \mathrm{~h}^{-1}$ for $c=6 \times 10^{-4} \mathrm{wt}^{\%}, 6 \times 10^{-5} \mathrm{wt}^{\%}$ and $6 \times 10^{-6} \mathrm{wt}^{\mathrm{o}} \%$, respectively. The highest reached values of $D_{H}$ are $220 \mathrm{~nm}, 640 \mathrm{~nm}$ and $1150 \mathrm{~nm}$ for $c=6 \times 10^{-4} \mathrm{wt} \%$ at $t=210 \mathrm{~h}, c=6 \times 10^{-5} \mathrm{wt} \%$ at $t=307 \mathrm{~h}$ and $c=6 \times 10^{-6}$ wt $\%$ at $t=337 \mathrm{~h}$, respectively. A scanning electron micrograph of a $\gamma-\mathrm{Fe}_{2} \mathrm{O}_{3}-$ $\mathrm{PAA} / \mathrm{pSe}$ PIC obtained at $c=6 \times 10^{-5} \mathrm{wt} \% 300 \mathrm{~h}$ after mixing is presented in Figure $2 \mathrm{~b}$. Its irregular shape and nano-structure are interpreted as resulting from 
Author manuscript version of paper accepted for publication in Mater. Sci. Eng. C, 2019, 109920, after peer review and technical editing by the publisher. DOI: 10.1016/j.msec.2019.109920

an inhomogeneous assembly of small and dense aggregates which suggest a diffusion-limited growth mechanism. ${ }^{[31]}$ The image also shows numerous single nanoparticles which indicate a low degree of interaction.

After the $\gamma-\mathrm{Fe}_{2} \mathrm{O}_{3}-\mathrm{PAA} / \mathrm{pSe}$ PICs are formed, they slowly auto-degrade. At $c=6 \times$ $10^{-4} \mathrm{wt} \%, D_{H}$ decreases from $220 \mathrm{~nm}$ at $235 \mathrm{~h}$ to $34 \mathrm{~nm}$ at $t=940 \mathrm{~h}$, which corresponds to an average rate of $-0.26 \mathrm{~nm} \mathrm{~h}^{-1}$ (Figure 2a, dark red symbols). The decrease of the average size of the colloidal objects is the consequence of the fragmentation of the clusters into smaller and smaller units until single nanoparticles are recovered, as shown in Figure 1. As ester groups of pSe undergo hydrolysis in aqueous solvent, pSe chains become shorter and unable to interconnect nanoparticles. Consequently, $\gamma-\mathrm{Fe}_{2} \mathrm{O}_{3}-\mathrm{PAA} / \mathrm{pSe}$ edifices progressively collapse. Without acid-base catalysis, hydrolysis of ester bonds is slow, explaining the $\approx 30$ days required to achieve complete degradation of the clusters into single nanoparticles. It is assumed that pSe is progressively degraded into biocompatible serine amino-acids. Time of degradation of clusters prepared at $c=6 \times 10^{-5} \mathrm{wt} \%$ and $c=6 \times 10^{-6} \mathrm{wt} \%$ are about $740 \mathrm{~h}$ and $1450 \mathrm{~h}$ with rates of $-1.75 \mathrm{~nm} \mathrm{~h}^{-1}$ and $1.19 \mathrm{~nm} \mathrm{~h}^{-1}$, respectively (Figure 2a, orange and yellow symbols). For these two samples, the final stage of degradation process is characterized by the presence of stable colloids of $D_{H}=85 \mathrm{~nm}$ and $D_{H}=270 \mathrm{~nm}$, respectively. This result could be a consequence of the tendency for the released serine molecules to coat the surface of $\gamma-\mathrm{Fe}_{2} \mathrm{O}_{3}-\mathrm{PAA}$, which would decrease their $\xi_{p}$ and trigger aggregate formation. Such phenomenon would be $I_{S}$ dependent and can explain why such colloidal assembly of nanoparticles exist at $c \leq 6 \times 10^{-5} \mathrm{wt} \%$ but not at $c=6 \times 10^{-4} \mathrm{wt}$. In an 
Author manuscript version of paper accepted for publication in Mater. Sci. Eng. C, 2019, 109920, after peer review and technical editing by the publisher. DOI: 10.1016/j.msec.2019.109920

additional set of experiments, $\gamma-\mathrm{Fe}_{2} \mathrm{O}_{3}$-PAA were mixed with serine molecules from solutions at $\left[\gamma-\mathrm{Fe}_{2} \mathrm{O}_{3}\right]=[$ serine $]=6 \times 10^{-4} \mathrm{wt} \%, 6 \times 10^{-5} \mathrm{wt} \%$ and $6 \times 10^{-6}$ $\mathrm{wt} \%$, respectively, and as $Z=1$ (Supporting Information). Figure S8 presents the $D_{H}$ of the mixtures according to the time. At $c=6 \times 10^{-4} \mathrm{wt} \%$, aggregation of $\gamma$ $\mathrm{Fe}_{2} \mathrm{O}_{3}-\mathrm{PAA}$ and serine does not occur whereas at $c=6 \times 10^{-5} \mathrm{wt} \%$ and $c=6 \times 10^{-6}$ $\mathrm{wt} \%$, aggregates of respectively $190 \pm 15 \mathrm{~nm}$ and $290 \pm 20 \mathrm{~nm}$ are formed $45 \mathrm{~h}$ after mixing and remain stable over time. These results are in good agreement with what is observed for $\gamma-\mathrm{Fe}_{2} \mathrm{O}_{3}-\mathrm{PAA} / \mathrm{pSe}$ mixtures after degradation (Figure 2a) and comfort previously made hypothesis. Moreover, absence of aggregation between $\gamma$ $\mathrm{Fe}_{2} \mathrm{O}_{3}-\mathrm{PAA}$ and serine at $6 \times 10^{-4} \mathrm{wt} \%$ and the relatively small sizes of the colloidal objects obtained at $c \leq 6 \times 10^{-5} \mathrm{wt} \%$ as well as their stability suggest that polymeric architecture of the cationic moiety is mandatory for self-assembly of large auto-degradable PICs.

Furthermore, study of the degradation of pSe-b-PEG in water at $50{ }^{\circ} \mathrm{C}$ (Figure S9, Supporting Information) shows that pSe blocks are only slightly degraded within a period of $240 \mathrm{~h}$ and suggests that pSe chains were indeed involved in PICs formation.

To summarize, self-assembly of $\gamma-\mathrm{Fe}_{2} \mathrm{O}_{3}$-PAA nanoparticles and pSe into colloidal PICs is a concentration- and ionic strength-dependant electrostatically driven process. Optimum control on the complexation and on the degradation of the synthesized clusters is obtained at higher concentration, as long as physicochemical conditions do not forbid electrostatic interactions. 
Author manuscript version of paper accepted for publication in Mater. Sci. Eng. C, 2019, 109920, after peer review and technical editing by the publisher. DOI: 10.1016/j.msec.2019.109920

\subsection{Synthesis and degradation of $\gamma-\mathrm{Fe}_{2} \mathrm{O}_{3}-\mathrm{PAA} / \mathrm{pSe}-b$-PEG polyion complexes}

$\gamma-\mathrm{Fe}_{2} \mathrm{O}_{3}$-PAA nanoparticles were complexed with pSe- $b$-PEG copolymer to form colloidal clusters. The purpose of adding a PEG block to pSe chains is manifold.

First, a polyelectrolyte- $b$-neutral double hydrophilic block copolymer helps to obtain spherical clusters with controlled size and polydispersity. ${ }^{[28]}$ Second, PEG surface blocks generate steric repulsion which participate to colloidal stability. ${ }^{[53,54]}$ Third, hydrophilic PEG coating of colloidal objects increases their stealth capability toward immune system, thereby permitting longer circulation in blood stream..$^{[53,55-57]}$

Growth and degradation of $\gamma-\mathrm{Fe}_{2} \mathrm{O}_{3}$-PAA/pSe- $b$-PEG PICs were studied by DLS and TEM. In particular, influence of the charge ratio in reactive species $Z$ (see Experimental section) on size, nanostructure and morphology of the clusters was investigated. Figure 3 presents $D_{H}$ measurements according to the time of mixtures of $\gamma-\mathrm{Fe}_{2} \mathrm{O}_{3}-\mathrm{PAA}$ and pSe- $b-\mathrm{PEG}$ in PBS1 $1 \times$ at $\left[\gamma-\mathrm{Fe}_{2} \mathrm{O}_{3}\right]=[\mathrm{pSe}-b-\mathrm{PEG}]=$ $6 \times 10^{-4} \mathrm{wt} \%$ and at charge ratio $Z$ going from 0.1 to 100 . The results show that size of $\gamma-\mathrm{Fe}_{2} \mathrm{O}_{3}$-PAA/pSe- $b$-PEG PICs strongly depends on $Z$. At $Z=0.1$ (excess of pSe- $b$-PEG, Figure 3, blue symbols), large colloidal objects with $D_{H}=759 \mathrm{~nm}$ are formed at $t=283 \mathrm{~h}$. Then, $D_{H}$ of these PICs remains almost constant for $\approx 170$ $\mathrm{h}$ before degradation occurs. TEM image at an early stage of degradation $(t=598$ h, $D_{H}=598 \mathrm{~nm}$ ) shows a non-spherical dense cluster with smooth irregular edges (Figure S10a, Supporting Information). This aspect suggests that the cluster is mainly made of polymer. Decrease of $D_{H}$ from $t \approx 500 \mathrm{~h}$ to $t \approx 2000 \mathrm{~h}$ is the signature of the degradation process. At $t>2000 \mathrm{~h}$, the dispersion contains 
Author manuscript version of paper accepted for publication in Mater. Sci. Eng. C, 2019, 109920, after peer review and technical editing by the publisher. DOI: 10.1016/j.msec.2019.109920

colloidal objects of $D_{H} \approx 180 \mathrm{~nm}$ in a quasi-equilibrium state. At $Z=0.5$ (Figure 3 , red symbols), clusters of $D_{H}=535 \mathrm{~nm}$ are formed at $t=260 \mathrm{~h}$. This size is maintained for $\approx 260 \mathrm{~h}$ before degradation occurs at $\approx-1 \mathrm{~nm} \mathrm{~h}^{-1}$ for $200 \mathrm{~h}$. Then, fragments are slowly degraded into single nanoparticles. TEM image at $t=598 \mathrm{~h}$ of a cluster made at $Z=0.5$ shows compact assembly with irregular edges (Figure S10b).

At $Z=1,10$ and 100 (Figure 3, black, green and pink symbols, respectively), $\gamma$ $\mathrm{Fe}_{2} \mathrm{O}_{3}-\mathrm{PAA} / \mathrm{pSe}-b$-PEG PICs with respective $D_{H}=420 \mathrm{~nm}, 285 \mathrm{~nm}$ and $185 \mathrm{~nm}$ are obtained at $t=295 \pm 10 \mathrm{~h}$. TEM images of these clusters show very well defined spherical objects with densely packed maghemite nanocrystals (Figure 4a $\mathrm{S} 10 \mathrm{c}$ and $\mathrm{S} 10 \mathrm{~d})$. With growth periods as long as $\approx 300 \mathrm{~h}$, diffusion limited aggregation leading to inhomogeneous assembly (such as the one of the $\gamma-\mathrm{Fe}_{2} \mathrm{O}_{3}$ PAA/pSe PIC pictured in Figure 2b) or fractal clusters would have been expected. ${ }^{[31]}$ Instead, spherical morphology and dense nanostructure of $\gamma$ - $\mathrm{Fe}_{2} \mathrm{O}_{3}$ PAA/pSe- $b$-PEG PICs made at $Z \geq 1$ indicate that they were grown by nucleation and growth process, ${ }^{[28]}$ during which diblock copolymers were regulating nanoparticle organisation at the surface of the growing clusters while surface PEG blocks forbade their precipitation. Complete degradation into single nanoparticles was achieved in about $1400 \mathrm{~h}, 960 \mathrm{~h}$ and $620 \mathrm{~h}$ for samples at $Z=1,10$ and 100 respectively (Figure 3). DLS study demonstrates that, for $Z \geq 1$, size and time of degradation of the dense spherical PICs can be finely tuned by playing on the charge ratio $Z$ of $\gamma-\mathrm{Fe}_{2} \mathrm{O}_{3}-\mathrm{PAA} / \mathrm{pSe}-b$-PEG mixtures. 
Author manuscript version of paper accepted for publication in Mater. Sci. Eng. C, 2019, 109920, after peer review and technical editing by the publisher. DOI: 10.1016/j.msec.2019.109920

Regarding PICs made with pSe homopolyelectrolyte at $c=6 \times 10^{-4} \mathrm{wt} \%$, complexation of the nanoparticles with pSe- $b$-PEG is not spontaneous. Delays before the start of self-assembly were found to vary from $22 \mathrm{~h}$ for $Z=0.1$ to $115 \mathrm{~h}$ for $Z=100$.

Mechanisms of degradation of $\gamma-\mathrm{Fe}_{2} \mathrm{O}_{3}-\mathrm{PAA} / \mathrm{pSe}-b$-PEG PICs in respectively PBS $1 \times$ and deionized water were investigated by TEM. Time evolution of $D_{H}$ of $\gamma-$ $\mathrm{Fe}_{2} \mathrm{O}_{3}$-PAA and pSe- $b$-PEG mixtures at $Z=1$ in $\mathrm{PBS} 1 \times$ and in water were found to be similar (Figure S11, Supporting Information) but TEM observation of the PICs at various times in these two media reveals different mechanisms of degradation (Figure 4). In PBS $1 \times$, elongated fragments are first detached from outer part of spherical clusters while cores remain dense (Figure 4b). Over time objects becomes increasingly fragmented into small aggregates and single nanoparticles (Figure 4c). In water, blocks of nanoparticles are progressively detached from the spherical PICs. At an intermediate state of the degradation process, clusters are perforated and porous (Figure 4e). As the process continues, clusters are dislocated in smaller dense fragments which are progressively degraded into single nanoparticles (Figure 4f).

\subsection{Magnetic performance of $\gamma$ - $\mathrm{Fe}_{2} \mathrm{O}_{3}-\mathrm{PAA} / \mathrm{pSe}-b$-PEG polyion complexes and hyperthermia experiment}

Characterization of $\gamma-\mathrm{Fe}_{2} \mathrm{O}_{3}-\mathrm{PAA} / \mathrm{pSe}-b$-PEG PICs by Vibrating Sample Magnetometry confirms their superparamagnetic behaviour with a value of magnetization at saturation of $42.5 \mathrm{emu}^{-1}$ (Figure S4). This value is slightly 
Author manuscript version of paper accepted for publication in Mater. Sci. Eng. C, 2019, 109920, after peer review and technical editing by the publisher. DOI: 10.1016/j.msec.2019.109920

lower than the 44.1 emu $\mathrm{g}^{-1}$ recorded for $\gamma-\mathrm{Fe}_{2} \mathrm{O}_{3}-\mathrm{PAA}$, which was already decreased compared to the original 46.2 emu $\mathrm{g}^{-1}$ value of specific magnetization of bare $\gamma-\mathrm{Fe}_{2} \mathrm{O}_{3}$ nanoparticles, presumably because stronger complexation of the iron oxide surface increase the disorder of the magnetic moments at the surface of the nanocrystals (spin canting effect).

$\gamma-\mathrm{Fe}_{2} \mathrm{O}_{3}-\mathrm{PAA} / \mathrm{pSe}-b$-PEG PICs ability to generate heat when exposed to high frequency alternating magnetic field (AMF) was investigated. In our magnetic hyperthermia experiment, temperature of a dispersion of $\gamma-\mathrm{Fe}_{2} \mathrm{O}_{3}-\mathrm{PAA} / \mathrm{pSe}-b-\mathrm{PEG}$ PICs at $\left[\gamma-\mathrm{Fe}_{2} \mathrm{O}_{3}\right]=8.8 \times 10^{-3} \mathrm{wt} \%$ was measured by a fibre optic probe as a function of time (Figure 5b). The two successive applications of the AMF (separated by a return to thermal equilibrium) induced increases of temperature of $\Delta T=0.4{ }^{\circ} \mathrm{C}$ and $\Delta T=0.7{ }^{\circ} \mathrm{C}$, respectively. Ability of the material to macroscopically increase the temperature of the whole sample under AMF gives a good indication about its potential ability to induce cell death. However, recent studies report the possibility of inducing significant cell death with internalized magnetic nanoparticles without observing a macroscopic temperature increase during AMF exposure. ${ }^{[58]}$ The Specific Absorption Rate $(S A R)$ corresponds to the generated thermal power per unit of mass of iron oxide. $S A R$ was calculated using calorimetric method as described in previous publication. ${ }^{[59]}$ Because in such diluted conditions, heat loss toward external environment is comparable to heat generated by the material, the heating rate was compensated by the cooling rate at same temperature in the $S A R$ calculation. ${ }^{[60]} S A R$ value of $31.0 \pm 1.5 \mathrm{~W} \mathrm{~g}^{-1}$ was estimated for these conditions. $\gamma-\mathrm{Fe}_{2} \mathrm{O}_{3}-\mathrm{PAA} / \mathrm{pSe}-b$-PEG PICs were observed by 
Author manuscript version of paper accepted for publication in Mater. Sci. Eng. C, 2019, 109920, after peer review and technical editing by the publisher. DOI: 10.1016/j.msec.2019.109920

TEM before and after hyperthermia (Figure 5a and 5c, respectively). The images reveal that the dense clusters were just slightly degraded during the cycles of hyperthermia as only $\approx 100 \pm 50 \mathrm{~nm}$ fragments were detached while cohesion of the clusters was maintained. To support this result, thermal stability of $\gamma-\mathrm{Fe}_{2} \mathrm{O}_{3}$ PAA/pSe- $b$-PEG PICs (made at $c=6 \times 10^{-4} \mathrm{wt} \%$ and $Z=1$ in water, $t=418 \mathrm{~h}$ ) was studied by DLS (Figure S12, Supporting Information). The almost constant values of $D_{H}$ of the clusters during incubation at $60{ }^{\circ} \mathrm{C}$ and $95{ }^{\circ} \mathrm{C}$ for $12 \mathrm{~h}$ demonstrate that a substantial increase of the thermal energy available in the medium does not trigger the macroscopic degradation of the PICs.

As shown on Figure S13, longitudinal $\left(r_{1}\right)$ and transverse $\left(r_{2}\right)$ proton relaxation rates of the $\gamma-\mathrm{Fe}_{2} \mathrm{O}_{3}-\mathrm{PAA} / \mathrm{pSe}-b$-PEG PICs were measured before and after hyperthermia. These values of $r_{1}=10.7$ and $r_{2}=54.1 \mathrm{~s}^{-1} \mathrm{mM}_{(\mathrm{Fe})}{ }^{-1}$ before hyperthermia and $r_{1}=11.2$ and $r_{2}=56.1 \mathrm{~s}^{-1} \mathrm{mM}_{(\mathrm{Fe})}^{-1}$ after hyperthermia, were almost unaffected by the application of the AMF, in accordance with the limited degradation of the clusters observed during the hyperthermia experiment. The longitudinal relaxivities are also almost the same as the original $r_{1}=10.8 \mathrm{~s}^{-1} \mathrm{mM}_{(\mathrm{Fe})}^{-1}$ measured on individual $\gamma-\mathrm{Fe}_{2} \mathrm{O}_{3}$ PAA nanoparticles, meaning that the surface of iron oxides are highly accessible to water molecules within the clusters. On the contrary, there was a significant (almost two-fold) increase of transverse relaxivity in the clusters compared to $r_{2}=30.3 \mathrm{~s}^{-1} \mathrm{mM}_{(\mathrm{Fe})}{ }^{-1}$ measured on individual $\gamma$ - $\mathrm{Fe}_{2} \mathrm{O}_{3}$-PAA nanoparticles in accordance to the well known effect on $r_{2}$ by aggregation of iron oxide nanoparticles. ${ }^{[61]}$ 
Author manuscript version of paper accepted for publication in Mater. Sci. Eng. C, 2019, 109920, after peer review and technical editing by the publisher. DOI: 10.1016/j.msec.2019.109920

These results tend to demonstrate that $\gamma-\mathrm{Fe}_{2} \mathrm{O}_{3}-\mathrm{PAA} / \mathrm{pSe}-b$-PEG PICs can endure multiple AMF hyperthermia cycles without dramatic modification of their structure and magnetic properties.

\subsection{Stability of $\gamma$-Fe $\mathrm{Fe}_{2} \mathrm{O}_{3}-\mathrm{PAA} / \mathrm{pSe}-\mathrm{b}$-PEG polyion complexes in bio-fluids}

Colloidal stability of $\gamma-\mathrm{Fe}_{2} \mathrm{O}_{3}-\mathrm{PAA} / \mathrm{pSe}-b$-PEG PICs in bio-fluids at $37{ }^{\circ} \mathrm{C}$ was investigated by DLS. Clusters with $D_{H}=417 \pm 15 \mathrm{~nm}\left(c=6 \times 10^{-4} \mathrm{wt} \%, Z=1, t=\right.$ 342 h) were first synthesized in water and then transferred in Simulated Body Fluid (SBF), DMEM and RPMI with or without sodium bicarbonate, and DMEM and RPMI containing 10 vol\% of fetal bovine serum (FBS).

Figure 6 presents the evolution of $D_{H}$ according to the time for $\gamma-\mathrm{Fe}_{2} \mathrm{O}_{3}-\mathrm{PAA} / \mathrm{pSe}-$ $b$-PEG PICs in these media. $\gamma-\mathrm{Fe}_{2} \mathrm{O}_{3}-\mathrm{PAA} / \mathrm{pSe}-b$-PEG are stable in SBF for $51 \mathrm{~h}$ before aggregation of the clusters occurs (Figure 6, blue symbols). Aggregates of $D_{H}=785 \mathrm{~nm}$ were found $165 \mathrm{~h}$ after transfer into SBF, which indicates a slow colloidal destabilization. Similar behaviour was observed for $\gamma-\mathrm{Fe}_{2} \mathrm{O}_{3}-\mathrm{PAA} / \mathrm{pSe}-b-$ PEG PICs in DMEM without $\mathrm{NaHCO}_{3}$ (Figure 6, closed green symbols). In DMEM supplemented with $3.7 \mathrm{~g} \mathrm{~L}^{-1}$ of sodium bicarbonate, PICs were stable for only $5 \mathrm{~h}$ before macroscopic precipitation occurred (Figure 6, empty green symbols). In RPMI with or without $\mathrm{NaHCO}_{3}, \mathrm{PICs}$ were stable for $32 \mathrm{~h}$ before precipitation (Figure 6, empty and closed red symbols). In DMEM and RPMI containing FBS (Figure 6, violet and pink symbols), the PICs were stable for respectively $27 \mathrm{~h}$ and $39 \mathrm{~h}$ before colloidal destabilization, which means that presence of proteins does not lead to spontaneous precipitation. Such behaviour in 
Author manuscript version of paper accepted for publication in Mater. Sci. Eng. C, 2019, 109920, after peer review and technical editing by the publisher. DOI: 10.1016/j.msec.2019.109920

protein-containing media is promising regarding in vivo applications. Indeed, the time of circulation of nanoparticles in the bloodstream, from magnetic nanoparticles coated with citrate or dextran to PEGylated vesicles, does not exceed 100 minutes with half-lives of the order of 10 minutes. ${ }^{[57,62-64]}$ Thus, it is expected that $\gamma-\mathrm{Fe}_{2} \mathrm{O}_{3}-\mathrm{PAA} / \mathrm{pSe}-b$-PEG PICs will be stable enough over the time-period required by biomedical applications.

\subsection{Cellular uptake and toxicity assays}

$\gamma-\mathrm{Fe}_{2} \mathrm{O}_{3}-\mathrm{PAA} / \mathrm{pSe}-b$-PEG PICs (synthesized at $c=6 \times 10^{-4} \mathrm{wt} \%$ as $Z=1, t=304 \mathrm{~h}, D_{H}=$ $414 \pm 10 \mathrm{~nm}$ ) were incubated with respectively MC3T3-E1 and HepG2 cells. Amounts of iron internalized or adsorbed by MC3T3-E1 cells at $24 \mathrm{~h}$, and MC3T3-E1 and HepG2 cell viability at $24 \mathrm{~h}, 48 \mathrm{~h}$ and $72 \mathrm{~h}$ were determined as a function of concentration. Figure 7a compares masses of iron taken up by MC3T3-E1 cells (empty black symbols) to masses of iron introduced (closed black symbols) in pg per cell at $[\mathrm{Fe}]=7.51 \times 10^{-3}$, $7.51 \times 10^{-2}, 0.751$ and $7.51 \mathrm{mM}$, respectively. Corresponding mass fractions of internalized iron are given in wt $\%$ (Figure $7 \mathrm{a}$, blue symbols). At $[\mathrm{Fe}]=7.51 \times 10^{-3} \mathrm{mM}$, $1.3 \mathrm{pg}$ of iron per cell were internalized, which corresponds to $25.5 \mathrm{wt} \%$ of the introduced iron. Therefore, internalization of the colloidally stable $\gamma-\mathrm{Fe}_{2} \mathrm{O}_{3}-\mathrm{PAA} / \mathrm{pSe}-b$ PEG PICs is a fast and relatively efficient phenomenon at low concentration. As the concentration of iron increases, the mass of iron internalized per cell increases until saturation is reached at $[\mathrm{Fe}]=0.751 \mathrm{mM}$ with a value of $25 \mathrm{pg}$ of iron per cell, corresponding to $4.75 \mathrm{wt} \%$ of the introduced iron. Compared with internalization of $\gamma$ $\mathrm{Fe}_{2} \mathrm{O}_{3}$-PAA nanoparticles by $\mathrm{NIH} / 3 \mathrm{~T} 3$ cells reported in a the literature, ${ }^{[33]} \gamma-\mathrm{Fe}_{2} \mathrm{O}_{3}$ - 
Author manuscript version of paper accepted for publication in Mater. Sci. Eng. C, 2019, 109920, after peer review and technical editing by the publisher. DOI: 10.1016/j.msec.2019.109920

PAA/pSe- $b$-PEG PICs have rates of internalization of the same order of magnitude at $0.01 \mathrm{mM}<[\mathrm{Fe}]<10 \mathrm{mM}$, but a higher value of mass of iron internalized at saturation (25 pg cell ${ }^{-1}$ for $\gamma-\mathrm{Fe}_{2} \mathrm{O}_{3}-\mathrm{PAA} / \mathrm{pSe}-b$-PEG instead of $\approx 10 \mathrm{pg}$ cell ${ }^{-1}$ for $\gamma-\mathrm{Fe}_{2} \mathrm{O}_{3}-\mathrm{PAA}$ ). Therefore, the presence of surface neutral PEG blocks combined with the size and morphology of $\gamma-\mathrm{Fe}_{2} \mathrm{O}_{3}-\mathrm{PAA} / \mathrm{pSe}-b$-PEG clusters result in slightly better uptake performance with adherent cells compared to highly negatively charged $\gamma-\mathrm{Fe}_{2} \mathrm{O}_{3}-\mathrm{PAA}$ nanoparticles.

Quantitative cell viability assays were conducted on MC3T3-E1 and HepG2 cells incubated with $\gamma$-Fe ${ }_{2} \mathrm{O}_{3}$-PAA/pSe- $b$-PEG PICs at $[\mathrm{Fe}]=0,7.51 \times 10^{-3}, 7.51 \times 10^{-2}, 0.751$ and $7.51 \mathrm{mM}$, respectively. For both types of cells and for all concentrations, optical densities, which are proportional to amount of living cells (Figure S6, Supporting Information), were measured $24 \mathrm{~h}, 48 \mathrm{~h}$ and $72 \mathrm{~h}$ after incubation of the material with the cells. Cell viabilities, expressed in \% relatively to control experiments, are presented in Figure $7 \mathrm{~b}$ and $\mathrm{c}$. Cell proliferation rates demonstrate the non-cytotoxicity of $\gamma-\mathrm{Fe}_{2} \mathrm{O}_{3}$ $\mathrm{PAA} / \mathrm{pSe}-b$-PEG PICs in the range of concentration investigated. Over time and in aqueous media, $\gamma-\mathrm{Fe}_{2} \mathrm{O}_{3}-\mathrm{PAA} / \mathrm{pSe}-b$-PEG systems are degraded into free $\gamma-\mathrm{Fe}_{2} \mathrm{O}_{3}-\mathrm{PAA}$ nanoparticles, soluble pSe- $b$-PEG chains, PEG blocks and serine molecules. Previous studies demonstrated the non-cytotoxicity of $\gamma-\mathrm{Fe}_{2} \mathrm{O}_{3}-\mathrm{PAA},{ }^{[33,34]}$ and the low cytotoxicity of pSe- $b$-PEG. ${ }^{[36]} \mathrm{PEG}_{10 \mathrm{~K}}$, as well as the hydrolytic product serine, are nontoxic at low doses and would probably be excreted in vivo. ${ }^{[65]}$ Cell viability assays show convincing results regarding short term non-toxicity of $\gamma-\mathrm{Fe}_{2} \mathrm{O}_{3}-\mathrm{PAA} / \mathrm{pSe}-b$-PEG PICs while low toxicity of the degradation byproducts has been recognized in literature reports. $\gamma-\mathrm{Fe}_{2} \mathrm{O}_{3}$ - 
Author manuscript version of paper accepted for publication in Mater. Sci. Eng. C, 2019, 109920, after peer review and technical editing by the publisher. DOI: 10.1016/j.msec.2019.109920

PAA/pSe- $b$-PEG based systems can therefore be considered as suitable tools for biomedical applications such as easily eliminable MRI contrast agents or nanomedicine.

\subsection{TEM analysis of $\gamma-\mathrm{Fe}_{2} \mathrm{O}_{3}$-PAA/pSe- $b$-PEG polyion complexes in cells}

MC3T3-E1 cells were incubated with $\gamma$-Fe ${ }_{2} \mathrm{O}_{3}$-PAA/pSe- $b$-PEG PICs $(Z=1, t=$ $\left.304 \mathrm{~h}, D_{H}=414 \mathrm{~nm}\right)$ at $\left[\gamma-\mathrm{Fe}_{2} \mathrm{O}_{3}\right]=6 \times 10^{-3} \mathrm{wt} \%$ and observed by TEM $24 \mathrm{~h}, 48 \mathrm{~h}$ and $72 \mathrm{~h}$ after exposure. Representative images of the cells at these exposure times are shown in Figure 8. After $24 \mathrm{~h}$ of incubation, nanoparticles were found inside cells either as individual units and oligomeric aggregates gathered in round-shaped domains (Figure 8a, red arrows) or as partially degraded clusters. These internalized clusters were found at different stages of degradation: almost undegraded dense and spherical objects are present (Figure 8a', green arrow), some dense clusters have already undergone destructuration of their outer layer (Figure 8a', orange arrows) and others are at a more advanced stage of degradation as indicated by low nanoparticle densities and extended interparticle distances (Figure 8a', yellow arrow).

Two arguments support the idea that single particles and fragments observed inside cells are degradation byproducts of $\gamma-\mathrm{Fe}_{2} \mathrm{O}_{3}-\mathrm{PAA} / \mathrm{pSe}-b$-PEG PICs and not the result of the internalization of already degraded material. First, no $\gamma-\mathrm{Fe}_{2} \mathrm{O}_{3}-$ PAA/pSe- $b$-PEG clusters, fragments or single particles were found adsorbed on cell membranes which indicates a rapid internalization of the material by cells. Second, almost no single particles were found in the cytosol and only either nanoparticles-free (Figure 8a, violet arrows) or highly populated intracellular 
Author manuscript version of paper accepted for publication in Mater. Sci. Eng. C, 2019, 109920, after peer review and technical editing by the publisher. DOI: 10.1016/j.msec.2019.109920

domains (Figure 8a, red arrows) are present in cells, which suggest a former internalization of large, undegraded, objects.

$48 \mathrm{~h}$ and $72 \mathrm{~h}$ after exposure, no dense clusters were found in cells but only single nanoparticles or oligomeric aggregates gathered in domains as pictured in Figure $8 \mathrm{~b}$ and $8 \mathrm{c}$. Compared to the biodegradation of chemically stable $\gamma-\mathrm{Fe}_{2} \mathrm{O}_{3}$ PAA/PTEA-PAM PICs which mainly consists of fragmentation of micro-sized objects into $\approx 500 \mathrm{~nm}$ dense clusters within $24 \mathrm{~h},{ }^{[33]}$ nanoassembly involving hydrolysable poly(ester serine) leads to almost complete separation of the $\gamma-\mathrm{Fe}_{2} \mathrm{O}_{3}$ PAA nanoparticles from each other in the same duration.

Figure 8c shows a degraded PIC in a membrane-enclosed compartment whereas other images such as the ones of Figure $8 a^{\prime}$ and $b$ do not indicate presence of membranes surrounding internalized PICs. Therefore, up taking of the PICs by cells could have happened by different mechanisms such as endocytosis, which leads to entrapment of the material in vesicular compartments, or by membrane fusion which results in direct transfer into cytosol without entrapment in endosomes. ${ }^{[66-68]}$ Remarkably, number and density of nanoparticles in the membrane-bound domain shown in Figure 8c seem lower than what could be expected from complete degradation of a whole $\gamma-\mathrm{Fe}_{2} \mathrm{O}_{3}-\mathrm{PAA} / \mathrm{pSe}-b$-PEG cluster. A reason for that could be the fast erosion and dissolution of coated iron oxide nanoparticles in intracellular compartments. ${ }^{[69]}$ An important consequence of rapid degradation of $\gamma-\mathrm{Fe}_{2} \mathrm{O}_{3}-\mathrm{PAA} / \mathrm{pSe}-b-\mathrm{PEG}$ clusters is the faster degradability of the $\gamma-\mathrm{Fe}_{2} \mathrm{O}_{3}$-PAA nanoparticles themselves as, generally, isolated nanoparticles erode faster than aggregated ones. ${ }^{[70]} \quad \gamma-\mathrm{Fe}_{2} \mathrm{O}_{3}-\mathrm{PAA} / \mathrm{pSe}-b-\mathrm{PEG}$ systems allow 
Author manuscript version of paper accepted for publication in Mater. Sci. Eng. C, 2019, 109920, after peer review and technical editing by the publisher. DOI: 10.1016/j.msec.2019.109920

accelerating this degradation process with enhanced biocompatibility due to the chemical nature of pSe- $b$-PEG.

These experiments demonstrate the rapid internalisation and degradation of $\gamma$ $\mathrm{Fe}_{2} \mathrm{O}_{3}-\mathrm{PAA} / \mathrm{pSe}-b$-PEG PICs in cells. Therefore, diagnosis and treatments involving this type of degradable nanoassembly should be performed within the few hours after injection to take advantage of the aggregated state of the nanoparticles.

\section{Conclusion}

In this study, auto-degradable and biocompatible SPION/polyelectrolyte colloidal polyion complexes (PICs) were developed to overcome potential long-term toxicity of this type of nanostructured hybrid materials while ensuring the high density of magnetic material required by biomedical applications. Poly(acrylic acid) coated maghemite nanoparticles $\left(\gamma-\mathrm{Fe}_{2} \mathrm{O}_{3}-\mathrm{PAA}\right)$ were complexed with either poly(serine ester) (pSe) or poly(serine ester)- $b$-PEG (pSe- $b$-PEG) as biocompatible and biodegradable polyelectrolytes. Once clusters were formed, hydrolysis of poly(ester) blocks triggered the disassembly of the whole edifices. The degradation process generated individual $\gamma-\mathrm{Fe}_{2} \mathrm{O}_{3}$-PAA nanoparticles, serine molecules and PEG blocks as biocompatible byproducts.

Interaction between $\gamma-\mathrm{Fe}_{2} \mathrm{O}_{3}$-PAA nanoparticles and pSe homopolyelectrolyte was studied. Polyion complexation of these building blocks was found to be a concentration and ionic strength dependent process mainly driven by screened electrostatic interaction. Self-assembly of $\gamma-\mathrm{Fe}_{2} \mathrm{O}_{3}-\mathrm{PAA}$ nanoparticles in presence of pSe chains lead to relatively dense $200-800 \mathrm{~nm}$ colloidal clusters yet with 
Author manuscript version of paper accepted for publication in Mater. Sci. Eng. C, 2019, 109920, after peer review and technical editing by the publisher. DOI: 10.1016/j.msec.2019.109920

irregular shape and inhomogeneous structure. Interestingly, kinetics of growth are particularly slow $(>250 \mathrm{~h})$ and, at high concentration, the aggregation of nanoparticles started only $100 \mathrm{~h}$ after direct mixing of the reactive species. Degradation of $\gamma-\mathrm{Fe}_{2} \mathrm{O}_{3}-\mathrm{PAA} / \mathrm{pSe}$ clusters in aqueous medium was confirmed by the decrease of the $D_{H}$ over several weeks.

Formation of $\gamma-\mathrm{Fe}_{2} \mathrm{O}_{3}-\mathrm{PAA} / \mathrm{pSe}-b-\mathrm{PEG}$ PICs as a function of the charge stoichiometry in reactive species $Z$ was then studied. In spite of the slow rate of aggregation, perfectly defined dense and spherical clusters were obtained at $Z \geq 1$ (excess of SPIONs), due to PEG blocks which regulate nanoparticle organisation at the surface of the growing clusters. Once formed, $\gamma-\mathrm{Fe}_{2} \mathrm{O}_{3}-\mathrm{PAA} / \mathrm{pSe}-b-\mathrm{PEG}$ PICs started to auto-degrade into individual nanoparticles over several weeks in aqueous media. The results show that size and time of degradation of the clusters can be finely tuned by variation of the charge ratio $Z$ during synthesis. Different mechanisms of degradation were identified depending on the solvent. In the first stage, clusters are "peeled" in PBS1× whereas in water, dense blocks are detached from the structure, leading to perforated clusters.

Superparamagnetic $\gamma-\mathrm{Fe}_{2} \mathrm{O}_{3}-\mathrm{PAA} / \mathrm{pSe}-b$-PEG PICs generated heat under magnetic stimulation with a $S A R$ value of $31.0 \pm 1.5 \mathrm{~W} \mathrm{~g}^{-1}$ of iron oxide. TEM, DLS and relaxometry analysis indicate that structure and properties of the clusters were not significantly affected by such magnetic hyperthermia cycles.

Cell viability assessments conducted on MC3T3-E1 cells incubated with $\gamma$-Fe $\mathrm{F}_{2} \mathrm{O}_{3}$ PAA/pSe- $b$-PEG PICs over a period of $72 \mathrm{~h}$ demonstrate the non-cytotoxicity of the material, even at $[\mathrm{Fe}]=7.51 \mathrm{mM}$, corresponding to $25 \mathrm{pg}$ of iron internalized 
Author manuscript version of paper accepted for publication in Mater. Sci. Eng. C, 2019, 109920, after peer review and technical editing by the publisher. DOI: 10.1016/j.msec.2019.109920

by cell. TEM observation of $\gamma-\mathrm{Fe}_{2} \mathrm{O}_{3}-\mathrm{PAA} / \mathrm{pSe}-\mathrm{b}-\mathrm{PEG}$ in cells $24 \mathrm{~h}, 48 \mathrm{~h}$ and $72 \mathrm{~h}$ after exposure reveals that clusters were rapidly internalized and degraded. Most of the PICs were degraded into individual nanoparticles within $24 \mathrm{~h}$ and only a part of the clusters were found in a less advanced stage of degradation. $72 \mathrm{~h}$ after incubation, no clusters were found in cells but only single SPIONs and oligomeric aggregates.

The present study showed a simple synthesis route to obtain dense spherical biocompatible and biodegradable SPION/polymer polyion complexes with great control of their size and time of degradation. The $\gamma-\mathrm{Fe}_{2} \mathrm{O}_{3}-\mathrm{PAA} / \mathrm{pSe}-b-\mathrm{PEG}$ clusters exhibit properties required for biomedical applications such as short-term colloidal stability, magnetic responsivity and nontoxicity. Finally, rapid degradation of the material in cells was demonstrated. For all these reasons, SPION/poly(serine ester) complexes are interesting tools for nano-architects designing dynamic multi-functional nanostructured systems for which both biocompatibility and high density of magnetic material are required.

\section{Conflicts of interest}

There are no conflicts to declare.

\section{Acknowledgements}

This research was supported by the "1000 talents" program (Sichuan, China) under the Southwest University of Science and Technology (SWUST) program 16QR003, by the National Natural Science Foundation of China (NSFC, project

numbers: 41650110481 and 41630646) and by the SWUST Postgraduate 
Author manuscript version of paper accepted for publication in Mater. Sci. Eng. C, 2019, 109920, after peer review and technical editing by the publisher. DOI: 10.1016/j.msec.2019.109920

Innovation Fund Project (No.17cyx010). Financial support from the CPER

CAMPUSB project funded by the French state and the Region Nouvelle Aquitaine

is acknowledged for acquisition of the Bruker Minispec ${ }^{\mathrm{TM}}$ mq60 relaxometer. The authors are also grateful to Amélie Vax-Weber (LCPO) for help on the GPC data acquisition, and to Prof Mark Julian Henderson and Dr Malak Safi for helpful discussions.

\section{References}

[1] S. Sharifi, S. Behzadi, S. Laurent, M. L. Forrest, P. Stroeve, M. Mahmoudi, Chem. Soc. Rev. 2012, 41, 2323.

[2] A. Bour, F. Mouchet, J. Silvestre, L. Gauthier, E. Pinelli, J. Hazard. Mater. 2015, 283, 764.

[3] G. V. Lowry, K. B. Gregory, S. C. Apte, J. R. Lead, Environ. Sci. Technol. 2012, 46, 6893.

[4] N. Lee, T. Hyeon, Chem. Soc. Rev. 2012, 41, 2575.

[5] R. Jin, B. Lin, D. Li, H. Ai, Curr. Opin. Pharmacol. 2014, 18, 18.

[6] M. Saeed, W. Ren, A. Wu, Biomater. Sci. 2018, 6, 708.

[7] M. Nedyalkova, B. Donkova, J. Romanova, G. Tzvetkov, S. Madurga, V. Simeonov, Adv. Colloid Interface Sci. 2017, 249, 192.

[8] Y. Hu, S. Mignani, J.-P. Majoral, M. Shen, X. Shi, Chem. Soc. Rev. 2018, 47, 1874.

[9] N. Lee, D. Yoo, D. Ling, M. H. Cho, T. Hyeon, J. Cheon, Chem. Rev. 2015, 115, 10637.

[10] K. Ulbrich, K. Holá, V. Šubr, A. Bakandritsos, J. Tuček, R. Zbořil, Chem. Rev. 2016, 116, 5338.

[11] E. Tombácz, R. Turcu, V. Socoliuc, L. Vékás, Biochem. Biophys. Res. Commun. 2015, 468, 442.

[12] R. Di Corato, A. Espinosa, L. Lartigue, M. Tharaud, S. Chat, T. Pellegrino, C. Ménager, F. Gazeau, C. Wilhelm, Biomaterials 2014, 35, 6400.

[13] E. A. Perigo, G. Hemery, O. Sandre, D. Ortega, E. Garaio, F. Plazaola, F. J. Teran, Appl. Phys. Rev. 2015, 2, 041302 (35 pp.).

[14] G. Hemery, C. Genevois, F. Couillaud, S. Lacomme, E. Gontier, E. Ibarboure, S. Lecommandoux, E. Garanger, O. Sandre, Mol. Syst. Des. Eng. 2017, 2, 629.

[15] D. Sakellari, K. Brintakis, A. Kostopoulou, E. Myrovali, K. Simeonidis, A. Lappas, M. Angelakeris, Mater. Sci. Eng. C 2016, 58, 187.

[16] Y. Liu, X. Yang, Z. Huang, P. Huang, Y. Zhang, L. Deng, Z. Wang, Z. Zhou, Y. Liu, H. Kalish, N. M. Khachab, X. Chen, Z. Nie, Angew. Chem. Int. Ed. 2016, 55, 15297.

[17] Z. Lu, Y. Yin, Chem. Soc. Rev. 2012, 41, 6874.

[18] S. Gun, M. Edirisinghe, E. Stride, Mater. Sci. Eng. C 2013, 33, 3129.

[19] Q. Dai, A. Nelson, Chem. Soc. Rev. 2010, 39, 4057.

[20] A. Faucon, H. Benhelli-Mokrani, F. Fleury, L. Dubreil, P. Hulin, S. Nedellec, T. Doussineau, R. Antoine, T. Orlando, A. Lascialfari, J. Fresnais, L. Lartigue, E. Ishow, J. Colloid Interface Sci. 2016, 479, 139.

[21] J. Li, X. Wang, D. Zheng, X. Lin, Z. Wei, D. Zhang, Z. Li, Y. Zhang, M. Wu, X. Liu, Biomater. Sci. 2018, 6, 1834. 
Author manuscript version of paper accepted for publication in Mater. Sci. Eng. C, 2019, 109920, after peer review and technical editing by the publisher. DOI: 10.1016/j.msec.2019.109920

[22] A. Shanavas, S. Sasidharan, D. Bahadur, R. Srivastava, J. Colloid Interface Sci. 2017, 486, 112.

[23] C. Nehate, M. R. Aji Alex, A. Kumar, V. Koul, Mater. Sci. Eng. C 2017, 75, 1128.

[24] E. M. Shapiro, Magn. Reson. Med. 2015, 73, 376.

[25] B. Mattix, T. R. Olsen, T. Moore, M. Casco, D. Simionescu, R. P. Visconti, F. Alexis, Adv. Funct. Mater. 2014, 24, 800.

[26] J. Mosafer, M. Teymouri, K. Abnous, M. Tafaghodi, M. Ramezani, Mater. Sci. Eng. C 2017, $72,123$.

[27] C. Saengruengrit, P. Ritprajak, S. Wanichwecharungruang, A. Sharma, G. Salvan, D. R. T. Zahn, N. Insin, J. Colloid Interface Sci. 2018, 520, 101.

[28] J. Fresnais, J.-F. Berret, B. Frka-Petesic, O. Sandre, R. Perzynski, Adv. Mater. 2008, 20, 3877.

[29] M. Yan, J. Fresnais, J.-F. Berret, Soft Matter 2010, 6, 1997.

[30] M. Yan, J. Fresnais, S. Sekar, J.-P. Chapel, J.-F. Berret, ACS Appl. Mater. Interfaces 2011, 3, 1049.

[31] H. Li, M. J. Henderson, K. Wang, X. Tuo, Y. Leng, K. Xiong, Y. Liu, Y. Ren, J. Courtois, M. Yan, Colloids Surf. -Physicochem. Eng. Asp. 2017, 514, 107.

[32] M. Yan, L. Qu, J. Fan, Y. Ren, Nanoscale Res. Lett. 2014, 9, 198.

[33] M. Safi, M. Yan, M.-A. Guedeau-Boudeville, H. Conjeaud, V. Garnier-Thibaud, N. Boggetto, A. Baeza-Squiban, F. Niedergang, D. Averbeck, J.-F. Berret, ACS Nano 2011, 5, 5354.

[34] M. Safi, H. Sarrouj, O. Sandre, N. Mignet, J.-F. Berret, Nanotechnology 2010, 21, 145103.

[35] K. Kim, W. C. W. Chen, Y. Heo, Y. Wang, Prog. Polym. Sci. 2016, 60, 18.

[36] Y. Wei, X. Li, X. Jing, X. Chen, Y. Huang, Chem. Res. Chin. Univ. 2013, 29, 177.

[37] T. Kokubo, H. Takadama, Biomaterials 2006, 27, 2907.

[38] R. Massart, E. Dubois, V. Cabuil, E. Hasmonay, J. Magn. Magn. Mater. 1995, 149, 1.

[39] J. Tang, M. Myers, K. A. Bosnick, L. E. Brus, J. Phys. Chem. B 2003, 107, 7501.

[40] A. Bee, R. Massart, S. Neveu, J. Magn. Magn. Mater. 1995, 149, 6.

[41] S. Lefebure, E. Dubois, V. Cabuil, S. Neveu, R. Massart, J. Mater. Res. 1998, 13, 2975.

[42] I. T. Lucas, S. Durand-Vidal, E. Dubois, J. Chevalet, P. Turq, J Phys Chem C 2007, 111, 18568.

[43] J. Fresnais, M. Yan, J. Courtois, T. Bostelmann, A. Bée, J.-F. Berret, J. Colloid Interface Sci. 2013, 395, 24.

[44] A. Sehgal, Y. Lalatonne, J.-F. Berret, M. Morvan, Langmuir 2005, 21, 9359.

[45] H. Li, K. Wang, X. Tuo, L. Almásy, Q. Tian, G. Sun, M. J. Henderson, Q. Li, A. Wacha, J. Courtois, M. Yan, Mater. Chem. Phys. 2018, 204, 236.

[46] M. Szekeres, E. Tombácz, Colloids Surf. Physicochem. Eng. Asp. 2012, 414, 302.

[47] D. A. H. Hanaor, M. Michelazzi, C. Leonelli, C. C. Sorrell, J. Eur. Ceram. Soc. 2012, 32, 235.

[48] A. Galimard, M. Safi, N. Ould-Moussa, D. Montero, H. Conjeaud, J.-F. Berret, Small 2012, 8, 2036.

[49] Y. Wei, X. Li, X. Jing, X. Chen, Y. Huang, Polym. Int. 2013, 62, 454.

[50] G. Hemery, E. Garanger, S. Lecommandoux, A. D. Wong, E. R. Gillies, B. Pedrono, T. Bayle, D. Jacob, O. Sandre, J. Phys. D: App. Phys. 2015, 48, 494001 (13 pp.).

[51] C. Henoumont, S. Laurent, L. V. Elst, Contrast Media Mol. Imaging 2009, 4, 312.

[52] J. Courtois, J.-F. Berret, Langmuir 2010, 26, 11750.

[53] D. Liu, W. Wu, J. Ling, S. Wen, N. Gu, X. Zhang, Adv. Funct. Mater. 2011, 21, 1498.

[54] Z. Cao, N. N. M. Adnan, G. Wang, A. Rawal, B. Shi, R. Liu, K. Liang, L. Zhao, J. J. Gooding, C. Boyer, Z. Gu, J. Colloid Interface Sci. 2018, 521, 242.

[55] J. V. Jokerst, T. Lobovkina, R. N. Zare, S. S. Gambhir, Nanomed. 2011, 6, 715.

[56] S. Parveen, S. K. Sahoo, Eur. J. Pharmacol. 2011, 670, 372.

[57] J. S. Suk, Q. Xu, N. Kim, J. Hanes, L. M. Ensign, Adv. Drug Deliv. Rev. 2016, 99, 28. 
Author manuscript version of paper accepted for publication in Mater. Sci. Eng. C, 2019, 109920, after peer review and technical editing by the publisher. DOI: 10.1016/j.msec.2019.109920

[58] V. T. A. Nguyen, M.-C. De Pauw-Gillet, M. Gauthier, O. Sandre, Nanomaterials 2018, 8, 1014.

[59] E. Garaio, J. M. Collantes, J. A. Garcia, F. Plazaola, S. Mornet, F. Couillaud, O. Sandre, J. Magn. Magn. Mater. 2014, 368, 432.

[60] N. lacob, G. Schinteie, P. Palade, V. Kuncser, J. Nanoparticle Res. 2015, 17, 190.

[61] J.-F. Berret, N. Schonbeck, F. Gazeau, D. El Kharrat, O. Sandre, A. Vacher, M. Airiau, J. Am. Chem. Soc. 2006, 128, 1755.

[62] A. G. Próspero, C. C. Quini, A. F. Bakuzis, P. Fidelis-de-Oliveira, G. M. Moretto, F. P. F. Mello, M. F. F. Calabresi, R. V. R. Matos, E. A. Zandoná, N. Zufelato, R. B. Oliveira, J. R. A. Miranda, J. Nanobiotechnology 2017, 15, 22.

[63] L. M. Lacava, Z. G. M. Lacava, R. B. Azevedo, S. B. Chaves, V. A. P. Garcia, O. Silva, F. Pelegrini, N. Buske, C. Gansau, M. F. Da Silva, P. C. Morais, J. Magn. Magn. Mater. 2002, $252,367$.

[64] S. A. A. Kooijmans, L. A. L. Fliervoet, R. van der Meel, M. H. A. M. Fens, H. F. G. Heijnen, P. M. P. van Bergen en Henegouwen, P. Vader, R. M. Schiffelers, J. Controlled Release 2016, 224, 77.

[65] R. Webster, V. Elliott, B. K. Park, D. Walker, M. Hankin, P. Taupin, in PEGylated Protein Drugs Basic Sci. Clin. Appl. (Ed: F.M. Veronese), Birkhäuser Basel, Basel, 2009, pp. 127-146.

[66] H. Hillaireau, P. Couvreur, Cell. Mol. Life Sci. 2009, 66, 2873.

[67] J. Klumperman, G. Raposo, Cold Spring Harb. Perspect. Biol. 2014, 6, a016857.

[68] F. Scaletti, J. Hardie, Y.-W. Lee, D. C. Luther, M. Ray, V. M. Rotello, Chem. Soc. Rev. 2018, $47,3421$.

[69] L. Lartigue, D. Alloyeau, J. Kolosnjaj-Tabi, Y. Javed, P. Guardia, A. Riedinger, C. Péchoux, T. Pellegrino, C. Wilhelm, F. Gazeau, ACS Nano 2013, 7, 3939.

[70] J. Kolosnjaj-Tabi, L. Lartigue, Y. Javed, N. Luciani, T. Pellegrino, C. Wilhelm, D. Alloyeau, F. Gazeau, Nano Today 2016, 11, 280. 
Author manuscript version of paper accepted for publication in Mater. Sci. Eng. C, 2019, 109920, after peer review and technical editing by the publisher. DOI: 10.1016/j.msec.2019.109920

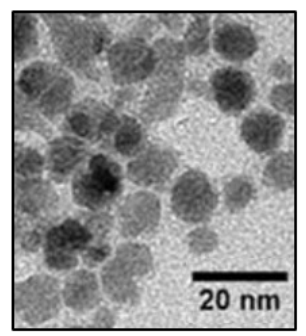

\begin{tabular}{|l|c|}
\hline$D_{0}^{T E M}$ of $\gamma-\mathrm{Fe}_{2} \mathrm{O}_{3}$ core $(\mathrm{nm})$ & $9.3 \pm 0.2$ \\
\hline$s^{T E M}$ of $\gamma-\mathrm{Fe}_{2} \mathrm{O}_{3}$ core $(\mathrm{nm})$ & $0.18 \pm 0.01$ \\
\hline$D_{H}$ of $\gamma-\mathrm{Fe}_{2} \mathrm{O}_{3}$-PAA $(\mathrm{nm})$ & $34 \pm 1$ \\
\hline$M_{S}\left(\mathrm{emu} \mathrm{g}^{-1}\right)$ & 46.2 \\
\hline$\xi_{p}(\mathrm{mV})$ & -48 \\
\hline
\end{tabular}

$\gamma$ - $\mathrm{Fe}_{2} \mathrm{O}_{3}$-PAA nanoparticles

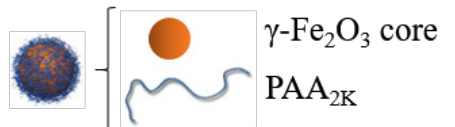<smiles>CC(=O)COCCOCC(N)COC(C)=O</smiles>
$+$ or

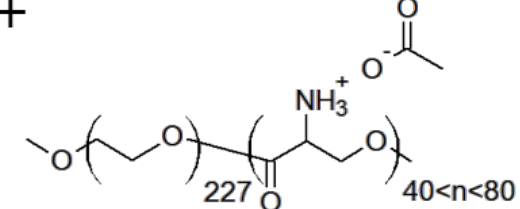

poly(serine ester)

poly(serine ester)-b-PEG

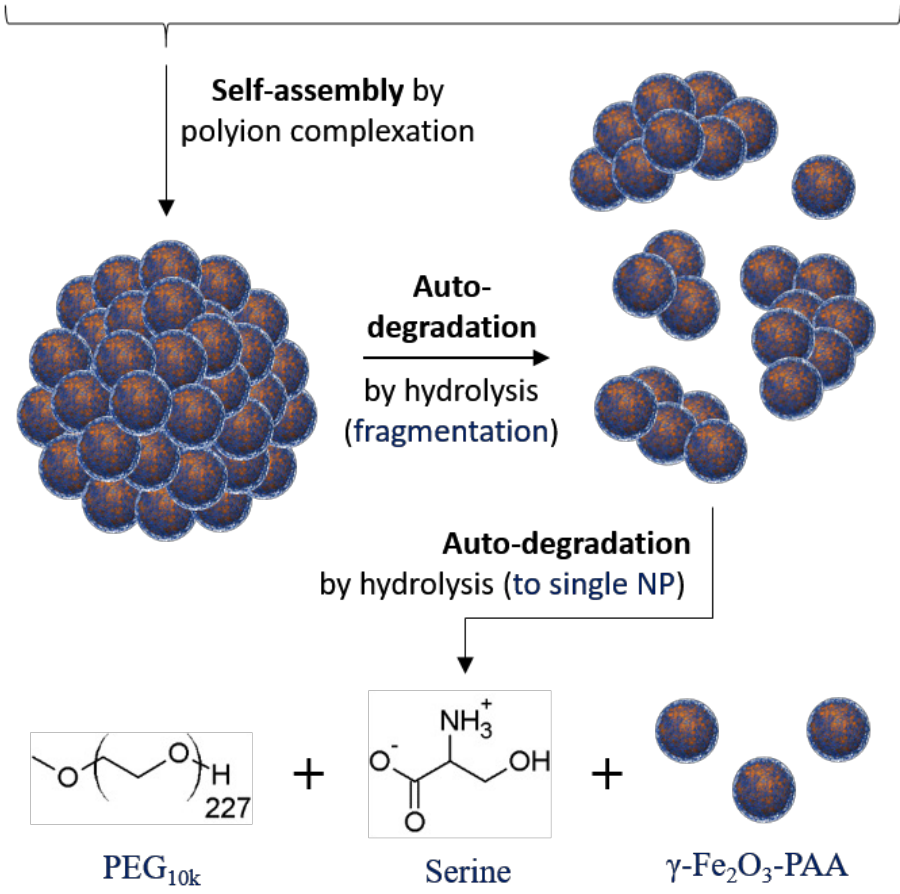

Figure 1. Schematic representation of the synthesis and auto-degradation of $\gamma-\mathrm{Fe}_{2} \mathrm{O}_{3}$ $\mathrm{PAA} /$ poly(serine ester) and $\gamma-\mathrm{Fe}_{2} \mathrm{O}_{3}-\mathrm{PAA} /$ poly(serine ester)- $b$-PEG polyion complexes. From top to bottom: TEM image of the superparamagnetic maghemite nanocrystals. Cartoon representation of the superparamagnetic maghemite nanoparticles coated with poly(acrylic acid) oligomers of $M_{W}=2000 \mathrm{~g} \mathrm{~mol}^{-1}\left(\gamma-\mathrm{Fe}_{2} \mathrm{O}_{3}-\mathrm{PAA}\right)$ and their physical properties $\left(D_{0}^{T E M}\right.$ and $s^{T E M}$ are the median diameter and the polydispersity of the 
Author manuscript version of paper accepted for publication in Mater. Sci. Eng. C, 2019, 109920, after peer review and technical editing by the publisher. DOI: 10.1016/j.msec.2019.109920

maghemite nanocrystals, and $D_{H}, M_{S}$ and $\xi_{p}$ are respectively the hydrodynamic diameter measured by DLS, the magnetization at saturation measured by Vibrating Sample Magnetometry and the Zeta potential of $\gamma-\mathrm{Fe}_{2} \mathrm{O}_{3}$-PAA). Molecular structure of poly(serine ester) homopolyelectrolyte (pSe) and poly(serine ester)- $b$-PEG copolymer (pSe- $b$-PEG) with their acetate counter-ions. Representation of a polyion complex made by electrostatically driven self-assembly of $\gamma-\mathrm{Fe}_{2} \mathrm{O}_{3}$-PAA nanoparticles and pSe or pSe- $b$ PEG chains, fragmentation of the aggregate triggered by the hydrolysis of poly(serine ester) blocks, and its presumed final degradation into PEG blocks, serine molecules and $\gamma-\mathrm{Fe}_{2} \mathrm{O}_{3}$-PAA single nanoparticles. 
Author manuscript version of paper accepted for publication in Mater. Sci. Eng. C, 2019, 109920, after peer review and technical editing by the publisher. DOI: 10.1016/j.msec.2019.109920
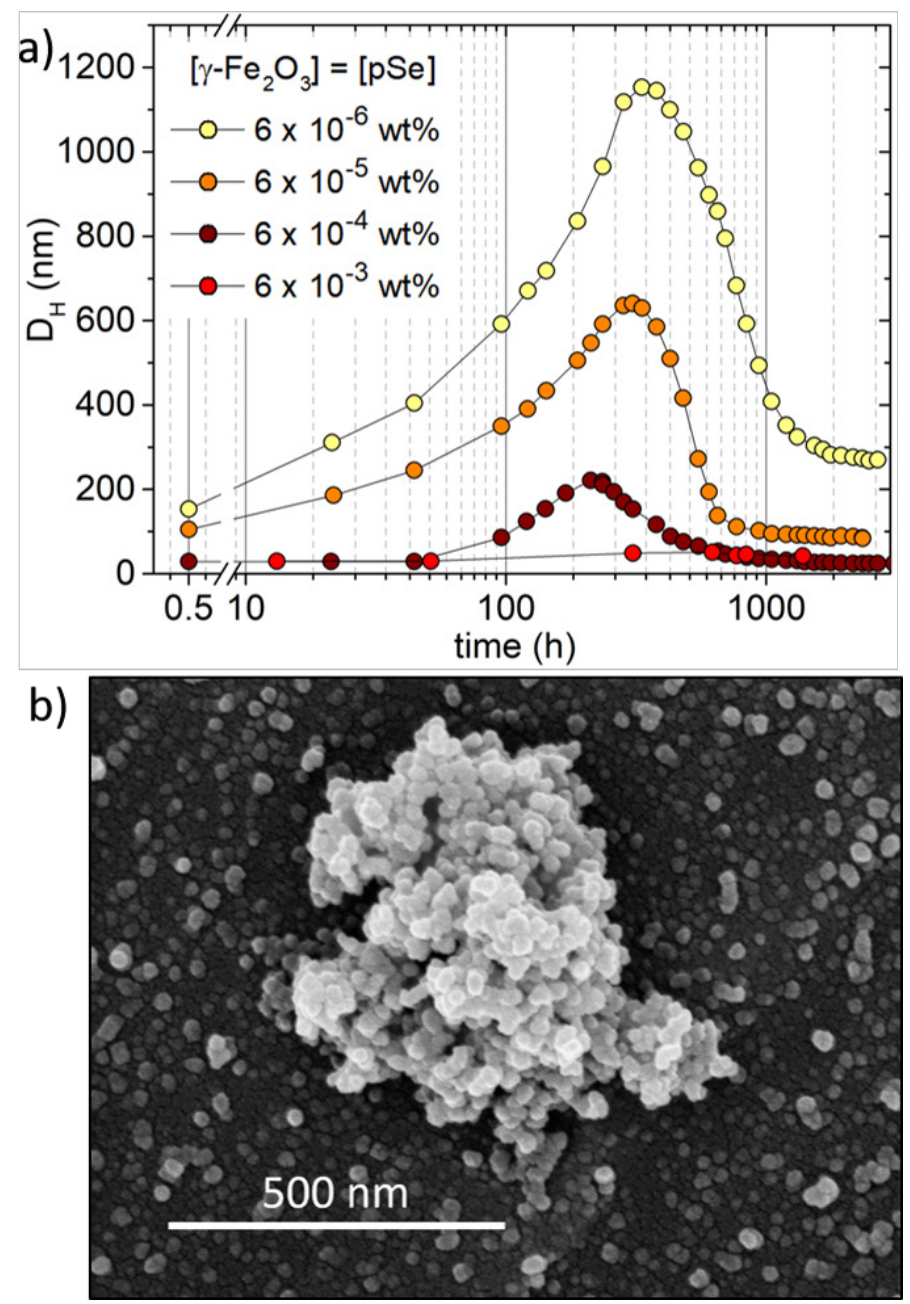

Figure 2. DLS and SEM analysis of $\gamma-\mathrm{Fe}_{2} \mathrm{O}_{3}-\mathrm{PAA} /$ poly(serine ester) polyion complexes synthesized in water at $\mathrm{pH}=7$. a) Hydrodynamic diameters $\left(D_{H}\right)$ versus time of $\gamma-\mathrm{Fe}_{2} \mathrm{O}_{3}$ PAA and pSe mixtures prepared from solutions at $\left[\gamma-\mathrm{Fe}_{2} \mathrm{O}_{3}\right]=[\mathrm{pSe}]=6 \times 10^{-6} \mathrm{wt} \%$ (yellow), $6 \times 10^{-5} \mathrm{wt} \%$ (orange), $6 \times 10^{-4} \mathrm{wt} \%$ (dark red) and $6 \times 10^{-3} \mathrm{wt} \%$ (red), respectively. Nanoparticles and pSe chains were mixed at $t=0$ and kept at $T=25{ }^{\circ} \mathrm{C}$. Increases and decreases of the $D_{H}$ are the respective signatures of the growth of $\gamma-\mathrm{Fe}_{2} \mathrm{O}_{3^{-}}$ $\mathrm{PAA} / \mathrm{pSe}$ polyion complexes by self-assembly followed by their auto-degradation. b) Representative SEM image of a $\gamma-\mathrm{Fe}_{2} \mathrm{O}_{3}-\mathrm{PAA} / \mathrm{pSe}$ cluster obtained at $\left[\gamma-\mathrm{Fe}_{2} \mathrm{O}_{3}\right]=[\mathrm{pSe}]=$ $6 \times 10^{-5} \mathrm{wt} \%$ and at $t=300 \mathrm{~h}$. 
Author manuscript version of paper accepted for publication in Mater. Sci. Eng. C, 2019, 109920, after peer review and technical editing by the publisher. DOI: 10.1016/j.msec.2019.109920

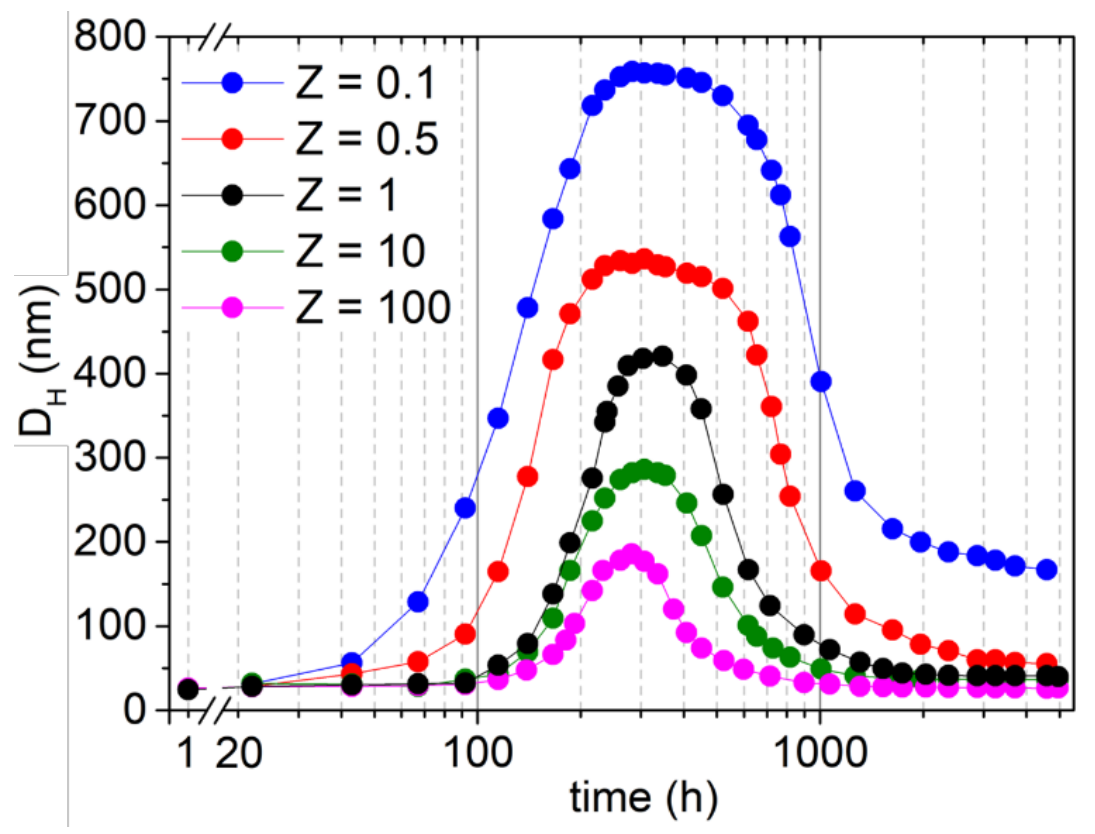

Figure 3. DLS analysis of $\gamma-\mathrm{Fe}_{2} \mathrm{O}_{3}-\mathrm{PAA} /$ poly(serine ester)- $b$-PEG polyion complexes synthesized in Phosphate Buffer Saline (PBS1×, $\mathrm{pH}=7.4)$. Hydrodynamic diameter $\left(D_{H}\right)$ versus time of $\gamma-\mathrm{Fe}_{2} \mathrm{O}_{3}$-PAA and $\mathrm{pSe}-b$-PEG mixtures prepared from solutions at $[\gamma-$ $\left.\mathrm{Fe}_{2} \mathrm{O}_{3}\right]=[\mathrm{pSe}]=6 \times 10^{-4} \mathrm{wt} \%$ at various charge ratio $Z=n^{-} / n^{+}$. The $Z$ of a $\gamma-\mathrm{Fe}_{2} \mathrm{O}_{3^{-}}$ $\mathrm{PAA} / \mathrm{pSe}-b$-PEG mixture is calculated as the amount of negative charges brought by the nanoparticles divided by the amount of positive charges brought by the polyelectrolyte chains. Nanoparticles and pSe- $b$-PEG were mixed at $t=0$ and kept at $T=25^{\circ} \mathrm{C}$. 
Author manuscript version of paper accepted for publication in Mater. Sci. Eng. C, 2019, 109920, after peer review and technical editing by the publisher. DOI: 10.1016/j.msec.2019.109920

In Phosphate Buffer saline (PBS1x), $\mathrm{pH}=7.4$
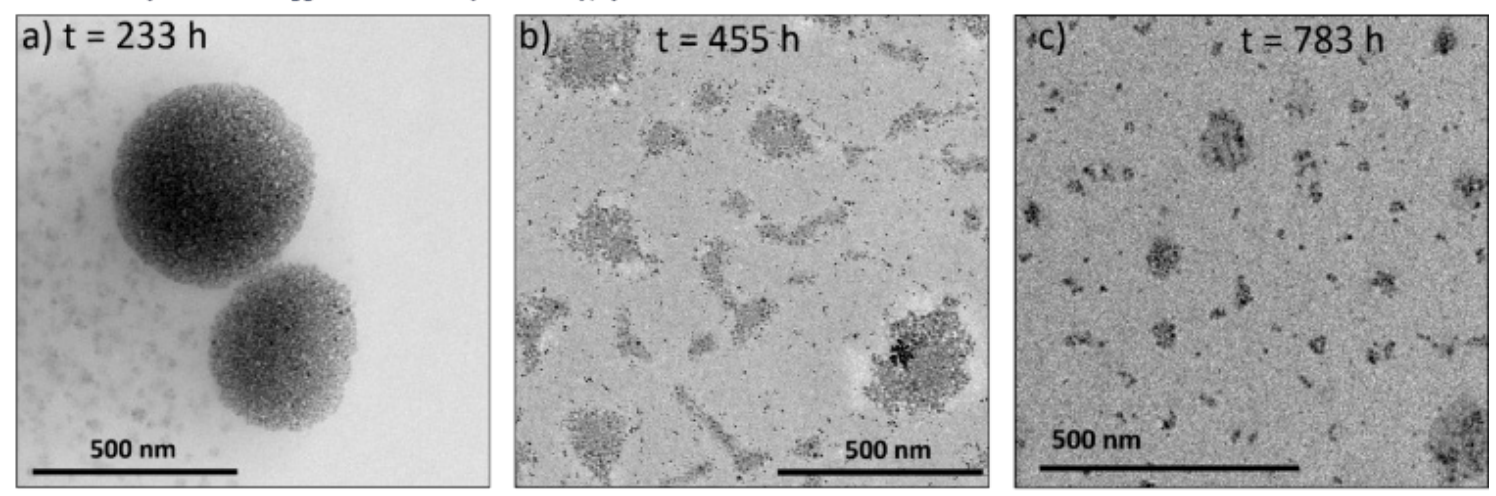

In pure water, $\mathrm{pH}=6.8$
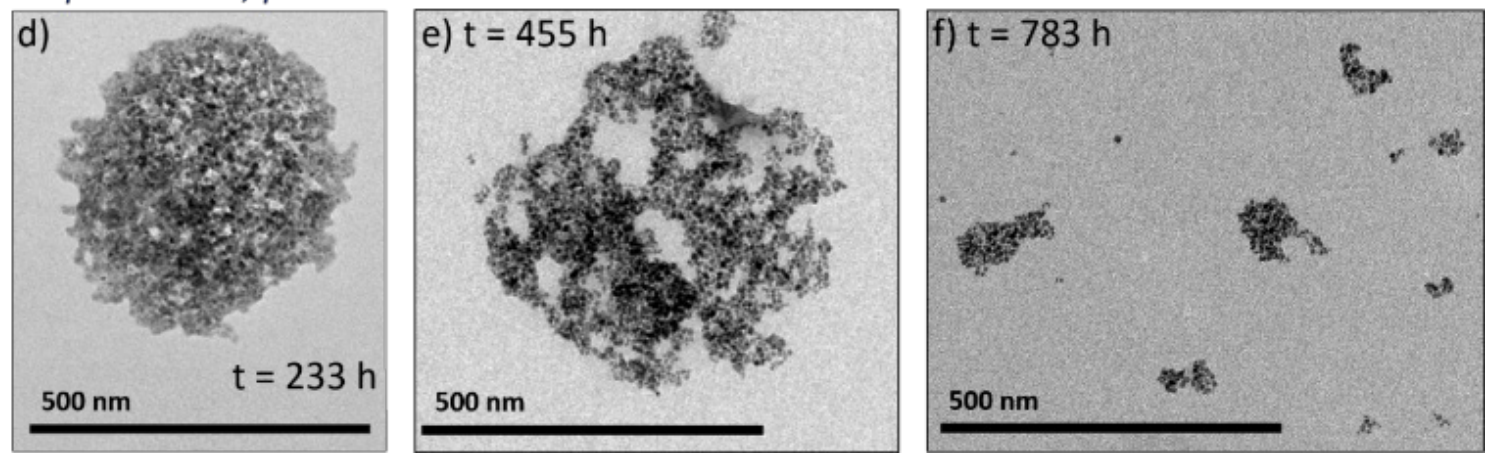

Figure 4. TEM study of the auto-degradation $\gamma-\mathrm{Fe}_{2} \mathrm{O}_{3}-\mathrm{PAA} / \mathrm{pSe}-b-\mathrm{PEG}$ polyion complexes in PBS1× (top) and deionized water (bottom). Polyion complexes were synthesized at $\left[\gamma-\mathrm{Fe}_{2} \mathrm{O}_{3}\right]=[\mathrm{pSe}-b-\mathrm{PEG}]=6 \times 10^{-4} \mathrm{wt} \%$ and at charge ratio $Z=1$ in $\operatorname{PBS} 1 \times(\mathrm{a}, \mathrm{b}, \mathrm{c})$ and deionized water $(\mathrm{d}, \mathrm{e}, \mathrm{f})$. TEM images of the clusters $233 \mathrm{~h}(\mathrm{a}, \mathrm{d})$, $455 \mathrm{~h}(\mathrm{~b}, \mathrm{e})$ and $783 \mathrm{~h}(\mathrm{c}, \mathrm{f})$ after mixing of $\gamma-\mathrm{Fe}_{2} \mathrm{O}_{3}$-PAA nanoparticles and pSe- $b$-PEG chains reveal different mechanisms of degradation in depending on the solvent. In PBS $1 \times$, elongated dense fragments are first detached from the outer part of the well-defined spherical clusters (a, b). Then, objects grow increasingly fragmented into small aggregates and single nanoparticles (c). In water, blocks are detached from outer and inner parts of the dense spherical clusters, resulting in porous structure (d, e). Over time, edifices collapse into small fragments and single nanoparticles (f). 
Author manuscript version of paper accepted for publication in Mater. Sci. Eng. C, 2019, 109920, after peer review and technical editing by the publisher. DOI: 10.1016/j.msec.2019.109920
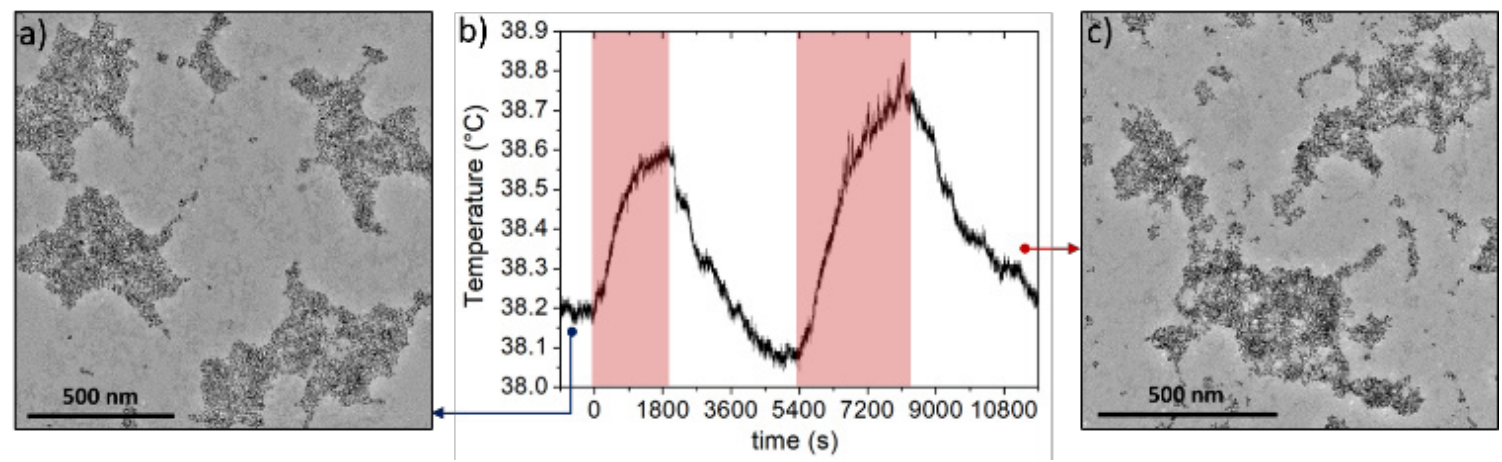

Figure 5. Hyperthermia experiment performed on $\gamma-\mathrm{Fe}_{2} \mathrm{O}_{3}-\mathrm{PAA} / \mathrm{pSe}-b$-PEG polyion complexes in water at $\left[\gamma-\mathrm{Fe}_{2} \mathrm{O}_{3}\right]=8.8 \times 10^{-3} \mathrm{wt} \%$. a) TEM image of the polyion complexes before hyperthermia treatment. The clusters show dense and compact structures. b) Temperature versus time diagram of the sample upon two cycles of hyperthermia. Red stripes indicate periods when alternating magnetic field was on. c) TEM image of the polyion complexes after hyperthermia treatment showing dense clusters and small fragments. 
Author manuscript version of paper accepted for publication in Mater. Sci. Eng. C, 2019, 109920, after peer review and technical editing by the publisher. DOI: 10.1016/j.msec.2019.109920

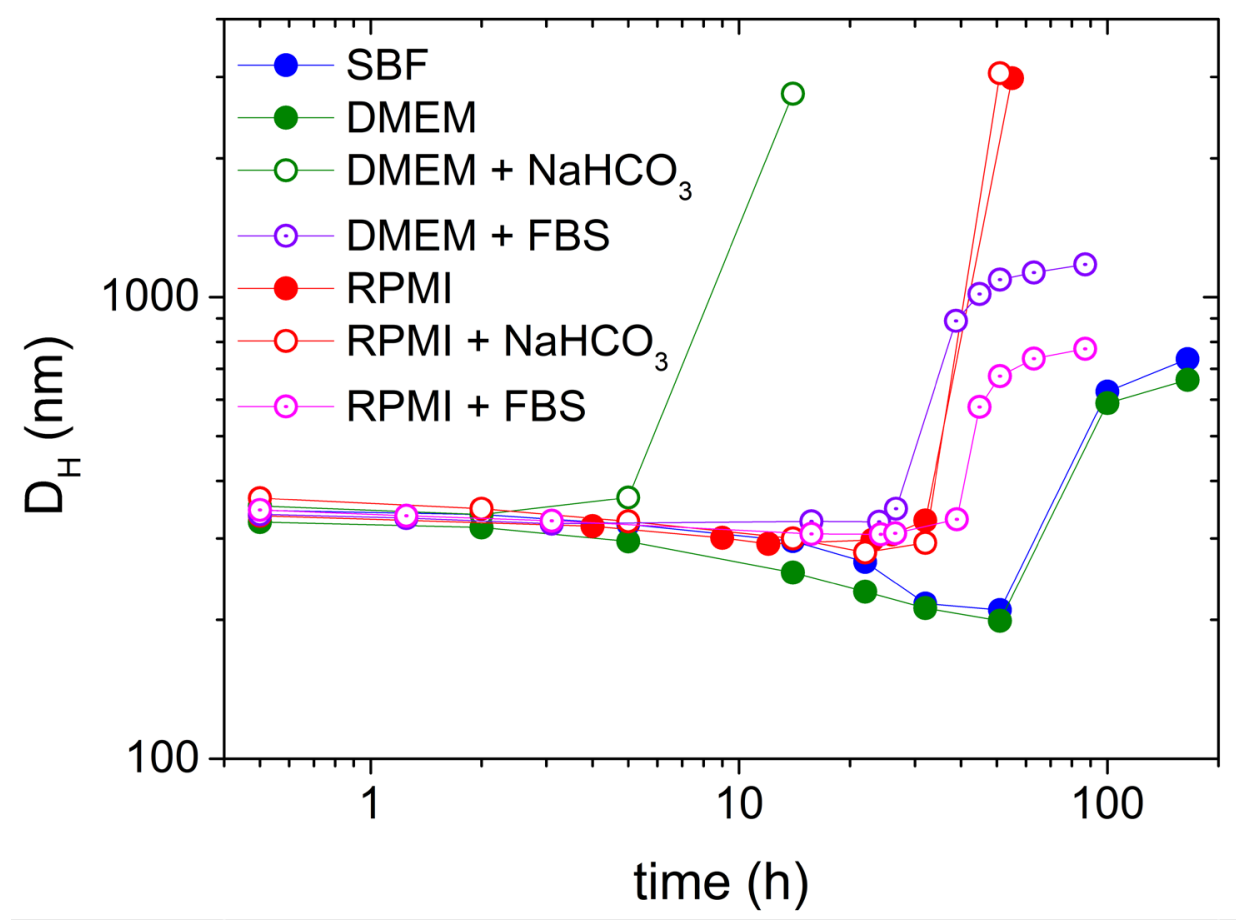

Figure 6. DLS study of the stability of $\gamma-\mathrm{Fe}_{2} \mathrm{O}_{3}-\mathrm{PAA} / \mathrm{pSe}-b$-PEG polyion complexes in bio-fluids. $\gamma-\mathrm{Fe}_{2} \mathrm{O}_{3}$-PAA/pSe- $b$-PEG polyion complexes at $Z=1$ were prepared in water from solutions at $\left[\gamma-\mathrm{Fe}_{2} \mathrm{O}_{3}\right]=[\mathrm{pSe}]=6 \times 10^{-4} \mathrm{wt} \% .342 \mathrm{~h}$ after mixing, clusters with $D_{H}$ $=417 \pm 15 \mathrm{~nm}$ were transferred into Simulated Body Fluid (SBF, blue symbols), DMEM (closed green symbols), DMEM supplemented with $\mathrm{NaHCO}_{3}$ (empty green symbols), DMEM containing 10 vol\% of fetal bovine serum (FBS) (violet symbols), RPMI (closed red symbols), RPMI supplemented with $\mathrm{NaHCO}_{3}$ (empty red symbols) and RPMI containing 10 vol $\%$ of FBS (pink symbols) as $\left[\gamma-\mathrm{Fe}_{2} \mathrm{O}_{3}\right]=6 \times 10^{-4} \mathrm{wt} \%$. Samples were then incubated at $T=37^{\circ} \mathrm{C}$ and hydrodynamic diameters $\left(D_{H}\right)$ measured according to the time. $t=0$ represents the time when clusters were transferred into SBF and cell culture media. 
Author manuscript version of paper accepted for publication in Mater. Sci. Eng. C, 2019, 109920, after peer review and technical editing by the publisher. DOI: 10.1016/j.msec.2019.109920
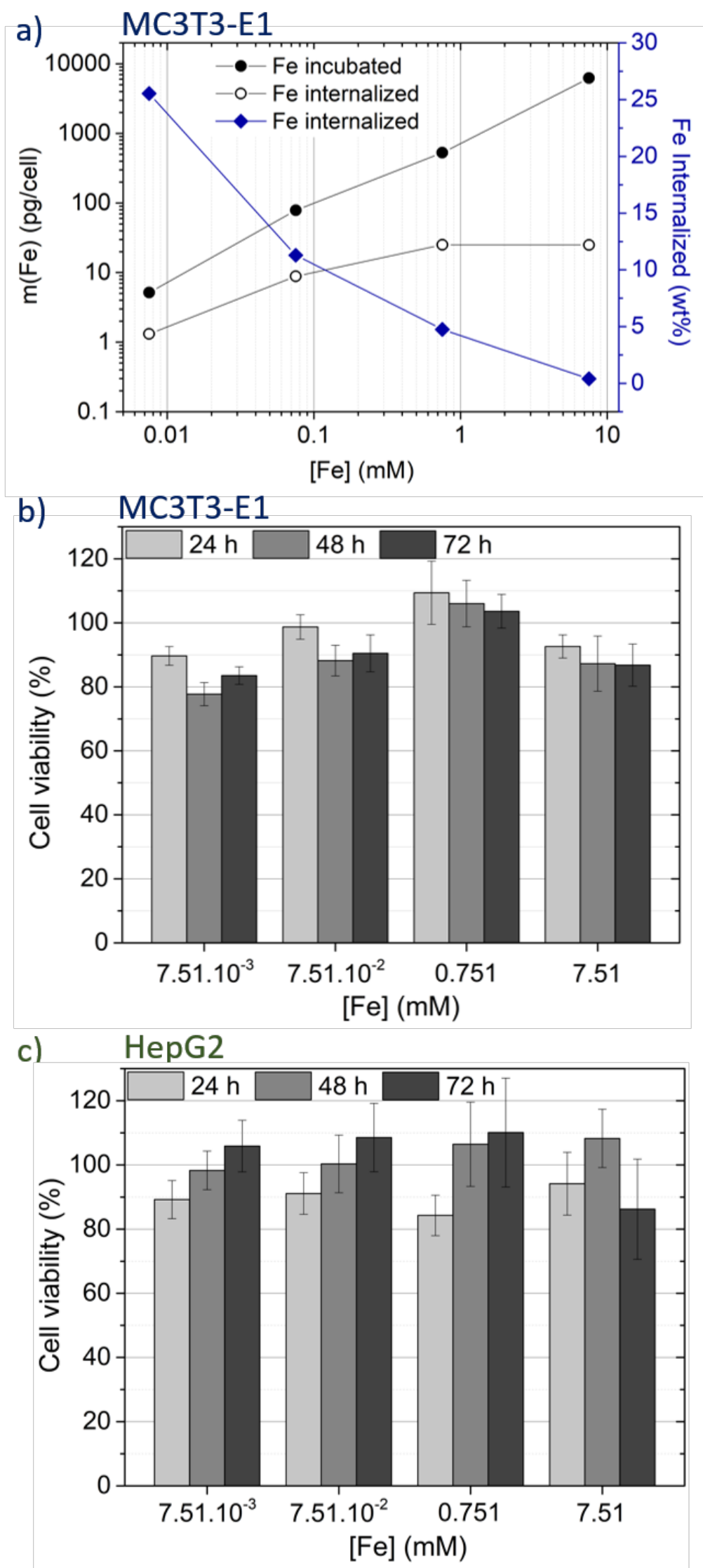
Author manuscript version of paper accepted for publication in Mater. Sci. Eng. C, 2019, 109920, after peer review and technical editing by the publisher. DOI: 10.1016/j.msec.2019.109920

Figure 7. Cellular uptake (a) and toxicity assays (b, c) of $\gamma-\mathrm{Fe}_{2} \mathrm{O}_{3}-\mathrm{PAA} / \mathrm{pSe}-b-\mathrm{PEG}$ polyion complexes. In these experiments, $\gamma-\mathrm{Fe}_{2} \mathrm{O}_{3}-\mathrm{PAA} / \mathrm{pSe}-b$-PEG clusters with $D_{H}=$ $414 \pm 10 \mathrm{~nm}$ (prepared at $c=6 \times 10^{-4} \mathrm{wt} \%$ in $\mathrm{PBS} 1 \times, Z=1, t=304 \mathrm{~h}$ after direct mixing) were incubated with respectively MC3T3-E1 (a, b) and HepG2 (c) cells $\left(\approx 2 \times 10^{4}\right.$ cells per well) at respectively $[\mathrm{Fe}]=0,7.51 \times 10^{-3}, 7.51 \times 10^{-2}, 0.751$ and $7.51 \mathrm{mM}$. a) Mass of Fe (in pg per cell, empty black symbols, left axis) and mass fraction of $\mathrm{Fe}$ (in $\mathrm{wt} \%$, blue symbols, right axis) which have been internalized or adsorbed by MC3T3-E1 cells $24 \mathrm{~h}$ after incubation in function of concentration in Fe. The mass of Fe incubated, in pg per cell (closed black symbols), represents the maximum amount of Fe that can be taken up by cells at a given concentration. b, c) Quantitative cell viability assessments conducted with a Cell Counting Kit-8 on MC3T3-E1 (b) and HepG2 (c) cells 24 h, 48 h and 72 h after incubation with $\gamma-\mathrm{Fe}_{2} \mathrm{O}_{3}-\mathrm{PAA} / \mathrm{pSe}-b$-PEG polyion complexes at various concentrations. Cell viabilities are expressed in \% relatively to control experiments. 
Author manuscript version of paper accepted for publication in Mater. Sci. Eng. C, 2019, 109920, after peer review and technical editing by the publisher. DOI: 10.1016/j.msec.2019.109920
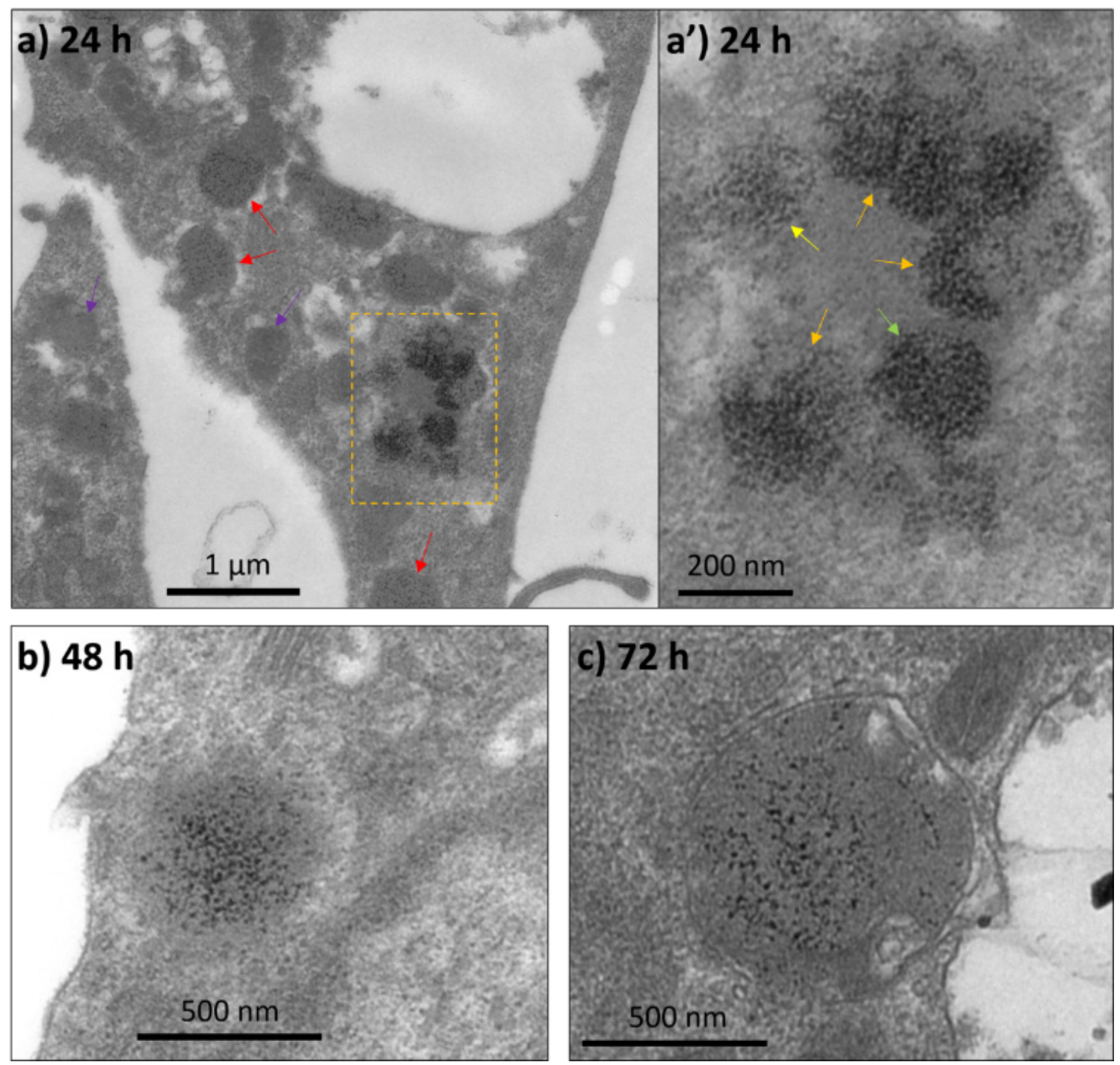

Figure 8. TEM images of MC3T3-E1 cells $24 \mathrm{~h}$ (a, a'), $48 \mathrm{~h}$ (b) and $72 \mathrm{~h}$ (c) after incubation with $\gamma$ - $\mathrm{Fe}_{2} \mathrm{O}_{3}$-PAA/pSe- $b$-PEG spherical clusters at $\left[\gamma-\mathrm{Fe}_{2} \mathrm{O}_{3}\right]=6 \times 10^{-3} \mathrm{wt} \%$ (corresponding to $[\mathrm{Fe}]=0.741 \mathrm{mM}$ ). a') close-up view of the area delimited by a yellow rectangle in panel a. At $24 \mathrm{~h}$ of exposure, $\gamma-\mathrm{Fe}_{2} \mathrm{O}_{3}-\mathrm{PAA} / \mathrm{pSe}-b$-PEG material completely degraded into single nanoparticles and oligomeric aggregates can be observed (a, red arrows) whereas almost undegraded clusters with dense structure (a', green arrow), dense clusters with destructured outer layer (a', orange arrows), and partly degraded clusters (a', yellow arrow) are visible. Round-shaped domains which do not contain nanoparticles 
Author manuscript version of paper accepted for publication in Mater. Sci. Eng. C, 2019, 109920, after peer review and technical editing by the publisher. DOI: 10.1016/j.msec.2019.109920

are also present (a, violet arrows). At $48 \mathrm{~h} \mathrm{(b)} \mathrm{and} 72 \mathrm{~h}$ (c), no dense clusters were found but only nanoparticles concentrated in round-shaped domains. These individual nanoparticles are interpreted as the degradation byproducts of $\gamma-\mathrm{Fe}_{2} \mathrm{O}_{3}-\mathrm{PAA} / \mathrm{pSe}-b-\mathrm{PEG}$ polyion complexes. 


\title{
Supporting Information
}

\section{Auto-degradable and biocompatible superparamagnetic iron oxide nanoparticles/polypeptides colloidal polyion complexes with high density of magnetic material}

\author{
Bin Wang ${ }^{\mathrm{a}}$, Olivier Sandre ${ }^{\mathrm{b}}$, Kunzhou Wang ${ }^{\mathrm{a}}$, Haishan Shi ${ }^{\mathrm{c}}$, Kun Xiong ${ }^{\mathrm{a}}$, Yu-bin Huang ${ }^{\mathrm{d}}$, \\ Tingting $\mathrm{Wu}^{\mathrm{e}}$, Minhao Yan ${ }^{\mathrm{a}, *}$ and Jérémie Courtois ${ }^{\mathrm{a}, *}$ \\ ${ }^{\text {a }}$ State Key Laboratory of Environment-friendly Energy Materials, Southwest University of Science \\ and Technology, Mianyang 621010, China. \\ ${ }^{\mathrm{b}}$ Univ. Bordeaux, CNRS, Bordeaux INP, LCPO, UMR 5629, F-33600, Pessac, France. \\ ${ }^{\mathrm{c}}$ College of Chemistry and Materials Science, Jinan University, Guangzhou 510632, China. \\ ${ }^{\mathrm{d}}$ State Key Laboratory of Polymer Physics and Chemistry, Changchun Institute of Applied Chemistry, \\ Chinese Academy of Sciences, Changchun 130022, P. R. China. \\ ${ }^{\mathrm{e}}$ Department of Bone and Joint Surgery, Institute of Orthopedic Diseases, The first Affiliated \\ Hospital, Jinan University, Guangzhou, 510630, China. \\ * Corresponding authors, E-mail addresses: yanminhao@swust.edu.cn (M. Yan); \\ jeremiecourtois@swust.edu.cn (J. Courtois); Fax: +86 (0816) 2419492; Tel: +86 13541724620.
}

\section{Keywords:}

Superparamagnetic iron oxide nanoparticle (SPION)

Polypeptide-based polyester

Polyion complex

Magnetic hyperthermia

Electrostatic complexation

Biodegradable

\section{Summary}

Transmission electron microscopy (TEM) analysis of $\gamma-\mathrm{Fe}_{2} \mathrm{O}_{3}$ nanocrystals

X-ray diffraction (XRD) analysis of the $\gamma-\mathrm{Fe}_{2} \mathrm{O}_{3}$ and $\gamma-\mathrm{Fe}_{2} \mathrm{O}_{3}$-PAA nanoparticles

Determination of the molecular weight of the $\gamma-\mathrm{Fe}_{2} \mathrm{O}_{3}$ nanoparticles by static light scattering

(SLS)

Acid-base titration of $\gamma$ - $\mathrm{Fe}_{2} \mathrm{O}_{3}$-PAA nanoparticles

Vibrating sample magnetometry (VSM) analysis of the $\gamma-\mathrm{Fe}_{2} \mathrm{O}_{3}$-PAA nanoparticles and $\gamma$ -

$\mathrm{Fe}_{2} \mathrm{O}_{3}$-PAA/pSe- $b$-PEG polyion complexes

Determination of the iron oxide concentration in dispersions by UV-vis spectroscopy

Preparation of $\gamma-\mathrm{Fe}_{2} \mathrm{O}_{3}-\mathrm{PAA} / \mathrm{pSe}$ and $\gamma-\mathrm{Fe}_{2} \mathrm{O}_{3}-\mathrm{PAA} / \mathrm{pSe}-b$-PEG polyion complexes

Determination of the numbers of cells during cell viability assessments

DLS study of $\gamma-\mathrm{Fe}_{2} \mathrm{O}_{3}-\mathrm{PAA} / \mathrm{pSe}$ in $\mathrm{NH}_{4} \mathrm{Cl}$ Solutions

DLS study of the interactions between $\gamma-\mathrm{Fe}_{2} \mathrm{O}_{3}-\mathrm{PAA}$, serine and PEG

GPC study of the degradation of pSe- $b$-PEG

TEM images of $\gamma-\mathrm{Fe}_{2} \mathrm{O}_{3}-\mathrm{PAA} / \mathrm{pSe}-b$-PEG polyion complexes in PBS1 $\times$

$\gamma$ - $\mathrm{Fe}_{2} \mathrm{O}_{3}-\mathrm{PAA} / \mathrm{pSe}-b$-PEG in PBS $1 \times$ and water: comparative study by DLS

DLS study of the thermal stability of $\gamma-\mathrm{Fe}_{2} \mathrm{O}_{3}-\mathrm{PAA} / \mathrm{pSe}-b$-PEG polyion complexes in water

Proton relaxation rates of $\gamma-\mathrm{Fe}_{2} \mathrm{O}_{3}$-PAA and $\gamma$ - $\mathrm{Fe}_{2} \mathrm{O}_{3}$-PAA/pSe- $b$-PEG polyion complexes 


\section{Transmission electron microscopy (TEM) analysis of $\gamma$-Fe $\mathrm{F}_{2} \mathrm{O}_{3}$ nanocrystals}

TEM analysis was performed on a Zeiss Libra200FE microscope. Figure S1a shows a TEM image of the maghemite nanocrystals $\left(\gamma-\mathrm{Fe}_{2} \mathrm{O}_{3}\right)$. The particles are characterized by a dense structure and an almost spherical shape.

a)

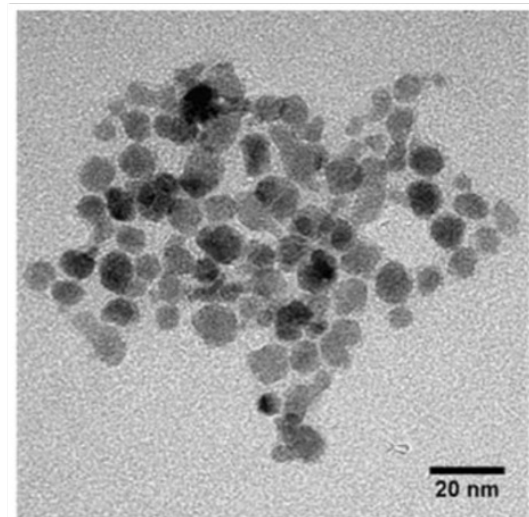

b) 80

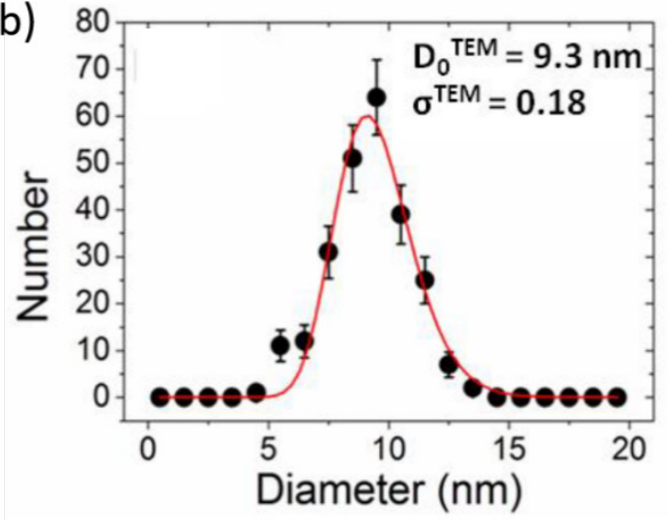

Figure S1. a) Maghemite superparamagnetic nanoparticles $\left(\gamma-\mathrm{Fe}_{2} \mathrm{O}_{3}\right)$ as observed by TEM. b)

Size distribution of the $\gamma-\mathrm{Fe}_{2} \mathrm{O}_{3}$ particles. The continuous line was derived from a best-fit calculation using a log-normal distribution. For these dispersions, the median size of the nanoparticles was found to be $9.3 \pm 0.2 \mathrm{~nm}$, and the polydispersity $0.18 \pm 0.01$.

The size distribution of the $\gamma-\mathrm{Fe}_{2} \mathrm{O}_{3}$ particles presented in Figure $\mathrm{S} 1 \mathrm{~b}$ was generated from a series of TEM images similar to Figure S1a, The data are fitted using a log-normal function (Equation S1) with physical median diameter $D_{0}^{T E M}=9.3 \pm 0.2 \mathrm{~nm}$ and polydispersity $s^{T E M}=0.18 \pm 0.01$ :

$$
p(D)=\frac{1}{\sqrt{2 \pi\left(s^{T E M}\right) D}} \exp \left(-\frac{\ln ^{2}\left(D / D_{0}^{T E M}\right)}{2 \times\left(s^{T E M}\right)^{2}}\right)
$$




\section{X-ray diffraction (XRD) analysis of the $\gamma-\mathrm{Fe}_{2} \mathrm{O}_{3}$ and $\gamma-\mathrm{Fe}_{2} \mathrm{O}_{3}-\mathrm{PAA}$ nanoparticles}

Concentrated $\gamma-\mathrm{Fe}_{2} \mathrm{O}_{3}$ and $\gamma-\mathrm{Fe}_{2} \mathrm{O}_{3}-\mathrm{PAA}$ nanoparticles dispersions were freeze-dried and the powders analyzed by XRD using a PANalytical X'Pert PRO X-ray diffractometer. The $2 \theta$ values were taken from $20^{\circ}$ to $70^{\circ}$ using $\mathrm{Cu} \mathrm{K \alpha}$ radiation ( $\lambda$ value is $1.5416 \AA$ ). Figure S2 presents the XRD patterns of the materials.

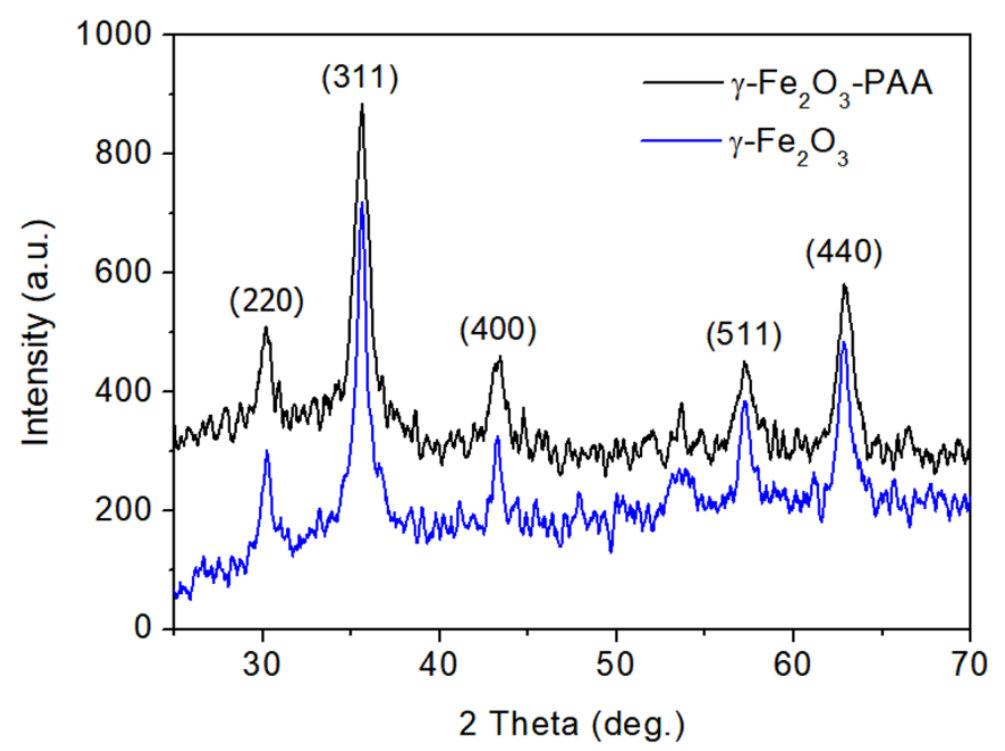

Figure S2. XRD patterns of $\gamma-\mathrm{Fe}_{2} \mathrm{O}_{3}$ and $\gamma-\mathrm{Fe}_{2} \mathrm{O}_{3}-\mathrm{PAA}$ nanoparticles.

For both bare and PAA-coated iron oxide particles, the (220), (311), (400), (511) and (440) diffraction peaks are indexed to cubic spinel structure (card number PDF\# : 39-1346) corresponding to maghemite. The average particle size is estimated from the most intense peak (311) by using the Debye-Scherrer formula. $d=0.9 \lambda / \beta \cos \theta$, where $\mathrm{d}$ is the particle size, $\beta$ is the full width at half-maxima, $\lambda$ is the incident copper $K \alpha$ wavelength of $1.546 \AA$, and $\theta$ is the maximum peak position. The average crystal size obtained from the Debye-Scherrer equation is found to be about $10 \mathrm{~nm}$. 
Supporting information of paper accepted for publication in Mater. Sci. Eng. C, 2019, 109920

\section{Determination of the molecular weight of the $\gamma-\mathrm{Fe}_{2} \mathrm{O}_{3}$ nanoparticles by static light scattering (SLS)}

SLS monitored on a Brookhaven 90plus was used to determine the molecular weight $\left(M_{w}\right)$ of the $\gamma-\mathrm{Fe}_{2} \mathrm{O}_{3}$ nanoparticles. Several dispersions at $\mathrm{pH}=2\left(\mathrm{HNO}_{3}\right)$ were prepared at concentrations from $10^{-3} \mathrm{wt} \%$ to $0.4 \mathrm{wt} \%$. The non-aggregated state of these nanoparticles dispersions was asserted DLS. The Rayleigh ratio was obtained from the scattered intensity $I(q, c)$ measured at the wave-vector $q$ according to Equation S2:

$$
R(q, c)=R_{\text {std }} \frac{I(q, c)-I_{\text {water }}}{I_{\text {Tol }}}\left(\frac{n}{n_{\text {tol }}}\right)^{2}
$$

where $R_{\text {std }}$ and $n_{T o l}$ are the standard Rayleigh ratio and refractive index of toluene, $I_{\text {Water }}$ and $I_{T o l}$ the intensities measured for the solvent and for the toluene in the same scattering configuration and $q=(4 \pi n / \lambda) \sin (\theta / 2)$ ( $n$ is the refractive index of the solution, $\theta$ is the scattering angle, and $\lambda$ is wavelength $633 \mathrm{~nm}) .{ }^{1}$ The scattering angle of the Brookhaven spectrometer was $\theta=90^{\circ}$, corresponding to wave-vectors $q=1.87 \times 10^{-3} \AA^{-1}$.

The linear evolution of the Rayleigh ratio as a function of concentration, $c$, is given by Equation S3 and is experimentally verified.

$$
R(c)=K c M_{W}^{a p p}
$$

In this equation, $M_{W}^{a p p}$ is the apparent molecular weight of the diffusing species and $K=\frac{4 \pi^{2} n^{2}(d n / d c)^{2}}{N_{A} \lambda^{4}}$ is the diffusion contrast with $N_{A}$ as Avogadro's number and $(d n / d c)$ as the refraction index increment as measured using a differential refractometer Chromatix KMX-16. The average molecular weight of the $\gamma-\mathrm{Fe}_{2} \mathrm{O}_{3}$ nanoparticles is found to be $5.82 \times 10^{6} \mathrm{~g} \mathrm{~mol}^{-1}$. 


\section{Acid-base titration of $\gamma$ - $\mathrm{Fe}_{2} \mathrm{O}_{3}$-PAA nanoparticles}

The ratio between carboxylic acid and carboxylate groups at the surface of the PAA coated particles depends on the $\mathrm{pH}$ of the dispersion. Acid-base titrations have been performed on $\gamma-\mathrm{Fe}_{2} \mathrm{O}_{3}$-PAA nanoparticles dispersed in pure water in order to determine their charge density as a function of $\mathrm{pH}$. The $\mathrm{pH}$-dependent protonation-deprotonation process has been characterized quantitatively following the method developed by Szekeres et al. ${ }^{2}$ Measurements lead to the calculation of the net proton surface excess, which is equivalent to the amount of carboxylate groups, as a function of $\mathrm{pH}$.

Titration experiments were performed at $25^{\circ} \mathrm{C}$, under nitrogen flow and with constant stirring speed of $200 \mathrm{rpm}$. Dispersions of $\gamma$ - $\mathrm{Fe}_{2} \mathrm{O}_{3}$-PAA particles $\left(20 \mathrm{~mL},\left[\gamma-\mathrm{Fe}_{2} \mathrm{O}_{3}\right]=0.05\right.$ wt $\%$ ) were freshly prepared from degassed deionized water (30 minutes at boiling point and subsequent Argon bubbling during 30 minutes), and degassed again by Argon bubbling prior to titration. $\mathrm{HCl}$ and $\mathrm{NaOH}$ titrant solutions were introduced using micropipette, and $\mathrm{pH}$ and E $(\mathrm{mV})$ measured after each injection once equilibrium was reach. Experiments were performed using an Accumet XL200 pH-meter. $\mathrm{pH}$ probe was washed with concentrated $\mathrm{HCl}$ and linearity of $\mathrm{E}(\mathrm{mV}) \mathrm{vs} \mathrm{pH}\left(\right.$ Nernst slope: $\left.\mathrm{R}^{2}>99.98\right)$ checked before each titration.

$\gamma-\mathrm{Fe}_{2} \mathrm{O}_{3}$ nanoparticles were coated with $\mathrm{PAA}_{2 \mathrm{~K}}$ using precipitation redispersion process. ${ }^{3} \mathrm{PAA}_{2 \mathrm{~K}}$ chains were adsorbed to iron oxide cores in acidic conditions $(\mathrm{pH}=2)$ and then redispersed at $\mathrm{pH}=10 \mathrm{using} \mathrm{NH}_{4} \mathrm{OH}$ before their purification by dialysis. $\gamma-\mathrm{Fe}_{2} \mathrm{O}_{3}$-PAA used in the study are therefore surrounded by $\mathrm{NH}_{4}{ }^{+}$counter-ions. As ammonium counter-ions could be involved in proton exchange processes or could chemically interact with $\gamma$ - $\mathrm{Fe}_{2} \mathrm{O}_{3}$ PAA surface, it was required to replace them by $\mathrm{Na}^{+}$counter-ions prior to titrations. Coated nanoparticles with ammonium counter-ions were precipitated in $\mathrm{HCl}$ and washed sequentially with large amount of $\mathrm{HCl}$ solution $(\mathrm{pH}=2)$ in order to remove $\mathrm{NH}_{4}^{+}$ions, and deionized water. $\gamma-\mathrm{Fe}_{2} \mathrm{O}_{3}$-PAA were then redispersed with $\mathrm{NaOH}$ to $\mathrm{pH}=9$, ensuring presence of $\mathrm{Na}^{+}$ 
counter-ions, and finally purified by dialysis versus deionized water. $\mathrm{pH}$ of purified $\gamma$ - $\mathrm{Fe}_{2} \mathrm{O}_{3}-$ PAA dispersion with $\mathrm{Na}^{+}$counter-ions is 6.5.

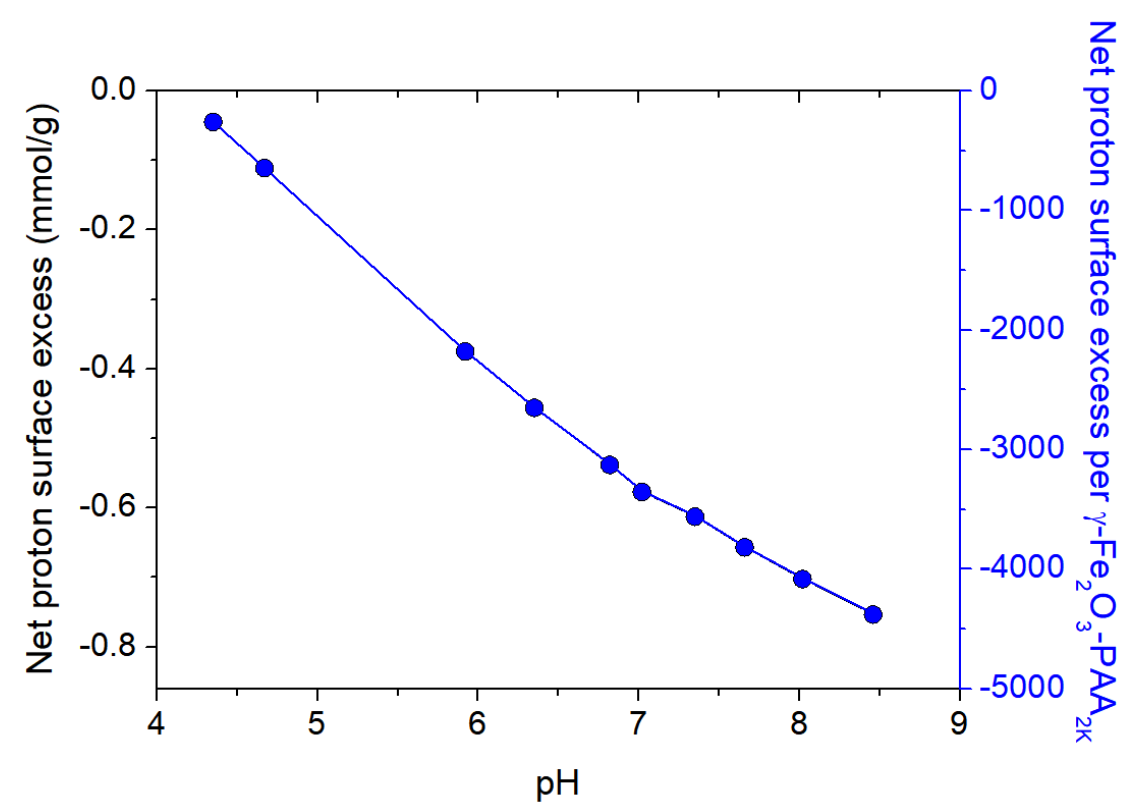

Figure S3. Net surface proton excess (expressed in $\mathrm{mmol}$ of $\mathrm{H}^{+}$per $\mathrm{g}$ of iron oxide (left ordinate axis) and in $\mathrm{H}^{+}$per nanoparticle (right ordinate axis)) as a function of $\mathrm{pH}$ for $\gamma$ $\mathrm{Fe}_{2} \mathrm{O}_{3}-\mathrm{PAA}_{2 \mathrm{~K}}$ nanoparticles. Net surface proton excess is proportional to the surface charge density of the nanoparticles.

Figure S3 displays the net surface proton excess expressed either in mmol per $\mathrm{g}$ of iron oxide or in number of proton per nanoparticle, as a function of the $\mathrm{pH}$. Indeed, knowing the molecular weight of the $\gamma-\mathrm{Fe}_{2} \mathrm{O}_{3}$ particles $\left(M_{w}=5.8 \times 10^{6} \mathrm{~g} \mathrm{~mol}^{-1}\right)$ and the mass of iron oxide in a sample, the number of nanoparticles can be calculated and net surface proton excess per $\mathrm{g}$ of iron oxide then converted in number of negative charges per nanoparticle. At $\mathrm{pH}=7$, the net surface proton excess is $-0.577 \mathrm{mmol} \mathrm{g}^{-1}$, corresponding to $3347 \pm 50$ negative charges per $\gamma-\mathrm{Fe}_{2} \mathrm{O}_{3}-\mathrm{PAA}_{2 \mathrm{~K}}$ nanoparticle. Results are in good agreement with previous work. ${ }^{4}$ 
Supporting information of paper accepted for publication in Mater. Sci. Eng. C, 2019, 109920

Vibrating sample magnetometry (VSM) analysis of the $\gamma-\mathrm{Fe}_{2} \mathrm{O}_{3}$-PAA nanoparticles and $\gamma-\mathrm{Fe}_{2} \mathrm{O}_{3}$-PAA/pSe-b-PEG polyion complexes

Vibrating sample magnetometry measures the magnetization, $M$, as a function of excitation, $H$, of a liquid dispersion containing a volume fraction of magnetic material from the signal induced in detection coils when the sample is moved periodically in an applied magnetic field (via synchronous detection and with an appropriate calibration). Figure S4 shows the evolution of the macroscopic magnetization $M(H)$ of the $\gamma-\mathrm{Fe}_{2} \mathrm{O}_{3}$ nanoparticles, $\gamma$ $\mathrm{Fe}_{2} \mathrm{O}_{3}$-PAA nanoparticles and $\gamma-\mathrm{Fe}_{2} \mathrm{O}_{3}$-PAA/pSe- $b$-PEG polyion complexes (PICs) at $T=$ $25{ }^{\circ} \mathrm{C}$.

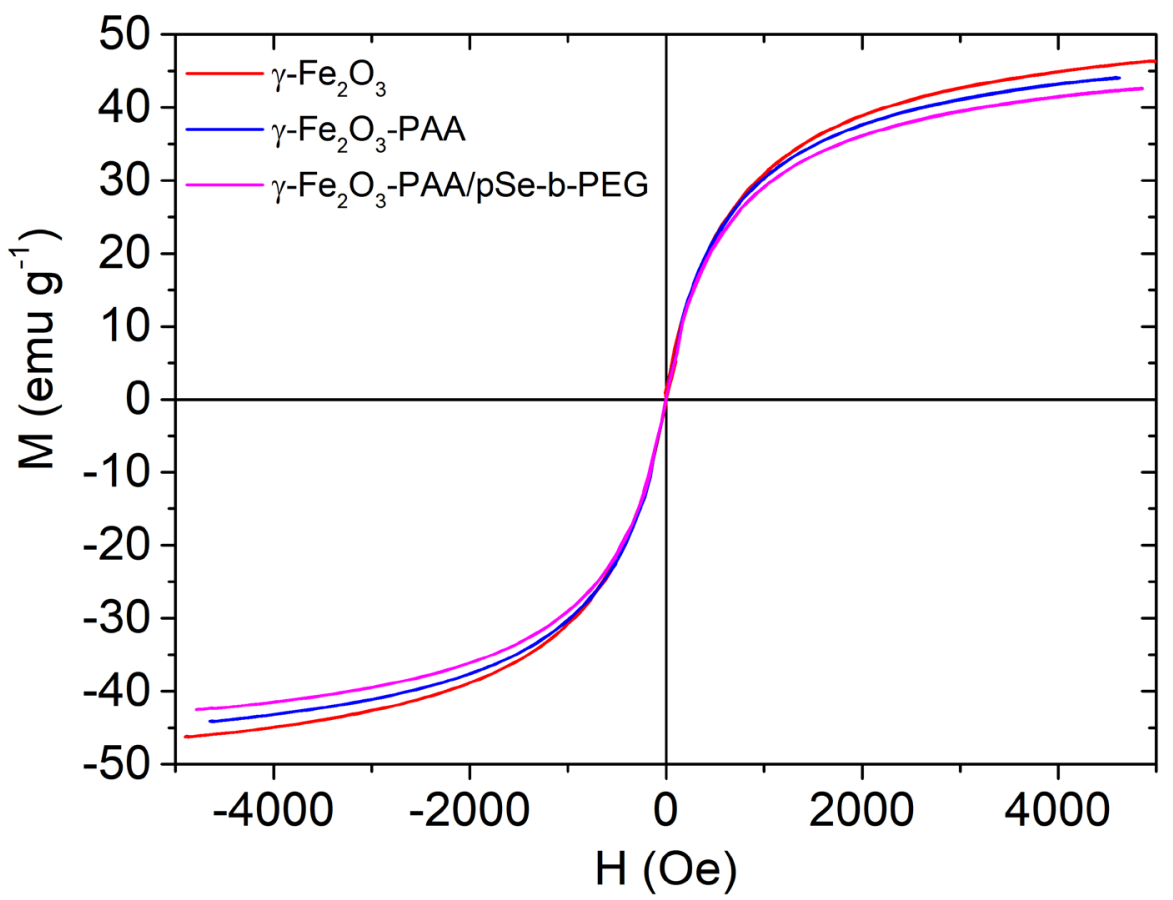

Figure S4. Magnetic field dependence of the macroscopic magnetization $M(H)$ for $\gamma-\mathrm{Fe}_{2} \mathrm{O}_{3}$ nanoparticles (red), $\gamma$ - $\mathrm{Fe}_{2} \mathrm{O}_{3}$-PAA nanoparticles (blue) and $\gamma-\mathrm{Fe}_{2} \mathrm{O}_{3}$-PAA/pSe- $b$-PEG polyion complexes (pink). 


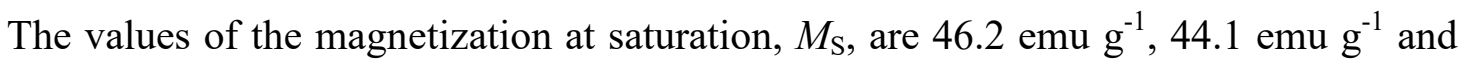
$42.5 \mathrm{emu} \mathrm{g}^{-1}$ for bare maghemite nanocrystals, PAA coated particles and $\gamma-\mathrm{Fe}_{2} \mathrm{O}_{3}-\mathrm{PAA} / \mathrm{pSe}-b-$ PEG PICs, respectively. Here, $M_{\mathrm{S}}=\phi m_{\mathrm{S}}$, where $\phi$ is the volume fraction of maghemite and $m_{\mathrm{S}}$ is the specific magnetization of colloidal maghemite $\left(m_{\mathrm{S}}=3.5 \times 10^{5} \mathrm{~A} \mathrm{~m}^{-1}\right)$, which is lower than that of bulk maghemite due to some disorder of the magnetic moments located near the surface. Absence of magnetization at $H=0$ combined to significant values of $M_{\mathrm{S}}$ are characteristic of superparamagnetic behavior.

\section{Determination of the iron oxide concentration in dispersions by UV-vis spectroscopy}

In this study, the iron oxide concentration of a colloidal dispersion of $\gamma-\mathrm{Fe}_{2} \mathrm{O}_{3}$-PAA nanoparticles or $\gamma-\mathrm{Fe}_{2} \mathrm{O}_{3}$-PAA/pSe- $b$-PEG PICs is determined by UV-vis spectroscopy. First, a master curve was established by measuring the absorbance between $220 \mathrm{~nm}$ and $800 \mathrm{~nm}$ of a $\gamma-\mathrm{Fe}_{2} \mathrm{O}_{3}$ nanoparticle dispersion of a known concentration determined by Inductively Coupled Plasma Atomic Emission Spectroscopy (ICP-AES). The master curve is presented in Figure S5 (black curve).

The Beer-Lambert law relates the absorption of light to the properties of the material through which the light is travelling and is usually written as: $A b s(\lambda)=\varepsilon(\lambda) \times l \times c$, where $\operatorname{Abs}(\lambda)$ is the absorbance at the wavelength $\lambda, \varepsilon$ the molar extinction coefficient, $l$ the path length $(1 \mathrm{~cm})$ and $c$ the concentration. According to this relationship, $A b s(\lambda) / c$ is a constant for a given material and at a given $\lambda$. Considering that absorbance of $\gamma-\mathrm{Fe}_{2} \mathrm{O}_{3}$-PAA and $\gamma$ $\mathrm{Fe}_{2} \mathrm{O}_{3}$-PAA/pSe- $b$-PEG PICs dispersions is mainly due to iron oxide, absorbance spectra of these colloidal materials were compared to the one of the master curve in the range $220 \mathrm{~nm}<$ $\lambda<800 \mathrm{~nm}$ in order to determine iron oxide concentration. Concentration in iron oxide of a sample $c_{\text {sample }}$ is determined as $A b s_{\text {sample }}=c_{\text {sample }} \times\left(A b s_{\text {Master curve }} / c_{\text {Master curve }}\right)$ and 
as the absorbance curve of the sample $A b s_{\text {sample }}$ is superimposed to the master curve $A b s_{\text {Master curve }}$. Figure S5 gives examples of the determination of iron oxide concentration of $\gamma$ - $\mathrm{Fe}_{2} \mathrm{O}_{3}$-PAA (orange curve) and $\gamma$ - $\mathrm{Fe}_{2} \mathrm{O}_{3}$-PAA/pSe- $b$-PEG PICs (blue curve) dispersions at $\mathrm{c}\left(\gamma-\mathrm{Fe}_{2} \mathrm{O}_{3}\right)=0.0066 \mathrm{wt} \%$ by this method.

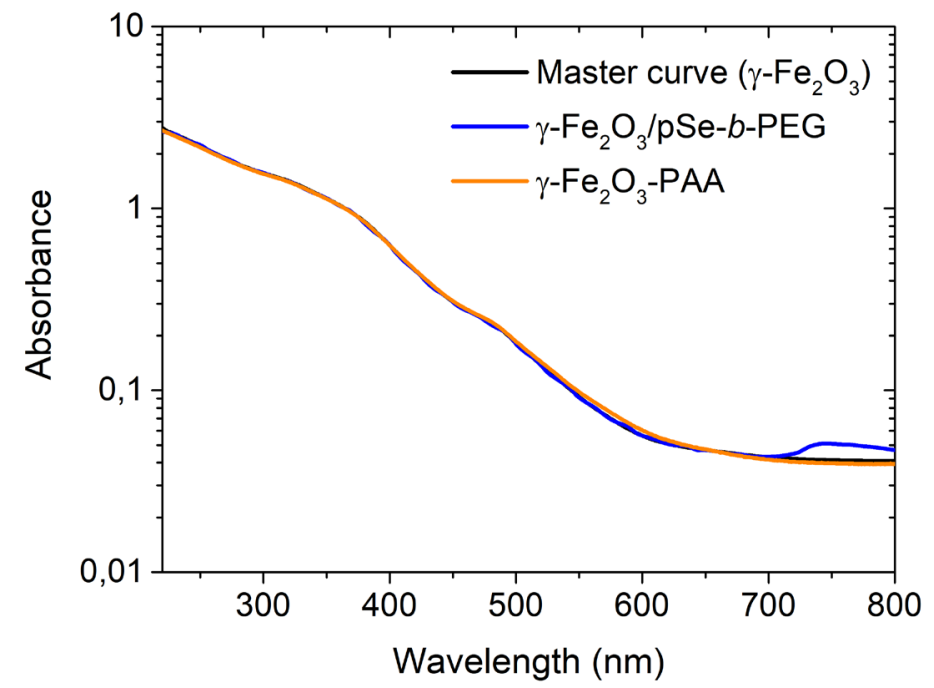

Figure S5. UV-vis spectra of $\gamma-\mathrm{Fe}_{2} \mathrm{O}_{3}$ (black curve, used as master curve for determination of $\gamma-\mathrm{Fe}_{2} \mathrm{O}_{3}$ containing colloidal dispersions), $\gamma-\mathrm{Fe}_{2} \mathrm{O}_{3}-\mathrm{PAA}$ (orange curve) and $\gamma-\mathrm{Fe}_{2} \mathrm{O}_{3}-$ PAA/pSe- $b$-PEG PICs (blue curve) dispersions at $\mathrm{c}\left(\gamma-\mathrm{Fe}_{2} \mathrm{O}_{3}\right)=0.0066 \mathrm{wt} \%$

\section{Preparation of $\gamma-\mathrm{Fe}_{2} \mathrm{O}_{3}-\mathrm{PAA} / \mathrm{pSe}$ and $\gamma$-Fe $\mathrm{Fe}_{2}-\mathrm{PAA} / \mathrm{pSe}-b$-PEG polyion complexes}

\section{Calculation of the charge ratio in reactive species}

For a given $\mathrm{pH}$, the amount of negative charges $N^{-}$(in mol) brought by the carboxylate groups of a $\gamma-\mathrm{Fe}_{2} \mathrm{O}_{3}-\mathrm{PAA}$ nanoparticle dispersion is given by:

$$
N^{-}=\frac{c_{N P}}{100} \times V_{N P} \times c^{-}
$$

where $c_{N P}$ and $V_{N P}$ are respectively the concentration in iron oxide in wt $\%$ and the volume in $\mathrm{mL}$ of the dispersion, and $c^{-}$is number of mol of negative charges per $\mathrm{g}$ of iron oxide of the 
dispersion. At $\mathrm{pH}=7, c^{-}=5.77 \times 10^{-4} \mathrm{~mol} \mathrm{~g}^{-1}$ (see "Acid-base titration of $\gamma$ - $\mathrm{Fe}_{2} \mathrm{O}_{3}$-PAA nanoparticles" of this document).

The amount of positive charges $N^{+}$(in mol) brought by the ammonium groups of a pSe solution is given by:

$$
N^{+}=\frac{\left({ }^{c_{\text {poly }}} / 100\right) \times V_{\text {poly }}}{M_{W}^{\text {poly }}} \times D P \times \alpha
$$

where $c_{\text {poly }}$ and $V_{\text {poly }}$ are respectively the concentration in polymer in $\mathrm{wt} \%$ and the volume in $\mathrm{mL}$ of the solution. $M_{W}^{\text {poly }}$ is the molecular weight of the polymer in $\mathrm{g} \mathrm{mol}^{-1} . D P$ is the average degree of polymerization of the polyelectrolyte block (average number of serine units per pSe or pSe-b-PEG per chain) and $\alpha$ is the proportion of the amino groups positively charged at a given $\mathrm{pH} . M_{W}(\mathrm{pSe}$ with Acetate counter-ions $)=11840 \mathrm{~g} \mathrm{~mol}^{-1}$ and $M_{W}(\mathrm{pSe}-b-$ PEG with Acetate counter-ions $)=21840 \mathrm{~g} \mathrm{~mol}^{-1}$. The $p K a\left(-\mathrm{NH}_{2} /-\mathrm{NH}_{3}{ }^{+}\right)$of serine being 9.15, $\alpha$ was approximated to 1 in the study as pSe and pSe- $b$-PEG solutions were used at $\mathrm{pH}=7$ or $\mathrm{pH}=7.4$ when in PBS1× buffer.

The charge ratio of a mixture of $\gamma-\mathrm{Fe}_{2} \mathrm{O}_{3}$-PAA and either pSe or pSe- $b$-PEG is defined by $Z=N^{-} / N^{+}$.

\section{Preparation of $\gamma-\mathrm{Fe}_{2} \mathrm{O}_{3}-\mathrm{PAA} / \mathrm{pSe}$ polyion complexes}

Before mixing, purified $\gamma$ - $\mathrm{Fe}_{2} \mathrm{O}_{3}$-PAA were dispersed in deionized water and $\mathrm{pH}$ was adjusted to 7 by addition of a tiny amount of $\mathrm{NaOH}$. pSe polyelectrolyte was dissolved in deionized water, giving solutions at $\mathrm{pH}=$ 7. $\gamma-\mathrm{Fe}_{2} \mathrm{O}_{3}-\mathrm{PAA} / \mathrm{pSe}$ PICs were obtained by mixing stock solutions prepared at the same weight concentrations: $c_{N P}=c_{\text {poly }}$. Table $\mathrm{S} 1$ resumes the parameters characterizing the $\gamma-\mathrm{Fe}_{2} \mathrm{O}_{3}-\mathrm{PAA} / \mathrm{pSe}$ mixtures of the study. 


\begin{tabular}{|c|c|c|c|c|c|c|c|c|}
\hline \multicolumn{6}{|c|}{ Solutions to mix } & \multicolumn{3}{|c|}{ Mixtures } \\
\hline \multicolumn{3}{|c|}{$\gamma-\mathrm{Fe}_{2} \mathrm{O}_{3}$-PAA dispersions } & \multicolumn{3}{|c|}{ pSe solutions } & \multicolumn{3}{|c|}{$\gamma-\mathrm{Fe}_{2} \mathrm{O}_{3}-\mathrm{PAA} / \mathrm{pSe}$ mixtures } \\
\hline $\begin{array}{c}c_{N P} \\
(\mathrm{wt} \%)\end{array}$ & $\begin{array}{c}V_{N P} \\
(\mathrm{~mL})\end{array}$ & $\begin{array}{c}N^{-} \\
(\mathrm{mol})\end{array}$ & $\begin{array}{l}c_{\text {poly }} \\
(\mathrm{wt} \%)\end{array}$ & $\begin{array}{l}V_{\text {poly }} \\
(\mathrm{mL})\end{array}$ & $\begin{array}{c}N^{+} \\
(\mathrm{mol})\end{array}$ & $\begin{array}{c}c_{N P} \\
(\mathrm{wt} \%)\end{array}$ & $\begin{array}{l}c_{\text {poly }} \\
(\mathrm{wt} \%)\end{array}$ & $Z=\frac{N^{-}}{N^{+}}$ \\
\hline $6.10^{-3}$ & 10 & $3.4 .10^{-7}$ & $6.10^{-3}$ & 0.85 & $3.4 .10^{-7}$ & $5.5 .10^{-3}$ & $4.7 .10^{-4}$ & 1 \\
\hline $6.10^{-4}$ & 10 & $3.4 .10^{-8}$ & $6.10^{-4}$ & 0.85 & $3.4 .10^{-8}$ & $5.5 .10^{-4}$ & $4.7 .10^{-5}$ & 1 \\
\hline $6.10^{-5}$ & 10 & $3.4 .10^{-9}$ & $6.10^{-5}$ & 0.85 & $3.4 .10^{-9}$ & $5.5 .10^{-5}$ & $4.7 .10^{-6}$ & 1 \\
\hline $6.10^{-6}$ & 10 & $3.4 .10^{-10}$ & $6.10^{-6}$ & 0.85 & $3.4 .10^{-10}$ & $5.5 .10^{-6}$ & $4.7 .10^{-7}$ & 1 \\
\hline
\end{tabular}

Table S1. Concentrations, volumes and amounts of charge of $\gamma-\mathrm{Fe}_{2} \mathrm{O}_{3}-\mathrm{PAA}$ dispersions and pSe solutions mixed to obtain $\gamma-\mathrm{Fe}_{2} \mathrm{O}_{3}-\mathrm{PAA} / \mathrm{pSe}$ mixtures, and, concentrations in iron oxide and in pSe, and charge ratio $Z$ of the mixtures.

\section{Preparation of $\gamma-\mathrm{Fe}_{2} \mathrm{O}_{3}-\mathrm{PAA} / \mathrm{pSe}-\mathrm{b}-\mathrm{PEG}$ polyion complexes}

$\gamma-\mathrm{Fe}_{2} \mathrm{O}_{3}-\mathrm{PAA}$ dispersions in water or $\mathrm{PBS} 1 \times$ at various concentrations were prepared by dilution of a $\gamma-\mathrm{Fe}_{2} \mathrm{O}_{3}$-PAA dispersion at $\left[\gamma-\mathrm{Fe}_{2} \mathrm{O}_{3}\right]=0.984 \mathrm{wt} \%$ in water. $\mathrm{pH}$ of diluted dispersions in water was adjusted to 7 by addition of a tiny amount of $\mathrm{NaOH}$.

pSe- $b$-PEG solutions were prepared as follow: pSe- $b$-PEG at $c_{\text {poly }}=1.3 \times 10^{-3} \mathrm{wt} \%$ in deionized water was first prepared and vigorously stirred for $12 \mathrm{~h}$ at $50^{\circ} \mathrm{C}$ until complete dissolution. The as-prepared stock solution was then diluted in either water or PBS1× to achieve the desired concentrations. The $\mathrm{pH}$ value of $\mathrm{pSe}-b$-PEG solutions in water is $7 . \gamma$ $\mathrm{Fe}_{2} \mathrm{O}_{3}$-PAA/pSe- $b$-PEG PICs were obtained by mixing stock solutions prepared at the same 
weight concentrations: $c_{N P}=c_{\text {poly }}=6 \times 10^{-4} w t \%$. Table $\mathrm{S} 2$ resumes the parameters characterizing the $\gamma-\mathrm{Fe}_{2} \mathrm{O}_{3}-\mathrm{PAA} / \mathrm{pSe}-b$-PEG mixtures of the study.

\begin{tabular}{|c|c|c|c|c|c|c|c|c|}
\hline & & Solutio & to $\operatorname{mix}$ & & & & Mixtures & \\
\hline$\gamma-\mathrm{Fe}_{2}$ & ${ }_{3-\mathrm{PAA} \mathrm{d}}$ & persions & $\mathrm{pS}$ & $b$-PEG & lutions & $\gamma-\mathrm{Fe}_{2} \mathrm{O}$ & $\mathrm{PAA} / \mathrm{pS}$ & $b$-PEG \\
\hline $\begin{array}{c}c_{N P} \\
\left(\mathrm{wt}^{2} \%\right)\end{array}$ & $\begin{array}{c}V_{N P} \\
(\mathrm{~mL})\end{array}$ & $\begin{array}{c}N^{-} \\
(\mathrm{mol})\end{array}$ & $\begin{array}{l}c_{\text {poly }} \\
(\mathrm{wt} \%)\end{array}$ & $\begin{array}{l}V_{\text {poly }} \\
(\mathrm{mL})\end{array}$ & $\begin{array}{c}N^{+} \\
(\mathrm{mol})\end{array}$ & $\begin{array}{c}c_{N P} \\
(\mathrm{wt} \%)\end{array}$ & $\begin{array}{l}c_{\text {poly }} \\
(\mathrm{wt} \%)\end{array}$ & $Z=\frac{N^{-}}{N^{+}}$ \\
\hline $6.10^{-4}$ & 4 & $1.38 .10^{-8}$ & $6.10^{-4}$ & 6.28 & $1.38 .10^{-7}$ & $2.3 .10^{-4}$ & $3.8 .10^{-4}$ & 0.1 \\
\hline $6.10^{-4}$ & 10 & $3.45 .10^{-8}$ & $6.10^{-4}$ & 3.14 & $6.90 .10^{-8}$ & $4.6 .10^{-4}$ & $1.4 .10^{-4}$ & 0.5 \\
\hline $6.10^{-4}$ & 10 & $3.45 .10^{-8}$ & $6.10^{-4}$ & 1.57 & $3.45 .10^{-8}$ & $5.18 .10^{-4}$ & $8.1 .10^{-5}$ & 1 \\
\hline $6.10^{-4}$ & 10 & $3.45 .10^{-8}$ & $6.10^{-4}$ & 0.157 & $3.45 .10^{-9}$ & $5.91 .10^{-4}$ & $9.3 .10^{-6}$ & 10 \\
\hline $6.10^{-4}$ & 10.191 & $3.52 .10^{-8}$ & $6.10^{-4}$ & 0.016 & $3.51 .10^{-10}$ & $5.99 .10^{-4}$ & $9.4 .10^{-7}$ & 100 \\
\hline
\end{tabular}

Table S2. Concentrations, volumes and amounts of charge of $\gamma-\mathrm{Fe}_{2} \mathrm{O}_{3}-\mathrm{PAA}$ dispersions and pSe- $b$-PEG solutions mixed to obtain $\gamma-\mathrm{Fe}_{2} \mathrm{O}_{3}-\mathrm{PAA} / \mathrm{pSe}-b$-PEG mixtures, and, concentrations in iron oxide and in pSe- $b$-PEG, and charge ratio $Z$ of the mixtures.

\section{Determination of the numbers of cells during cell viability assessments}

During the cell viability assessments, numbers of MC3T3 and HepG2 viable cells were determined using calibration curves. The "Optical density (OD) versus Number of cells" calibration curves were established as follow: cells were grown as described in "2.2.7 Cell culture", detached by $0.25 \%$ trypsin/EDTA and pelleted by centrifugation. Then, supernatant was removed and cell pellets re-suspended in assay medium and counted using a cell-count 
board. 0, 10000, 40000, 60000, 80000 and 100000 MC3T3-E1 cells, and 0, 10000, 20000, 40000, 160000 and 200000 HepG2 cells in assay medium were deposited in well plates.
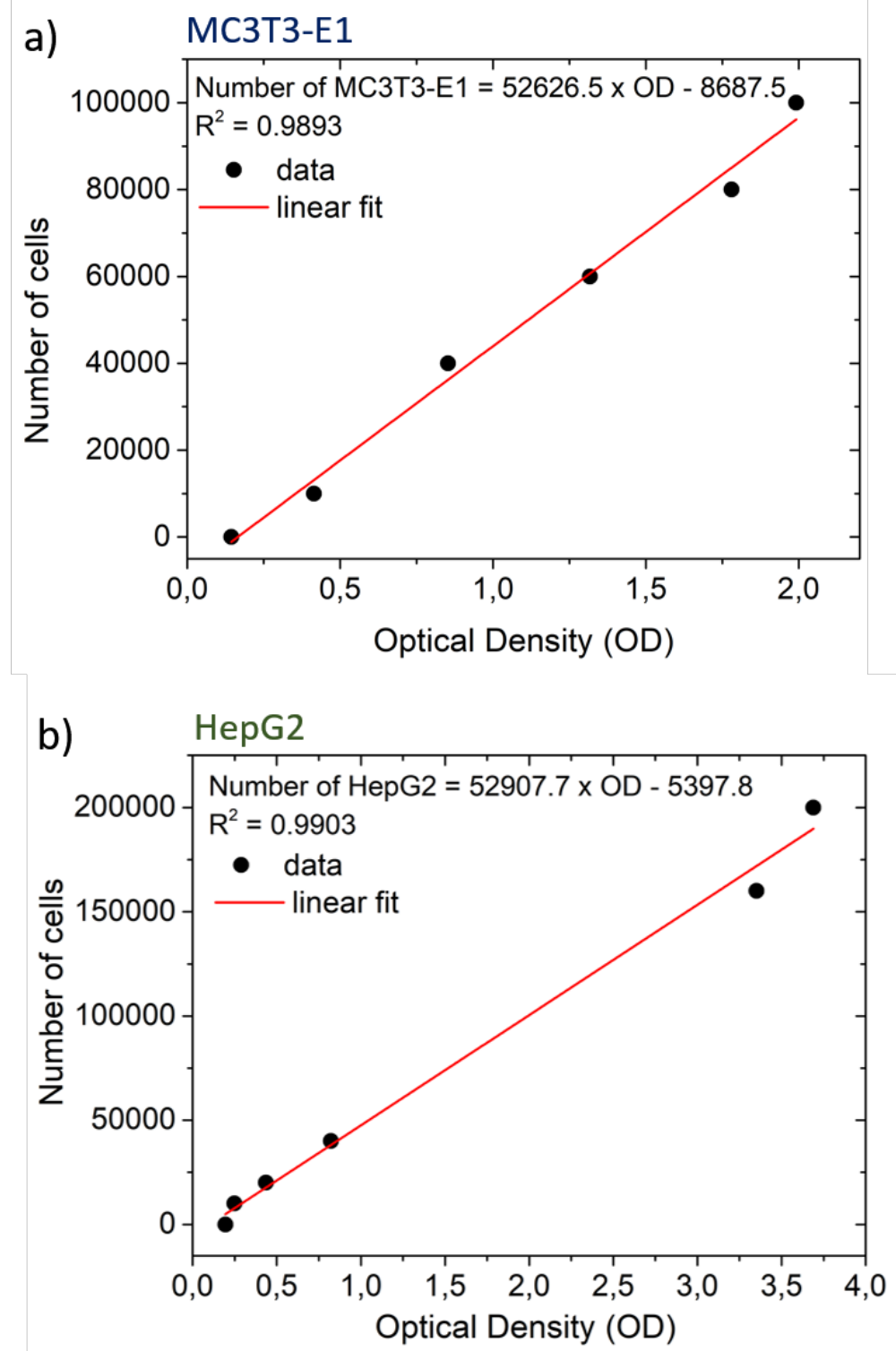

Figure S6. Calibration curves used for the determination of the number of MC3T3 (a) and HepG2 (b) cells corresponding to the optical densities (OD) measured during cell viability assessments. For the MC3T3-E1 (respectively HepG2) cells, the linear fit (red line) of the data (black points) corresponds to the following equation: Number of MC3T3-E1 cells = $52626.5 \times O D-8687.5$, with $\mathrm{R}^{2}=0.9893$ (respectively: Number of HepG 2 cells $=$ 52907.7 $\times O D-5397.8$, with $\left.\mathrm{R}^{2}=0.9903\right)$. 
After incubation at $T=37^{\circ} \mathrm{C}$ for $1 \mathrm{~h}$, the corresponding optical densities (OD) were measured (see: 2.2.7 Cell viability assessment). Figure S6 presents the number of MC3T3-E1 (a) and HepG2 (b) cells according to the measured OD. For MC3T3-E1 (respectively HepG2) the linear fit of the data with the following equation: Number of MC3T3-E1 cells = $52626.5 \times O D-8687.5$ (respectively: Number of HepG 2 cells $=52907.7 \times O D-$ 5397.8), was used for the determination of the number of cells corresponding to the measurement of an OD under the same conditions.

\section{DLS study of $\gamma-\mathrm{Fe}_{2} \mathrm{O}_{3}$-PAA/pSe in $\mathrm{NH}_{4} \mathrm{Cl}$ Solutions}

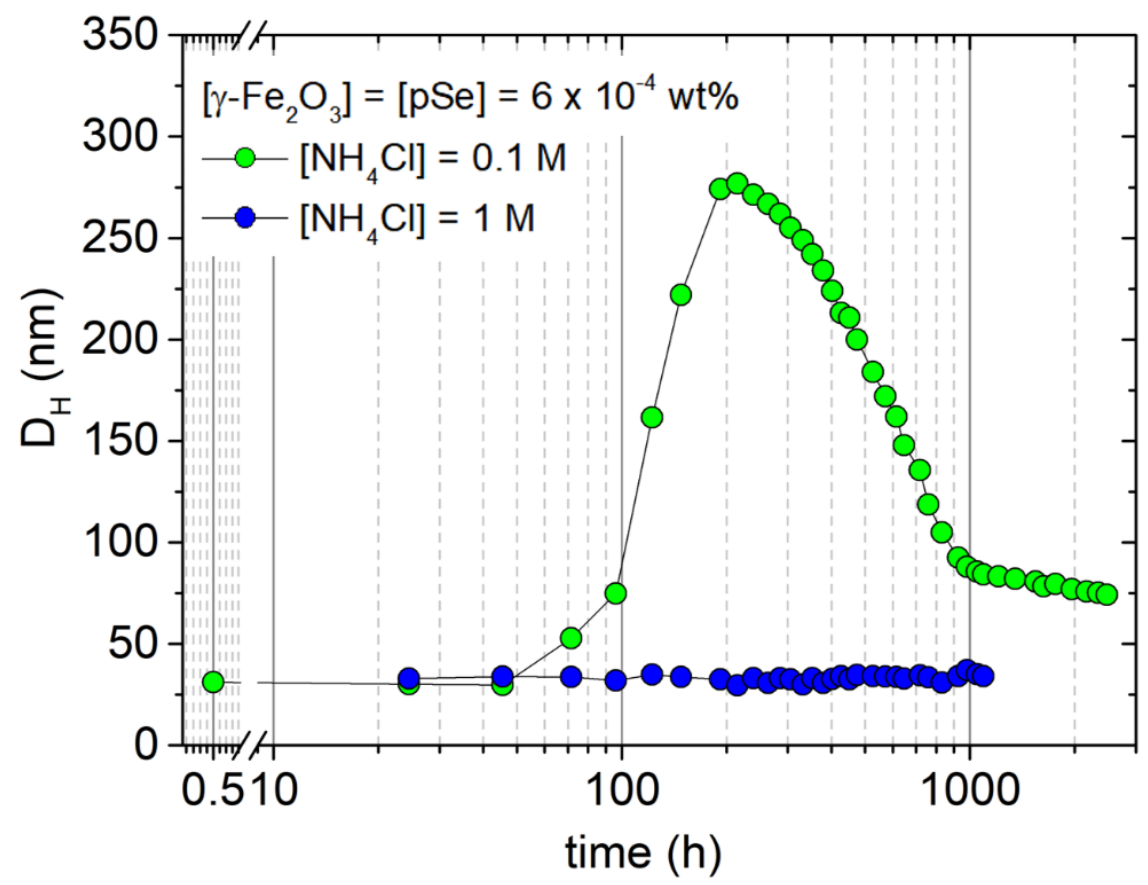

Figure S7. DLS analysis of $\gamma-\mathrm{Fe}_{2} \mathrm{O}_{3}-\mathrm{PAA} /$ poly(serine ester) mixtures in presence of $\mathrm{NH}_{4} \mathrm{Cl}$. Hydrodynamic diameters $\left(D_{H}\right)$ as a function of time of $\gamma-\mathrm{Fe}_{2} \mathrm{O}_{3}$-PAA and pSe mixtures in aqueous media at $\left[\mathrm{NH}_{4} \mathrm{Cl}\right]=0.1 \mathrm{M}($ green $)$ and $\left[\mathrm{NH}_{4} \mathrm{Cl}\right]=1 \mathrm{M}$ (blue), respectively. Samples were prepared by mixing solutions at $\left[\gamma-\mathrm{Fe}_{2} \mathrm{O}_{3}\right]=[\mathrm{pSe}]=6 \times 10^{-4} \mathrm{wt} \%$ as $Z=1$. pH of mixed 
nanoparticles dispersions and pSe solutions were adjusted to 7 with $\mathrm{NaOH}$ or $\mathrm{HCl}$ prior to mixing. Nanoparticles and pSe were mixed at $t=0$.

First, $\gamma-\mathrm{Fe}_{2} \mathrm{O}_{3}$-PAA at $\left[\gamma-\mathrm{Fe}_{2} \mathrm{O}_{3}\right]=0.84 \mathrm{wt} \%$ in water were diluted in $\mathrm{NH}_{4} \mathrm{Cl}$ aqueous solutions to obtain $\gamma-\mathrm{Fe}_{2} \mathrm{O}_{3}$-PAA at $\left[\gamma-\mathrm{Fe}_{2} \mathrm{O}_{3}\right]=6 \times 10^{-4} \mathrm{wt} \%$ in $\left[\mathrm{NH}_{4} \mathrm{Cl}\right]=0.1 \mathrm{M}$ and $\gamma-$ $\mathrm{Fe}_{2} \mathrm{O}_{3}$-PAA at $\left[\gamma-\mathrm{Fe}_{2} \mathrm{O}_{3}\right]=6 \times 10^{-4} \mathrm{wt} \%$ in $\left[\mathrm{NH}_{4} \mathrm{Cl}\right]=1 \mathrm{M}$. Second, pSe was dissolved in $\mathrm{NH}_{4} \mathrm{Cl}$ aqueous solutions as $[\mathrm{pSe}]=6 \times 10^{-4} \mathrm{wt} \%$ and as the final concentrations in $\mathrm{NH}_{4} \mathrm{Cl}$ were $0.1 \mathrm{M}$ and $1 \mathrm{M}$, respectively. $\mathrm{pH}$ of nanoparticles dispersions and $\mathrm{pSe}$ solutions were adjusted to 7 with $\mathrm{NaOH}$ or $\mathrm{HCl}$ prior to mixing. Third, mixtures of $\gamma-\mathrm{Fe}_{2} \mathrm{O}_{3}-\mathrm{PAA}$ and pSe at $Z=1$ were prepared from solutions at $\left[\gamma-\mathrm{Fe}_{2} \mathrm{O}_{3}\right]=[\mathrm{pSe}]=6 \times 10^{-4} \mathrm{wt} \%$ following the protocol described in the Experimental Section of the article and in "Preparation of $\gamma-\mathrm{Fe}_{2} \mathrm{O}_{3^{-}}$ PAA/pSe and $\gamma-\mathrm{Fe}_{2} \mathrm{O}_{3}-\mathrm{PAA} / \mathrm{pSe}-b$-PEG polyion complexes" and Table $\mathrm{S} 1$ of this document.

\section{DLS study of the interactions between $\gamma$-Fe $\mathrm{O}_{2} \mathrm{O}_{3}$-PAA, serine and PEG}

$\gamma$ - $\mathrm{Fe}_{2} \mathrm{O}_{3}$-PAA nanoparticles were mixed in water with respectively DL-serine (serine) and poly(ethylene glycol) of $\mathrm{M}_{\mathrm{W}}=10000 \mathrm{~g} \mathrm{~mol}^{-1}\left(\mathrm{PEG}_{10 \mathrm{~K}}\right) \cdot \gamma-\mathrm{Fe}_{2} \mathrm{O}_{3}-\mathrm{PAA}$ were dispersed in deionized water at $\mathrm{c}=0.984 \mathrm{wt} \% \mathrm{pH}$ was adjusted to 7 by addition of a tiny amount of $\mathrm{NaOH}$ and dispersions at $\mathrm{c}=6 \times 10^{-4} \mathrm{wt} \%, 6 \times 10^{-5} \mathrm{wt} \%$ and $6 \times 10^{-6} \mathrm{wt} \%$ were prepared by dilution in water. Serine solutions at $6 \times 10^{-4} \mathrm{wt} \%, 6 \times 10^{-5} \mathrm{wt}^{\mathrm{o}} \%$ and $6 \times 10^{-6} \mathrm{wt} \%$ in water were prepared. $\mathrm{PEG}_{10 \mathrm{~K}}$ was dissolved in deionized water as $\left[\mathrm{PEG}_{10 \mathrm{~K}}\right]=6 \times 10^{-4} \mathrm{wt} \%$.

$\gamma-\mathrm{Fe}_{2} \mathrm{O}_{3}$-PAA and serine mixtures were obtained by mixing stock solutions prepared at the same weight concentrations: $c=c_{N P}=c_{\text {serine }}$ (with $\mathrm{c}=6 \times 10^{-4} \mathrm{wt} \%, 6 \times 10^{-5} \mathrm{wt} \%$ and $6 \times 10^{-6} \mathrm{wt} \%$, respectively), and as $Z=\frac{N^{-}}{N^{+}}=1 \cdot \gamma-\mathrm{Fe}_{2} \mathrm{O}_{3}-\mathrm{PAA}$ and $\mathrm{PEG}_{10 \mathrm{~K}}$ mixture was obtained by mixing stock solutions prepared at $c=c_{N P}=c_{P E G}=6 \times 10^{-4} w t \%$, and as 
$\left(\frac{N^{-}}{N_{\text {monomer }}}\right)$, the ratio between negative charges brought by the nanoparticles and the amount of ethylene oxide monomer units, equals 1.

$\gamma-\mathrm{Fe}_{2} \mathrm{O}_{3}$-PAA mixtures with respectively serine and $\mathrm{PEG}_{10 \mathrm{~K}}$ were prepared according to the formulations given in Table S3 and stored at $T=25^{\circ} \mathrm{C}$.

\begin{tabular}{|c|c|c|c|c|c|c|c|c|}
\hline \multicolumn{6}{|c|}{ Solutions to mix } & \multicolumn{3}{|c|}{ Mixtures } \\
\hline \multicolumn{3}{|c|}{$\gamma-\mathrm{Fe}_{2} \mathrm{O}_{3}-\mathrm{PAA}$ dispersions } & \multicolumn{3}{|c|}{ Serine solutions } & \multicolumn{3}{|c|}{$\gamma-\mathrm{Fe}_{2} \mathrm{O}_{3}-\mathrm{PAA} /$ serine mixtures } \\
\hline $\begin{array}{c}c_{N P} \\
(\mathrm{wt} \%)\end{array}$ & $\begin{array}{l}V_{N P} \\
(\mathrm{~mL})\end{array}$ & $\begin{array}{c}N^{-} \\
(\mathrm{mol})\end{array}$ & $\begin{array}{l}c_{\text {serine }} \\
(\mathrm{wt} \%)\end{array}$ & $\begin{array}{c}V_{\text {serine }} \\
(\mathrm{mL})\end{array}$ & $\begin{array}{c}N^{+} \\
(\mathrm{mol})\end{array}$ & $\begin{array}{c}c_{N P} \\
(\mathrm{wt} \%)\end{array}$ & $\begin{array}{l}c_{\text {serine }} \\
(\mathrm{wt} \%)\end{array}$ & $Z=\frac{N^{-}}{N^{+}}$ \\
\hline $6.10^{-4}$ & 2 & $6.8 .10^{-9}$ & $6.10^{-4}$ & 0.119 & $6.8 .10^{-9}$ & $5.7 .10^{-4}$ & $3.4 .10^{-5}$ & 1 \\
\hline $6.10^{-5}$ & 2 & $6.8 .10^{-10}$ & $6.10^{-5}$ & 0.119 & $6.8 .10^{-10}$ & $5.7 .10^{-5}$ & $3.4 .10^{-6}$ & 1 \\
\hline $6.10^{-6}$ & 2 & $6.8 .10^{-11}$ & $6.10^{-6}$ & 0.119 & $6.8 .10^{-11}$ & $5.7 .10^{-6}$ & $3.4 .10^{-7}$ & 1 \\
\hline \multicolumn{3}{|c|}{$\gamma-\mathrm{Fe}_{2} \mathrm{O}_{3}-\mathrm{PAA}$ dispersion } & \multicolumn{3}{|c|}{$\mathrm{PEG}_{10 \mathrm{~K}}$ solution } & \multicolumn{3}{|c|}{$\gamma-\mathrm{Fe}_{2} \mathrm{O}_{3}-\mathrm{PAA} / \mathrm{PEG}_{10 \mathrm{~K}}$ mixture } \\
\hline $\begin{array}{c}c_{N P} \\
\left(\mathrm{wt}^{0} \%\right)\end{array}$ & $\begin{array}{l}V_{N P} \\
(\mathrm{~mL})\end{array}$ & $\begin{array}{c}N^{-} \\
(\mathrm{mol})\end{array}$ & $\begin{array}{c}C_{P E G} \\
(\mathrm{wt} \%)\end{array}$ & $\begin{array}{l}V_{P E G} \\
(\mathrm{~mL})\end{array}$ & $\begin{array}{c}N_{\text {monomer }} \\
(\mathrm{mol})\end{array}$ & $\begin{array}{c}c_{N P} \\
(\mathrm{wt} \%)\end{array}$ & $\begin{array}{c}c_{P E G} \\
(\mathrm{wt} \%)\end{array}$ & $\frac{N^{-}}{N_{\text {monomer }}}$ \\
\hline $6.10^{-4}$ & 2 & $6.8 .10^{-9}$ & $6.10^{-4}$ & 0.050 & $6.8 .10^{-9}$ & $5.9 .10^{-4}$ & $1.5 .10^{-5}$ & 1 \\
\hline
\end{tabular}

Table S3. Concentrations, volumes and amounts of charge or monomer units (for $\left.\mathrm{PEG}_{10 \mathrm{~K}}\right)$ of $\gamma-\mathrm{Fe}_{2} \mathrm{O}_{3}-\mathrm{PAA}$ dispersions and either serine or $\mathrm{PEG}_{10 \mathrm{~K}}$ solutions mixed to obtain $\gamma$ $\mathrm{Fe}_{2} \mathrm{O}_{3}-\mathrm{PAA} /$ serine and $\gamma-\mathrm{Fe}_{2} \mathrm{O}_{3}-\mathrm{PAA} / \mathrm{PEG}_{10 \mathrm{~K}}$ mixtures. Concentrations in iron oxide and concentrations in either serine or $\mathrm{PEG}_{10 \mathrm{~K}}$, and charge ratio $Z$ or ratio between negative charges brought by the nanoparticles and the amount of ethylene oxide monomeric units

$$
\left(\frac{N^{-}}{N_{\text {monomer }}}\right) \text { of the mixtures. }
$$

Figure S8 presents $\mathrm{D}_{\mathrm{H}}$ measurements according to the time of the $\gamma-\mathrm{Fe}_{2} \mathrm{O}_{3}-\mathrm{PAA} /$ serine and $\gamma-\mathrm{Fe}_{2} \mathrm{O}_{3}-\mathrm{PAA} / \mathrm{PEG}_{10 \mathrm{~K}}$ mixtures described above (see Table $\mathrm{S} 3$ ). The $\mathrm{D}_{\mathrm{H}}$ of $\gamma-\mathrm{Fe}_{2} \mathrm{O}_{3}-\mathrm{PAA}$ 
nanoparticles mixed with serine at $\mathrm{c}=6 \times 10^{-4} \mathrm{wt} \%$ (Figure S8, red symbols) and of $\gamma-\mathrm{Fe}_{2} \mathrm{O}_{3}-$ PAA mixed with $\mathrm{PEG}_{10 \mathrm{~K}}$ (Figure S8, grey symbols) remain at constant values corresponding to the $\mathrm{D}_{\mathrm{H}}$ of single nanoparticles over periods of $425 \mathrm{~h}$, demonstrating that these mixtures do not lead to the formation of aggregates. Mixtures of $\gamma-\mathrm{Fe}_{2} \mathrm{O}_{3}$-PAA and serine at $\mathrm{c}=6 \times 10^{-5}$ $\mathrm{wt} \%$ (Figure S8, blue symbols) and $\mathrm{c}=6 \times 10^{-6} \mathrm{wt} \%$ (Figure S8, green symbols) lead to spontaneous formation of aggregates with $\mathrm{D}_{\mathrm{H}}=112 \mathrm{~nm}$ and $190 \mathrm{~nm}$, respectively. $45 \mathrm{~h}$ after mixing, stable colloidal objects with $\mathrm{D}_{\mathrm{H}}=190 \pm 15 \mathrm{~nm}$ and $290 \pm 20 \mathrm{~nm}$ for mixtures at $6 \times$ $10^{-5} \mathrm{wt} \%$ and $6 \times 10^{-6} \mathrm{wt} \%$, respectively, are obtained.

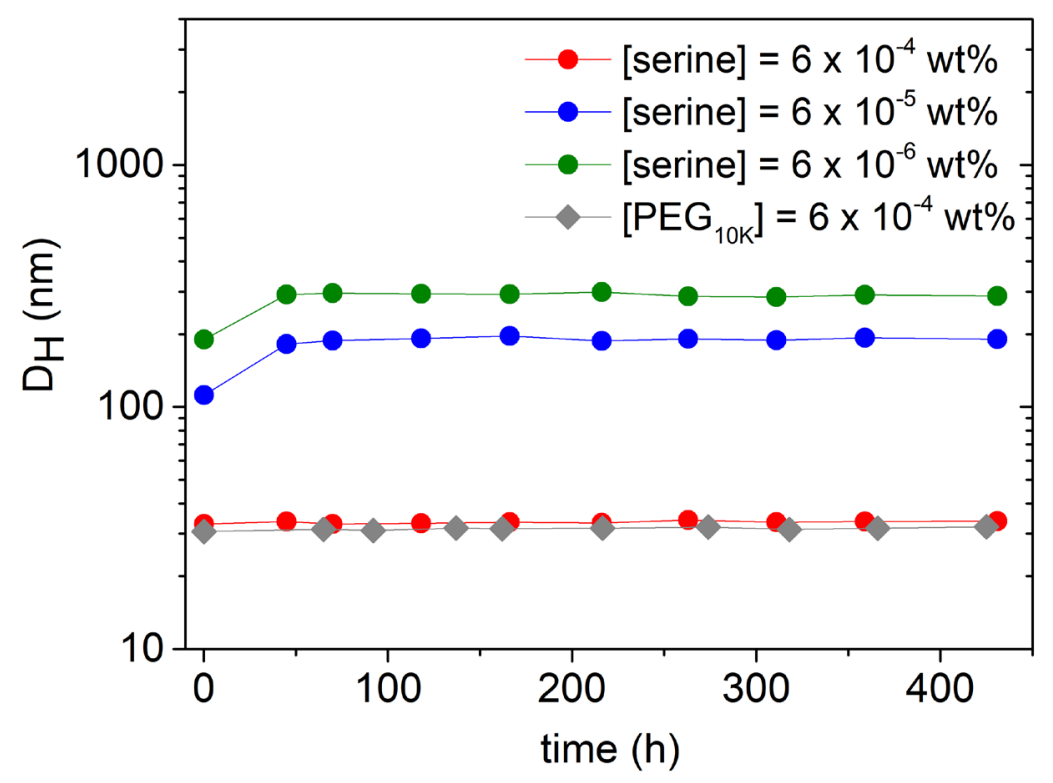

Figure S8. DLS analysis of the interactions between $\gamma-\mathrm{Fe}_{2} \mathrm{O}_{3}-\mathrm{PAA}$ nanoparticles and, respectively, serine and $\mathrm{PEG}_{10 \mathrm{~K}} \cdot \gamma-\mathrm{Fe}_{2} \mathrm{O}_{3}-\mathrm{PAA}$ /serine mixtures in water were prepared by mixing solutions at $\left[\gamma-\mathrm{Fe}_{2} \mathrm{O}_{3}\right]=[\mathrm{pSe}]=6 \times 10^{-4} \mathrm{wt} \%(\mathrm{red}),\left[\gamma-\mathrm{Fe}_{2} \mathrm{O}_{3}\right]=[\mathrm{pSe}]=6 \times 10^{-5} \mathrm{wt} \%$ (blue) and $\left[\gamma-\mathrm{Fe}_{2} \mathrm{O}_{3}\right]=[\mathrm{pSe}]=6 \times 10^{-6} \mathrm{wt} \%$ (green) and as $Z=1 . \gamma-\mathrm{Fe}_{2} \mathrm{O}_{3}-\mathrm{PAA} / \mathrm{PEG}_{10 \mathrm{~K}}$ mixture in water was prepared by mixing solutions at $\left[\gamma-\mathrm{Fe}_{2} \mathrm{O}_{3}\right]=\left[\mathrm{PEG}_{10 \mathrm{~K}}\right]=6 \times 10^{-4} \mathrm{wt} \%$ (grey) and as the ratio between the negative charges brought by the nanoparticles and the amount of ethylene oxide monomer units equals 1 . Nanoparticles and either serine or $\mathrm{PEG}_{10 \mathrm{~K}}$ were mixed at $t=0$. Hydrodynamic diameters $\left(D_{H}\right)$ were measured at $T=25^{\circ} \mathrm{C}$. 
Supporting information of paper accepted for publication in Mater. Sci. Eng. C, 2019, 109920

\section{GPC study of the degradation of pSe- $b$-PEG}

Degradation of pSe- $b$-PEG copolymer in water was studied by Gel Permeation Chromatography (GPC). A concentrated solution of pSe- $b$-PEG in tetrahydrofuran (THF) was prepared and immediately analyzed by GPC at $T=40{ }^{\circ} \mathrm{C}$ (Figure S9, $t=0 \mathrm{~h}$ ). A solution of pSe- $b$-PEG at $0.0119 \mathrm{mg} \mathrm{mL}^{-1}$ in deionized water $(\mathrm{pH} \approx 5.8)$ was prepared and kept at $T=$ $50{ }^{\circ} \mathrm{C}$ under gentle stirring. After respectively $120 \mathrm{~h}, 240 \mathrm{~h}$ and $400 \mathrm{~h}$ of ageing, fractions of the solution were extracted, lyophilized, and the recovered materials were dissolved in THF before analysis by GPC at $T=40{ }^{\circ} \mathrm{C}$ (Figure S9, $t=120 \mathrm{~h}, t=240 \mathrm{~h}$ and $t=400 \mathrm{~h}$, respectively).

GPC analyses were performed with THF as eluent and 1,2,4-trichlorobenzene as flow marker on an UltiMate 3000 system from Thermo Fisher Scientific equipped with a diode array detector (DAD), a multi-angle light scattering (MALS) detector and a differential refractive index (dRI) detector from Wyatt Technology Corp. (France). Polymers were separated on three G2000, G3000 and G4000 TOSOH HXL gel columns (300 mm $\times 7.8 \mathrm{~mm})$ (size exclusion limits from 1000 to $400000 \mathrm{~g} \mathrm{~mol}^{-1}$ ) held at $40{ }^{\circ} \mathrm{C}$ and under THF flowrate of $1 \mathrm{~mL} \mathrm{~min}^{-1}$. Polystyrene EasiVial ${ }^{\mathrm{TM}}$ kit (Agilent ${ }^{\circledR}$ ) was used as calibration standard (from 162 to $364000 \mathrm{~g} \mathrm{~mol}^{-1}$ ). Chromatograms were analyzed with Astra ${ }^{\circledR} 7.1$ software (Wyatt Technology).

Figure S9 presents the GPC chromatograms of pSe- $b$-PEG copolymer at $t=0 \mathrm{~h}, 120 \mathrm{~h}$, $240 \mathrm{~h}$ and $400 \mathrm{~h}$. 


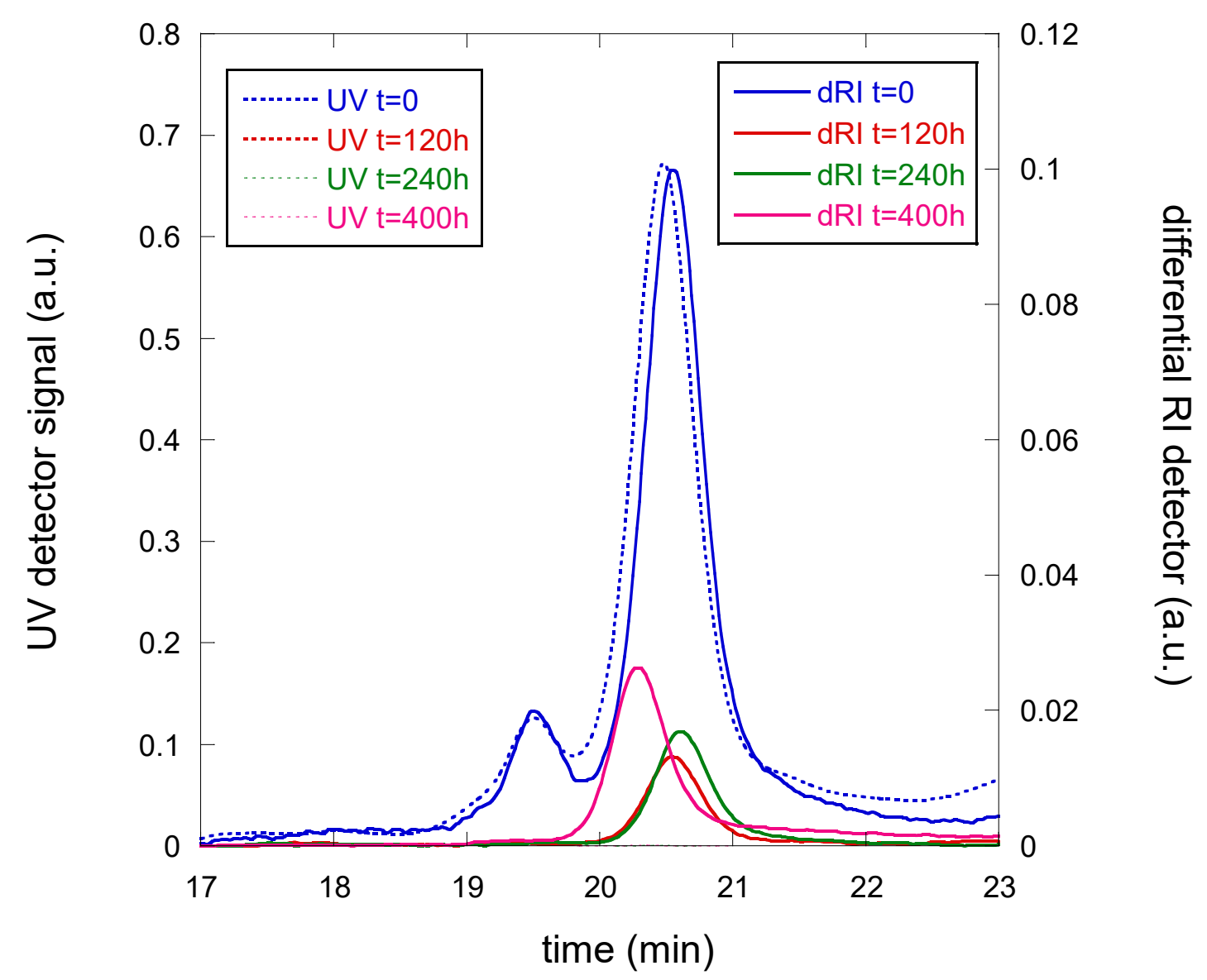

Figure S9. GPC chromatograms measured in THF at $T=40^{\circ} \mathrm{C}$ for the original pSe- $b$-PEG copolymer $(t=0)$ and for fractions collected after ageing in water at $T=50{ }^{\circ} \mathrm{C}$ and $\mathrm{pH} \approx 5.8$ after times $t=120 \mathrm{~h}, 240 \mathrm{~h}$ and $400 \mathrm{~h}$. The equivalent weight-average molar masses and dispersities obtained are $M_{\mathrm{w}}(t=0 \mathrm{~h})=14290 \mathrm{~g} \mathrm{~mol}^{-1}$ and $Đ(t=0 \mathrm{~h})=1.029, M_{\mathrm{w}}(t=120 \mathrm{~h})=$ $14060 \mathrm{~g} \mathrm{~mol}^{-1}$ and $Ð(t=120 \mathrm{~h})=1.016, M_{\mathrm{w}}(t=240 \mathrm{~h})=13950 \mathrm{~g} \mathrm{~mol}^{-1}$ and $Ð(t=240 \mathrm{~h})=$ 1.024 and $M_{\mathrm{w}}(t=400 \mathrm{~h})=14440 \mathrm{~g} \mathrm{~mol}^{-1}$ and $\bigoplus(t=400 \mathrm{~h})=1.021$. The secondary (minor) peak at $t=0 \mathrm{~h}$ corresponds to $M_{\mathrm{w}}=29360 \mathrm{~g} \mathrm{~mol}^{-1}(Ð=1.026)$ and could be ascribed to slightly aggregates chains (the concentration being higher).

The equivalent weight-average molar mass and dispersity (i.e. having same hydrodynamic diameters than polystyrene standards of corresponding mass) obtained are $M_{\mathrm{w}}(t=0 \mathrm{~h})=14290 \mathrm{~g} \mathrm{~mol}^{-1}$ and $Ð(t=0 \mathrm{~h})=1.029, M_{\mathrm{w}}(t=120 \mathrm{~h})=14060 \mathrm{~g} \mathrm{~mol}^{-1}$ and $Ð(t=$ $120 \mathrm{~h})=1.016, M_{\mathrm{w}}(t=240 \mathrm{~h})=13950 \mathrm{~g} \mathrm{~mol}^{-1}$ and $Ð(t=240 \mathrm{~h})=1.024$, and $M_{\mathrm{w}}(t=400 \mathrm{~h})=$ 
$14440 \mathrm{~g} \mathrm{~mol}^{-1}$ and $Ð(t=400 \mathrm{~h})=1.021$. The slight increase of the apparent mass at $t=400 \mathrm{~h}$ might is not explained but, at least, demonstrate that significant degradation did not occur. These results show only a slight degradation of pSe-b-PEG in water over a period of $240 \mathrm{~h}$ at $T=50^{\circ} \mathrm{C}$

It is important to note that the $10.5 \mathrm{mg}$ of $\mathrm{pSe}-b$-PEG used from these degradation experiments came from a different batch (with different storage conditions) than the pSe- $b$ PEG used for the rest of the study, explaining the different $\mathrm{M}_{\mathrm{w}}$ at $t=0$.

\section{TEM images of $\gamma$-Fe $\mathrm{F}_{2} \mathrm{O}_{3}$-PAA/pSe- $b$-PEG polyion complexes in PBS1×}
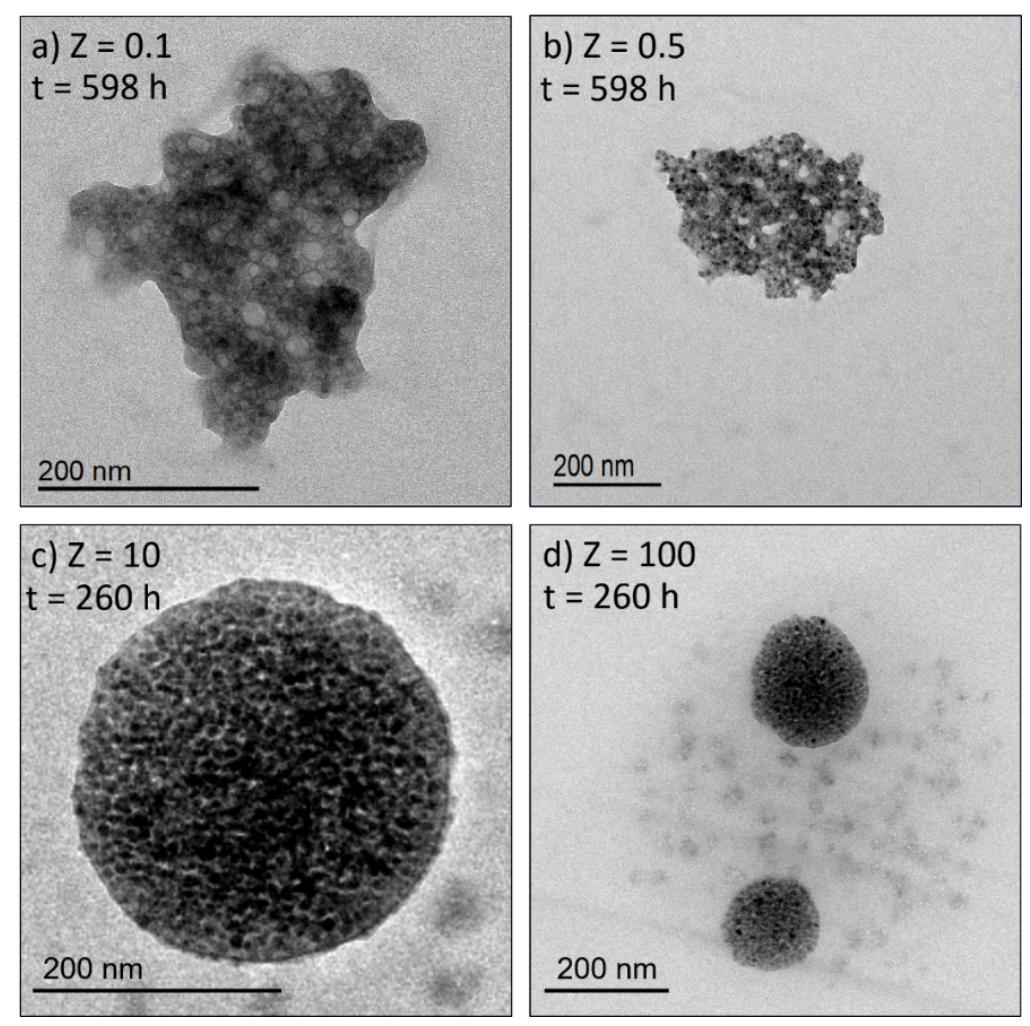

Figure S10. TEM images of $\gamma-\mathrm{Fe}_{2} \mathrm{O}_{3}-\mathrm{PAA} /$ poly(serine ester)- $b$-PEG polyion complexes synthesized in $\mathrm{PBS} 1 \times$ at different charge ratio $Z$ from solutions at $\left[\gamma-\mathrm{Fe}_{2} \mathrm{O}_{3}\right]=[\mathrm{pSe}-b-\mathrm{PEG}]=$ $6 \times 10^{-4} \mathrm{wt} \%$. TEM images of $\gamma-\mathrm{Fe}_{2} \mathrm{O}_{3}-\mathrm{PAA} / \mathrm{pSe}-b$-PEG made at $Z=0.1,598 \mathrm{~h}$ after mixing (a), at $Z=0.5,598 \mathrm{~h}$ after mixing (b), at $Z=10,260 \mathrm{~h}$ after mixing and $Z=100,260 \mathrm{~h}$ after $\operatorname{mixing}(\mathrm{d})$. 


\section{$\gamma$-Fe $\mathrm{O}_{2} \mathrm{O}_{3}$-PAA/pSe- $b$-PEG in PBS1 $\times$ and water: comparative Study by DLS}

Mixtures of $\gamma-\mathrm{Fe}_{2} \mathrm{O}_{3}-\mathrm{PAA}$ and pSe- $b$-PEG at $Z=1$ in either PBS1 $1 \times$ or deionized water were prepared from solutions at $\left[\gamma-\mathrm{Fe}_{2} \mathrm{O}_{3}\right]=[\mathrm{pSe}]=6 \times 10^{-4} \mathrm{wt} \%$ following the protocol described in the Experimental Section of the article and in "Preparation of $\gamma-\mathrm{Fe}_{2} \mathrm{O}_{3}-\mathrm{PAA} / \mathrm{pSe}$ and $\gamma-\mathrm{Fe}_{2} \mathrm{O}_{3}$-PAA/pSe- $b$-PEG polyion complexes" and Table $\mathrm{S} 1$ of this document.

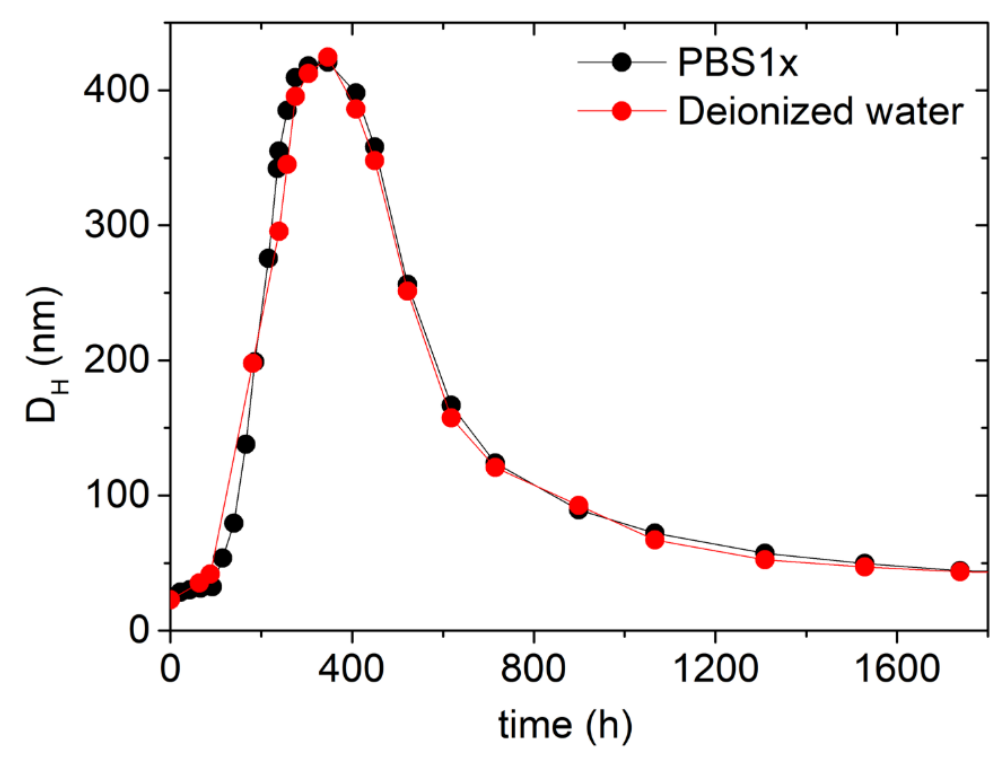

Figure S11. DLS analysis of $\gamma-\mathrm{Fe}_{2} \mathrm{O}_{3}-\mathrm{PAA} /$ poly(serine ester)- $b$-PEG polyion complexes synthesized in PBS1× (black symbols) and deionized water (red symbols), respectively. Hydrodynamic diameters $\left(D_{H}\right)$ as a function of time of $\gamma-\mathrm{Fe}_{2} \mathrm{O}_{3}-\mathrm{PAA}$ and $\mathrm{pSe}-b$-PEG mixtures at $Z=1$ and prepared from solutions at $\left[\gamma-\mathrm{Fe}_{2} \mathrm{O}_{3}\right]=[\mathrm{pSe}]=6 \times 10^{-4} \mathrm{wt} \%$. Nanoparticles and pSe were mixed at $t=0$.

\section{DLS study of the thermal stability of $\gamma-\mathrm{Fe}_{2} \mathrm{O}_{3}-\mathrm{PAA} / \mathrm{pSe}-b$-PEG polyion complexes in water}

Mixtures of $\gamma-\mathrm{Fe}_{2} \mathrm{O}_{3}$-PAA and pSe- $b$-PEG at $Z=1$ in deionized water were prepared from solutions at $\left[\gamma-\mathrm{Fe}_{2} \mathrm{O}_{3}\right]=[\mathrm{pSe}]=6 \times 10^{-4} \mathrm{wt} \%$ following the protocol described in the 
Experimental Section of the article and in "Preparation of $\gamma-\mathrm{Fe}_{2} \mathrm{O}_{3}-\mathrm{PAA} / \mathrm{pSe}$ and $\gamma-\mathrm{Fe}_{2} \mathrm{O}_{3}-$ PAA/pSe- $b$-PEG polyion complexes" and Table S1 of this document. $418 \mathrm{~h}$ after the mixing of $\gamma$ - $\mathrm{Fe}_{2} \mathrm{O}_{3}$-PAA and pSe- $b$-PEG, dispersions of $\gamma$-Fe $\mathrm{F}_{2} \mathrm{O}_{3}$-PAA/pSe- $b$-PEG PICs were incubated at respectively $25{ }^{\circ} \mathrm{C}, 60{ }^{\circ} \mathrm{C}$ and $95{ }^{\circ} \mathrm{C}$ in oil bath. Regularly, a fraction of each sample was cooled to $T=25^{\circ} \mathrm{C}$ and analyzed by DLS for determination of hydrodynamic diameter $\left(D_{H}\right)$.

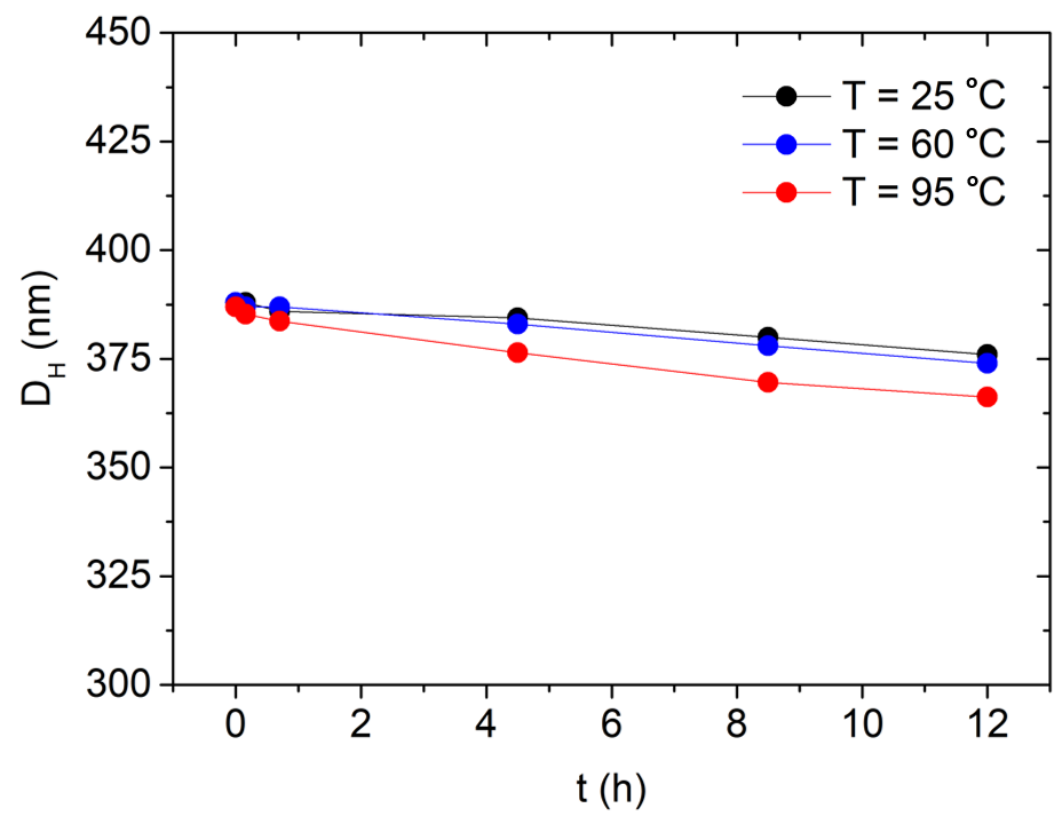

Figure S12. DLS analysis of the thermal stability of $\gamma-\mathrm{Fe}_{2} \mathrm{O}_{3}-\mathrm{PAA} / \mathrm{pSe}-b-\mathrm{PEG}$ polyion complexes (PICs) in water. $\gamma-\mathrm{Fe}_{2} \mathrm{O}_{3}-\mathrm{PAA} / \mathrm{pSe}-b$-PEG PICs were prepared from solutions at $\left[\gamma-\mathrm{Fe}_{2} \mathrm{O}_{3}\right]=[\mathrm{pSe}]=6 \times 10^{-4} \mathrm{wt} \%$ as $Z=1$. After $418 \mathrm{~h}$ of growth at $25^{\circ} \mathrm{C}$, PICs were incubated at respectively $25{ }^{\circ} \mathrm{C}, 60^{\circ} \mathrm{C}$ and $95{ }^{\circ} \mathrm{C}(t=0)$ and their hydrodynamic diameters $\left(D_{H}\right)$ as a function of time measured regularly over a $12 \mathrm{~h}$ period. 
Proton relaxation rates of $\gamma-\mathrm{Fe}_{2} \mathrm{O}_{3}-\mathrm{PAA}$ and $\gamma$-Fe $\mathrm{F}_{2} \mathrm{O}_{3}-\mathrm{PAA} / \mathrm{pSe}-b$-PEG polyion complexes
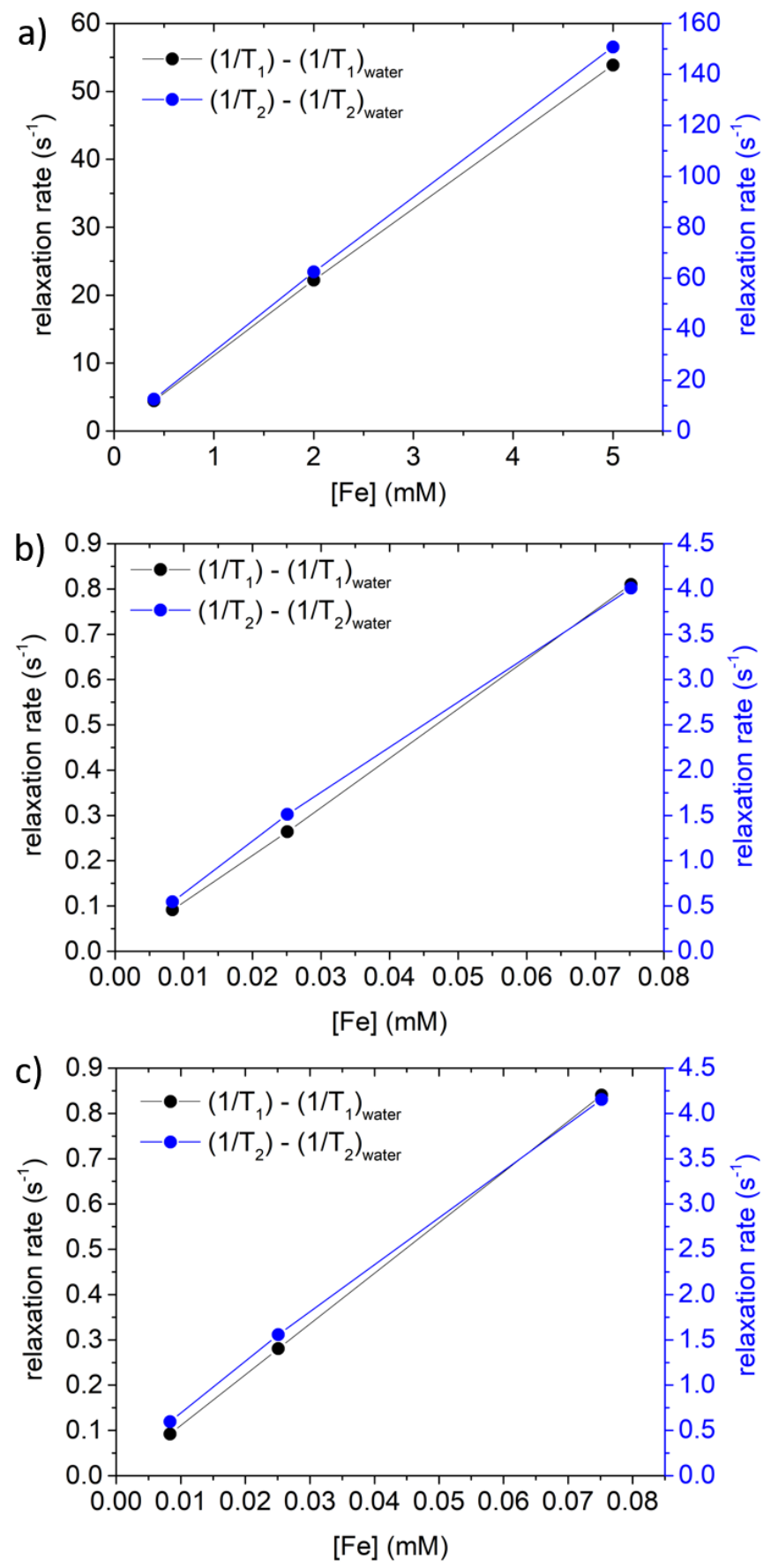

Figure S13. Relaxometric properties at $1.41 \mathrm{~T}(60 \mathrm{MHz})$ and $37{ }^{\circ} \mathrm{C}$ of individual $\gamma-\mathrm{Fe}_{2} \mathrm{O}_{3^{-}}$ PAA nanoparticles (a) and $\gamma$ - $\mathrm{Fe}_{2} \mathrm{O}_{3}-\mathrm{PAA} / \mathrm{pSe}-b$-PEG polyion complexes before (b) and after (c) application of magnetic hyperthermia treatment. The relaxation rate $r_{l}$ and $r_{2}$ are defined by $r_{i}=\left(1 / T_{i}\right)-\left(1 / T_{i}\right)_{\text {water }}$ where $T_{1}=3977 \mathrm{~ms}$ and $T_{2}=819 \mathrm{~ms}$ are the longitudinal and transverse proton relaxation times measured on pure water. 
Supporting information of paper accepted for publication in Mater. Sci. Eng. C, 2019, 109920

\section{References}

1 P. Lindner and T. Zemb, Neutrons, X-rays, and light : scattering methods applied to soft condensed matter, Amsterdam; Boston : Elsevier, 1st ed., 2002.

2 M. Szekeres and E. Tombácz, Colloids Surf. Physicochem. Eng. Asp., 2012, 414, 302313.

3 A. Sehgal, Y. Lalatonne, J.-F. Berret and M. Morvan, Langmuir, 2005, 21, 9359-9364.

4 H. Li, M. J. Henderson, K. Wang, X. Tuo, Y. Leng, K. Xiong, Y. Liu, Y. Ren, J.

Courtois and M. Yan, Colloids Surf. -Physicochem. Eng. Asp., 2017, 514, 107-116. 